\title{
Origen del nombre de los géneros de plantas vasculares nativas de Chile y su representatividad en Chile y el mundo
}

\section{Name origin of the native genera of vascular plants from Chile and its presence in Chile and the world}

\author{
Mélica Muñoz-Schick ${ }^{1}$, Andrés Moreira-Muñoz ${ }^{2}$ \& Sergio Moreira Espinoza ${ }^{3}$ \\ ${ }^{1}$ Museo Nacional de Historia Natural. Interior Quinta Normal s/n, Casilla 787; Santiago, Chile \\ 2Instituto de Geografía, Pontificia Universidad Católica de Chile, Avda. Vicuña Mackenna 4860, Santiago, Chile \\ ${ }^{3}$ Montana 7516, Santiago, Chile \\ mmunoz@mnhn.cl; asmoreir@uc.cl; sergiomoreiraespinoza@gmail.com
}

\begin{abstract}
RESUMEN
La presente contribución constituye un aporte al conocimiento de la flora vascular de Chile, reuniendo en un solo texto la información acerca del significado del nombre de los géneros chilenos de plantas vasculares. Para ello se ha actualizado la lista de géneros nativos válidos a la fecha y se ha recopilado la información eminentemente dispersa en relación con el origen de los nombres. Adicionalmente se incluye información relevante acerca de la distribución de cada género y el número de especies nativas presentes en Chile.
\end{abstract}

Palabras clave: Flora de Chile, géneros nativos, etimología, distribución geográfica, número de especies.

\begin{abstract}
This paper is a contribution to the knowledge of the vascular flora of Chile, bringing together in one text the information about the meaning of names of the Chilean genera of vascular plants. For this purpose, we updated the list of valid genera native to Chile and revised all the available and currently dispersed literature in relation to the origin of the names. We also included relevant information about the distribution of each genus and the number of native species present in Chile.
\end{abstract}

KEYwORDS: Chilean Flora, native genera, etymology, geographic distribution, number of species.

\section{INTRODUCCIÓN}

Una consulta frecuente en reuniones, conferencias y publicaciones botánicas, se refiere al origen del nombre científico de las especies. Es una pregunta simple que pareciera tener una respuesta obvia y concisa, que no siempre es el caso, especialmente para los géneros que componen la flora de Chile. Esto se hace aún más difícil al no existir una sola obra de referencia que permita acceder al conocimiento del origen de los nombres de los géneros chilenos. Esta contribución permite llenar este vacío en relación con los nombres de los géneros actualmente válidos para la flora de Chile.

\section{METODOLOGÍA}

Catálogo de los géneros de plantas vasculares de Chile Los persistentes avances en taxonomía botánica implican una constante revisión y actualización de los nombres válidos de plantas, en este caso, de los taxones chilenos. Hubo intentos tempranos por sistematizar este conocimiento, realizados por Federico Philippi (1881), Carlos Reiche (1907), Muñoz Pizarro (1966). La lista más completa que existió en su momento fue el Catálogo de la Flora Vascular de Chile (Marticorena \& Quezada 1985), posteriormente revisada por C. Marticorena (1990). Los avances en la sistemática, ahora último con la incorporación de técnicas moleculares, le otorgan mucho dinamismo a este campo. A fines de la década pasada se publicó un notable esfuerzo de colaboración internacional que comprende Argentina, Chile, Paraguay, Uruguay, y el SE de Brasil: el Catálogo de las Plantas Vasculares del Cono Sur (Zuloaga et al. 2008). En este importante trabajo, nuevamente se observan cambios en la actualización de los géneros y el número de especies para Chile. Más recientemente se encuentra a disposición de la comunidad botánica el libro "Plant 
Geography of Chile" de Moreira-Muñoz (2011), el cual aborda, desde una perspectiva geobotánica, todos los géneros válidos presentes hoy en Chile y su distribución geográfica mundial.

Algunos géneros incorporados en los últimos 15 años a la flora de Chile son Nasa (Weigend 1997) y Guynesomia, de Bonifacino \& Sancho (2004). Otros géneros han sido revalidados últimamente como Dysphania (Mosyakin \& Clemants 2002) Ochetophyla Poepp. \& Endl. (Kellermann et al. 2005), Ocyroe Phil. (Bonifacino 2008), Oriastrum Poepp. \& Endl. (Davies 2010), Sibara Greene (Al-Shehbaz 2010) y Nothomyrcia Kausel (Murillo-Aldana \& Ruiz 2011). También hay casos de géneros nuevos como Calorezia (Panero 2007), que han sido traspasados rápidamente a la sinonimia (Katinas et al. 2008).

\section{NOMBRES CIENTíFICOS}

Para acceder al origen y significado de los nombres de los géneros chilenos se ha revisado la literatura pertinente, que se encuentra bastante dispersa. Existe un libro clásico del Dr. Wittstein (1856), en alemán, que tiene un alto porcentaje de los significados, y más recientemente la extensa obra del Dr. Humberto Quatrocchi "World Dictionary of Plant Names" (1999), publicada en cuatro volúmenes, que incluye 22.500 géneros. El acceso a esta extensa obra no disponible en Chile, ha sido posible gracias a la ayuda de la comunidad botánica internacional. Últimamente hemos accedido a la obra The Names of Plants de D. Gledhill (2008); aún así, hemos constatado la ausencia de muchos de los géneros chilenos en estas obras.

De los trabajos clásicos chilenos debemos citar el de C. Gay que en sus 8 tomos de Botánica (1845-1854) indica una gran proporción de los nombres de los géneros y aun de las especies cuando son en honor a alguien, y luego Gunckel (1982). Hay algunas Floras como "A California Flora" (Munz \& Keck 1949), Flores silvestres de Chile (Muñoz Pizarro 1966), Flora del Parque Nacional Puyehue (Muñoz-Schick 1980), Flores del Norte Chico (MuñozSchick 1985), Flora Patagónica (Correa 1969-1988), Aromas de la flora nativa de Chile (Niemeyer \& Teillier 2007) que también indican los significados. El resto hubo de ser resuelto revisando las monografías o publicaciones pertinentes y en algunos casos la consulta directa al autor del género.

\section{RESULTADOS}

LOS GÉNEROS CHILENOS DE PLANTAS VASCULARES

Los primeros nombres son por supuesto de Carlos Linneo, quien con su trabajo "Species Plantarum" publicado en 1753, es el iniciador de la nomenclatura binominal. Había autores anteriores a él, pero según las Reglas de Nomenclatura Botánica no es necesario citarlos, y entonces sólo se agrega al taxón la letra "L.".

Nos fue difícil encontrar la palabra de la cual derivaban muchos géneros, solamente se encontró el significado, y ello se refleja en este trabajo. Los nombres en general los ponen los autores tomando características de las plantas, sin embargo y como es lógico, se refieren a la primera especie de dicho género y nombran alguna característica o variación geográfica que no siempre coincidirá cuando se descubren nuevas especies para el género en cuestión; otras muchas veces son en honor a alguien. Pero no siempre los autores indicaban el significado y hubo que deducirlo de la descripción. En algunos casos R. A. Philippi, por ejemplo, puso nombres tomándolos de la mitología griega (Oziroe, Metharme) y hay otros en que es difícil entender su pensamiento, como en Lactoris, que dice: "nombre antiguo de una planta que ya no se conoce"; el diccionario latín dice: planta que aumenta la leche al ser comida por las cabras. Igualmente Onuris, para el cual Philippi dice: nombre antiguo griego de una planta que ya no se conoce.

Se concluye que un alto número de los nombres son en honor a alguna persona (27\%), mientras que otros provienen de nombres de la mitología (cerca de 11 nombres); el resto alude a las características de las plantas.

Según el conocimiento actual, los géneros de plantas vasculares nativas presentes en Chile, que son los tratados en esta publicación, alcanzan a 839. Con respecto a MoreiraMuñoz (2011), se agregan 4 géneros: Dysphania, Oriastrum, Sibara y Nothomyrcia; en cambio se suprime Werdermannia que ahora corresponde a Sibara.

Se destaca que los géneros endémicos alcanzan a 67 en Chile continental y 17 en las islas chilenas del Pacífico, especialmente de Juan Fernández (Moreira-Muñoz 2011), donde recientemente se revalida el género Nothomyrcia. Es interesante indicar que la mayoría de ellos (47) son monoespecíficos, es decir con una sola especie.

De los géneros se entrega el o los autores, año de publicación, la familia (entre paréntesis aquellas a las cuales pertenecían tradicionalmente) y el significado del nombre. Se agrega su distribución mundial y el número de especies nativas de Chile.

Como parte de esta información va a seguir variando, pretendemos que este trabajo se siga actualizando a través de la plataforma internet.

SignifiCAdo DE LOS NOMBRES DE GÉNEROS CHILENOS, DIVERSIDAD Y DISTRIBUCIÓN

Aa Reichb.f. 1858. ORCHIDACEAE

Nombre incierto, quizás en honor al botánico holandés Mynheer Pieter van der Aa (1823-1889)

27 especies desde los Andes colombianos a Argentina y Chile, con 1 especie. 
Abrotanella Cass. 1825. Asteraceae

Diminutivo de Abrotanum: género elegante por sus hojas y aroma. También del nombre vulgar abrótano (Artemisia arborescens)

Cerca de 20 especies de Nueva Guinea, Australia, Tasmania, Nueva Zelanda, Sudamérica (Tierra del Fuego), Islas Malvinas y Juan Fernández. En Chile 6 especies.

Acacia Mill. 1754. (Mimosaceae) FABACEAE

Del celta ápice. Por las puntas y filos debido a las espinas en tronco y ramas de la mayoría de las especies.

Cerca de 1.200 especies, principalmente en regiones subtropicales, especialmente en Australia y África. En Chile 3 especies.

Acaena Mutis ex L. 1771. Rosaceae

Del griego acanthos=espina, ya que sus frutos están rodeados de espinas.

Cerca de 100 especies en Sud África (1 especie), Nueva Guinea, Australia, Tasmania, Nueva Zelanda, Islas subantárticas, Polinesia, Hawaii, desde California a Sudamérica y Juan Fernández. En Chile 19 especies.

\section{Acantholippia Griseb. 1874. Verbenaceae}

Del griego acanthos=espina y Lippia, otro género de Verbenáceas.

6 especies de las regiones áridas de Argentina, Bolivia y Chile, con 3 especies en el norte.

Achyrocline (Less.) DC. 1837. Asteraceae

Del griego achyro=uña, garra y $\operatorname{cline}=$ cama, por las brácteas agudas que rodean las flores.

32 especies, principalmente en los trópicos y subtrópicos de Sudamérica, unas pocas en África tropical, 1 en Madagascar y Comores. En Chile 1 especie, en Parinacota.

Acrisione Nordenstam 1985. Asteraceae

De la mitología griega en honor a Acrisios, rey de Argos.

2 especies endémicas de Chile Central.

Adenocaulon Hook. 1830. Asteraceae

Del griego aden=glándula y caulon=tallo.

5 especies en los Himalayas, E de Asia, O de Norteamérica, Hawaii, México, Guatemala, Argentina y Chile con 1 especie.

Adenopeltis Bert. 1830. EuPHORBIACEAE

Del griego aden=glándula y pelti=escudo, por la forma de las glándulas involucrales.

Género endémico de Chile con una especie.

Adesmia DC. 1825. FABACEAE

Del griego $a=\sin$; desmos $=$ envoltorio; ya que los estambres son libres.
Cerca de 230 especies en Sudamérica. En Chile cerca de 130 especies.

Adiantum L. 1753. Pteridaceae

Del griego $a=\sin$ y diaine $=$ dejar correr; o adiantos $=$ no mojado, en relación a que las hojas no retienen las gotas de lluvia.

Cerca de 150 especies cosmopolitas especialmente en los neotrópicos y Madagascar. En Chile 5 especies.

Aextoxicon Ruiz \& Pav. 1794. Aextoxicaceae

Del griego aix $=$ cabra y toxicon $=$ veneno, porque es dañino para estos animales.

1 especie nativa de Chile y también en Argentina, donde es escasa.

Agalinis Raf. 1836. (Scrophulariaceae) Orobanchaceae Según Rafinesque parecido a Linum y con el mismo hábito. 40 especies de las regiones tropicales y cálidas de Norte, Centro y Sudamérica, generalmente parasitarias de las raíces de otras plantas. En Chile 2 especies.

Ageratina Spach. 1841. Asteraceae Es un diminutivo de Ageratum, $a=$ sin, no, geras $=$ viejo, porque las flores retienen por largo tiempo su color.

Cerca de 265 especies del E de Estados Unidos, Centro y O de Sudamérica y Caribe. En Chile 1 especie. Según el Catálogo del Cono Sur el nombre válido es Eupatorium glechonophyllum Less.

Agoseris Raf. 1817. Asteraceae

Del griego $a g o=$ semejante y seris $=$ ensalada o achicoria.

11 especies: en Norteamérica y México 9 especies. 2 especies en Chile y Argentina

Agrostis L. 1753. POACEAE

Del griego agros $=$ campo, tierra, para indicar su uso como pasto de forraje.

Cerca de 220 especies en regiones templadas y cálidas de ambos hemisferios, montañas tropicales, Juan Fernández, Isla de Pascua. En Chile 22 especies.

Allionia L. 1753. NyCtaginaceae

En honor a Carlo Allioni (1725-1804), profesor de botánica en Turín. Escribió la "Flora Pedemontana".

3 especies en Centro y SO de Estados Unidos, desde México hasta Argentina y Chile con 1 especie.

Alonsoa Ruiz \& Pav. 1798. Scrophulariaceae

En honor a Zenón Alonso, oficial español que vivió en Santa Fé de Bogotá alrededor de 1798.

16 especies en México, Venezuela, Brasil y región andina de Sudamérica y 2 especies en Sud África. En Chile 2 especies. 
Alopecurus L. 1753. POACEAE

Del griego alopecos $=$ zorro y oura $=$ cola o alopekouros $=$ cola de zorro, debido a la forma de la inflorescencia.

36 especies en regiones cálido-templadas, subtropicales y trópicos de altura. En Chile 6 especies.

\section{Aloysia Ort. ex Jussieu 1806. Verbenaceae En honor a María Luisa, esposa del rey español Carlos IV, madre de Fernando VII, murió en Roma en 1809. \\ 30 especies americanas. En Chile 1 especie.}

\section{Alstroemeria L. 1762. Alstroemeriaceae}

En honor a Claus de Alstroemer (1736-1794), Canciller de Gotemburgo, quien fue uno de los primeros recolectores de Linneo, escribió sobre Pinus viminalis en 1770.

75 especies en S de Brasil, Perú, Argentina y Chile, con 35 especies, 8 subespecies y 8 variedades.

\section{Alternanthera Forsk. 1775. Amaranthaceae \\ Del latín alternus $=$ alterno y anther $a=$ antera, ya que de los seis estambres, tres alternos son sin antera. \\ Cerca de 100 especies de las regiones tropicales y subtropicales de Norteamérica, Sudamérica y Australia. \\ 1 especie en el Cáucaso. En Chile 2 especies.}

Amaranthus L. 1754. Amaranthaceae

Del griego latinizado: no marchitable, ya que no pierde su fresca apariencia al secarse.

60 especies de las regiones tropicales y subtropicales de Europa, Norteamérica y Sudamérica. 16 especies en Rusia. En Chile 2 especies.

\section{Amblyopappus Hook. \& Arn. 1841. Asteraceae}

Del griego latinizado: amblus $=$ romo y pappos $=$ barba, ya que el papo tiene aristas romas.

Género monotípico de California, NO de México y Chile.

\section{Ambrosia L. 1753. Asteraceae}

Antiguo nombre griego y latín (ambrosia) para plantas que al frotar sus hojas despiden un fuerte olor.

30 especies de Canadá, México, Caribe y Sudamérica. En Chile 1 especie.

Amelichloa Arriaga \& Barkworth, 2006. PoACEAE En honor a la agrostóloga argentina Dra. María Amelia Torres, quien compartió generosamente con las autoras, sus vastos conocimientos en las Stipeae y chloa $=$ pasto.

5 especies de Sudamérica y México, en Chile dos especies.

Amomyrtus (Burret) Legrand \& Kausel 1949. Myrtaceae Combinación de los géneros Amomis (por su placentación) y Myrtus (por su aspecto).

2 especies endémicas de Argentina y Chile.
Amphibromus Nees 1843. PoAcEAe

Del griego amphi=próximo o ambos y el género Bromus. 12 especies de Australia, Nueva Zelanda, Tasmania y Sudamérica. En Chile 1 especie.

Amphiscirpus Oteng-Yeboah, 1974. Cyperaceae Del griego amphi=próximo o ambos y Scirpus, otro género de Ciperáceas.

1 especie de Canadá, EstadosUnidos, Argentina y Chile.

Amsinckia Lehm. 1831. Boraginaceae

En honor a Wilhelm Amsinck (1752-1831), botánico alemán, creador de un jardín botánico en Hamburgo.

15 especies del $\mathrm{O}$ de Estados Unidos y O templado de Sudamérica. En Chile 2 especies.

Anagallis L. 1753. Primulaceae

Del griego ana $=$ de nuevo, hacia arriba y gallos=adornar, porque la planta florece de nuevo en otoño.

20 especies de Eurasia, África, Madagascar, Himalayas, $\mathrm{N}$ de Australia y 2 especies en Sudamérica. En Chile 1 especie.

Anaphalis DC. 1838. AsteraceAe

Del griego, nombre de una planta similar a ésta, o también transformado del nombre genérico Gnaphalium.

110 especies de Asia, N y Sudamérica. En Chile 1 especie.

Anarthrophyllum Benth. 1865. FABACEAE

Del latín an=prefijo negativo sin, arthros=unir $\mathrm{y}$ phyllon=hojas. Alude a la rigidez de los folíolos, ya que perdieron el pecíolulo.

15 especies en los Andes de Argentina y Chile con 6 especies.

Anatherostipa (Hack. ex Kuntze) Peñail. 1996. PoAcEAe Del griego $a n=\sin$, atheras $=$ arista y Stipa, nombre de otro género, ya que la primera especie descrita tiene una arista reducida en forma de pequeño mucrón triangular.

11 especies de Ecuador, Perú, Bolivia, Argentina y Chile, con 4 especies.

Andeimalva J.A. Tate 2003. Malvaceae

De Andes y Malva, otro género, ya que las especies son de los Andes de Sudamérica.

4 especies de Perú, Bolivia y Chile, con 1 especie.

Androsace L. 1754. Primulaceae

Del griego andros $=$ hombre y sakos=escudo; la forma de las hojas de algunas especies recuerda a los antiguos escudos. Cerca de 150 especies del Hemisferio Norte, China y pocas especies en Tierra del Fuego. En Chile 1 especie. 
Anemone L. 1754. Ranunculaceae

Del griego (viento), porque abre sus flores sólo cuando sopla el viento; muchas especies de este género viven en lugares ventosos.

Cerca de 90 especies de Eurasia, Sumatra, S y E de África, Nueva Zelanda. En América desde Norteamérica hasta Chile, con 7 especies.

\section{Anisomeria D. Don 1832. Phytolaccaceae}

Del griego aniso=desigual y mero=partes, ya que los angostos carpidios (frutos) son de porte desigual.

Género endémico de Chile con 2 especies.

Antennaria Gaertn. 1791. AsteraceAe

Del latín antenna=antena, debido al parecido de los pelos del vilano, o de las flores masculinas, con las antenas de los insectos.

50 especies de regiones templadas y frías del Hemisferio Norte y Andes de Sudamérica. En Chile 1 especie.

Anthochloa Nees \& Meyen 1834. POACEAE

Del griego anthos=flor y $c l o a=$ gramínea o pasto.

Género monotípico de los Andes de Perú y Chile.

Anthoxanthum L. 1753. POACEAE

Del griego anthos $=$ flor y xanthos $=$ café amarillento, en relación al color de la inflorescencia.

20 especies de las regiones cálidas y templadas de Eurasia, $\mathrm{N}$ de África y trópicos de altura. En Chile 7 especies.

Antidaphne Poepp. \& Endl. 1838. Santalaceae Del griego anti=opuesto y Daphne, otro género. 8 especies de las regiones tropicales del S de México, Cuba, Haití, Costa Rica y toda Sudamérica. En Chile 1 especie.

Aphanes L. 1753. Rosaceae

Del griego aphanes=pequeña, poco vistosa.

20 especies de América, Europa y Mediterráneo, Etiopía, Australia y Cáucaso. En Chile 3 especies.

Aphyllocladus Wedd. 1855. Asteraceae

Del griego: aphylla $=$ sin hojas, clados=ramas, ramas $\sin$ hojas, por el aspecto de ellas.

5 especies de los Andes del S de Bolivia, N de Chile y NO de Argentina. En Chile 1 especie.

\section{Apium L. 1753. APIACEAE}

Del celta apon=agua, debido al hábitat cerca del agua. Otra versión supone que de apis=abeja, porque las abejas viven en el Apio; o de apex=ápice, cabeza, porque el vencedor principal de las guerras santas era coronado con ella.

27 especies de Europa, Mediterráneo, $\mathrm{N}$ y S de África, Madagascar, O y E de Asia, Malasia, Australia, América, Juan Fernández e Isla de Pascua. En Chile 5 especies.
Apodasmia B.G.Briggs \& L.A.S.Johnson 1998. RestionACEAE Del griego $a p o=$ separado o apodasmios $=$ separado; se refiere a la amplia distribución disyunta de las especies.

10 especies del SE de Asia, Malasia, Nueva Guinea, Australia, Tasmania, Nueva Zelanda, Argentina y Chile, con 1 especie.

Arachnitis Phil. 1864. CORSIACEAE

Del griego arachnos=araña, porque la flor parece una araña.

Una especie de Chile, Argentina y Bolivia.

Araeoandra Lefor 1975. ViviAnIACEAE

Del griego araeos $=$ pocos y andra=masculino, referido al androceo de 5 estambres.

Género monotípico endémico de Chile.

Araucaria Juss. 1789. Araucariaceae

De araucano, pues el árbol es oriundo de la región de Arauco cuyos habitantes se llamaban Araucos o Araucanos.

18 especies de Nueva Guinea, Australia, Nueva Caledonia, SE de Brasil y S de Argentina y Chile con 1 especie.

Arenaria L. 1753. CARYOPHYLlaCEAE

Del latín: arena.

Cerca de 160 especies de América, Eurasia templada y N de África. En Chile 7 especies.

Argemone L. 1753. PapaveraceAe

Del griego $\operatorname{argemos}=$ catarata del ojo; porque se suponía que el jugo de la planta servía de remedio para esta enfermedad. 28 especies de Norte y Sudamérica, Caribe y Hawaii. En Chile 4 especies.

Argylia D. Don 1823. BignOniaCeAE

En honor al escocés Archibald Duque de Argyle, distinguido mecenas de la botánica.

12 especies del sur de Perú y Bolivia, norte y centro de Chile y Argentina. En Chile 11 especies.

Argyrochosma (J. Smith) Windham 1987. (Pteridaceae) AdiAnTACEAE

Del griego argyros=plateado y chosma, choma=polvo, tierra, por la superficie con polvillo, de las frondas de algunas especies.

17 especies desde EUA a Chile, con 2 de ellas en el país.

Aristeguietia King \& Robinson 1975. AsterACEAE

En honor del Dr. Leandro Aristeguieta, del Instituto Botánico de Caracas, autor de las Asteráceas en la Flora de Venezuela.

21 especies de Colombia, Ecuador, Perú y Chile con 1 especie. Según el Catálogo del Cono Sur el nombre válido es Eupatorium salvium Colla. 
Aristida L. 1753. POACEAE

Del latín arista=arista, ya que la glumela termina en una arista de tres puntas.

Cerca de 290 especies de Norteamérica, Mediterráneo, Asia templada, trópicos y subtrópicos. En Chile 3 especies.

\section{Aristolochia L. 1753. Aristolochiaceae}

Del latín aristos=muy bien y loquios=descarga vaginal de sangre o locheia = parición; ya que se usaba como remedio para las mujeres recién paridas.

Cerca de 300 especies de trópicos y subtrópicos, algunas en regiones templadas. En Chile 2 especies.

Aristotelia L'Hér. 1784. Elaeocarpaceae

En honor a Aristóteles, filósofo y naturalista griego (384322 a.C.) quien también escribió dos libros sobre plantas.

5 especies en el E de Australia, Tasmania, Nueva Zelanda, Argentina y Chile con 1 especie.

\section{Arjona Cav. 1797. Santalaceae}

En honor de Francisco Arjona, profesor de botánica en Cádiz, España.

10 especies de la zona templada de Sudamérica, la mayoría chileno-argentinas. En Chile 3 especies.

Armeria Willd. 1809. Plumbaginaceae

Del celta $a r=$ cerca y $m o r=$ mar, en referencia a su hábitat costero, o del nombre francés "armoires" para las flores de una especie de Dianthus.

90 especies desde los Andes de Sudamérica hasta Tierra del Fuego, Europa y Rusia. En Chile 1 especie.

\section{Artemisia L. 1753. Asteraceae}

Del griego Artemis=Diana, la patrona de las jóvenes, pues esta planta se usaba para hacerles llegar la menstruación.

Cerca de 522 especies de Eurasia templada, América, África y Sudamérica. En Chile 2 especies.

Arthropteris J. Sm. ex Hook. f. 1854. (Tectarinaceae) Oleandraceae

Del griego artro=articulación, y pteris $=$ helecho, por ser helechos articulados.

15 especies de África, Madagascar, Polinesia, Nueva Guinea, Nueva Zelanda, y Juan Fernández, Chile, con 1 especie.

\section{Asplenium L. 1753. Aspleniaceae}

Del griego $a=\sin$, splen=bazo; hierba que alivia el dolor del bazo, antiguamente se creía que el uso continuo de esta planta producía la expulsión del bazo.

Cerca de 650 especies subcosmopolitas, Madagascar y Juan Fernández, Chile, con 10 especies.

Astelia Banks y Sol. ex R. Br. 1810. Asteliaceae

Del griego: significa sin columna, ya que como son plantas dioicas, en algunas flores falta el pistilo.

25 especies, en Mascareñas (islas Reunión y Mauricio), Nueva Guinea, Australia, Nueva Zelanda, Polinesia, Hawai, Argentina (Islas Malvinas) y Chile con 1 especie.

Asteranthera Hanst. 1854 emend. Pérez-Moreau 1945. Gesneriaceae

Del griego aster $=$ estrella y anther $=$ antera, alude a la disposición estrellada de las anteras en cierto período de la antesis.

Género monotípico endémico de Chile y Argentina.

Asteriscium Cham. \& Schltdl. 1826. ApIACEAE

Del griego aster $=$ estrella, en relación a los dientes del cáliz.

8 especies de México a Patagonia. En Chile 4 especies.

Astragalus L. 1753. FABACEAE

Del griego huesito o nudito, debido a los engrosamientos de tallos y raíces en algunas especies.

Cerca de 2.000 especies de Norteamérica, Andes, Eurasia templada y montañas de África tropical. En Chile 49 especies.

Astrolepis D.M.Benham \& Windham 1992. PTERIDACEAe Del griego astron=estrella y lepis=escama por las escamas en la superficie de las frondas.

6 especies desde EUA a Chile, con una especie.

Atriplex L. 1753. Amaranthaceae

De un antiguo nombre griego ater-plexus, negro y entrelazado. Otra versión es que toleran la sal y se les llaman "plantas de sal" y de allí deriva su nombre.

Cerca de 250 especies cosmopolitas, especialmente en Eurasia y Australia e Islas Desventuradas. En Chile 21 especies.

Austrocactus Britton \& Rose 1922. CACTACEAE Significa: cacto del sur, por su distribución austral. 4 especies de Argentina y Chile, con 3 especies.

Austrocedrus Florin \& Boutelje 1954. CuPRESSACEAE Del griego austro=sur y Cedrus, otro género similar.

Género monotípico endémico de Chile y Argentina.

Avellanita Phil. 1864-65. EupHORBIACEAE

Del nombre vulgar de sus semillas comestibles, con sabor a avellana.

Género monotípico endémico de Chile.

Axonopus P. Beauv. 1812. Poaceae

Del griego axon=eje y pous=pie; por la base de las espigas más o menos digitadas.

Cerca de 110 especies pantropicales e Isla de Pascua, Chile con 1 especie. 
Azara Ruiz \& Pav. 1799. (Flacourtiaceae) SAlicaceae En honor a José Nicolás de Azara (1731-1804), diplomático, literato, géografo y gran protector de las ciencias en España.

10 especies sudamericanas y Juan Fernández. En Chile 8 especies.

Azolla Lam. 1783. (Salviniaceae) Azollaceae

Del griego $a z o=$ secar y olluo=destruir, en relación a que estas plantas mueren en hábitats secos.

6 especies en las zonas tropicales y cálidas de Europa, Asia, Madagascar, Tristán da Cunha, Hawai. En Chile 1 especie.

Azorella Lam. 1793. Apiaceae

Probablemente del latín azor=halcón, y pequeño; por el aspecto de la planta en cojín, con hojas cuyos pecíolos tienen pelos blancos.

70 especies de los Andes a zonas templadas de Sudamérica. Islas Malvinas e Islas antárticas. En Chile 17 especies.

\section{Baccharis L. 1753. AsTERACEAE}

De Bacchus, dios del vino, debido al buen olor de sus raíces usadas como especia.

Cerca de 360 especies de América, la mayoría sudamericanas. En Chile 40 especies.

Bacopa Aublet 1775. (Scrophulariaceae) Plantaginaceae De un nombre indígena en la Guyana francesa.

60 especies de las regiones tropicales y subtropicales, Hawai, Madagascar y Australia. En Chile 1 especie.

\section{Bahia Lag. 1816. AsterAcEAe}

En honor a Juan Francisco Bahí (1775-1841), médico y profesor de botánica en Barcelona, que participó en la creación del Jardín Botánico de esa ciudad.

10 especies del SO de Estados Unidos, México y Chile con 1 especie.

Bakerolimon Lincz. 1968. Plumbaginaceae En honor de Herbert G. Baker (1920-2001), decano de la biología de la evolución, quien gran parte de su labor la desarrolló en la Universidad de Berkeley, California, y limon por Limonium (nombre anterior) que viene del antiguo nombre griego "leimonium".

Género monotípico de Chile.

Balbisia Cav. 1804. (Ledocarpaceae) VivianiaCEAE En honor a Giovanni Battista Balbis (1765-1831), profesor de botánica en Turín y Lyon, escribió diversas obras botánicas.

8 especies en Perú, Bolivia, Argentina y Chile con 4 especies.

Balsamocarpon Clos 1846. FABACEAE

Del griego: balsamos=exudación u olor y carpon=fruto, por su fruto resinoso.

Género monotípico endémico de Chile

Barneoudia Gay 1845. RANUNCULACEAE

En honor a Marius Barnéoud, botánico francés, colaborador de Claudio Gay en la Flora de Chile.

3 especies endémicas de Chile y Argentina.

Bartsia L. 1753. (Scrophulariaceae) OROBANCHACEAE En honor a Johann Bartsch (1709-1738) médico y botánico de Königsberg, Prusia.

60 especies de Europa, O y E de África, NE de Canadá y Sudamérica en Venezuela y Colombia a lo largo de los Andes hasta Chile central. En Chile 3 especies.

Beilschmiedia Nees 1831. LAURACEAE En honor a C. T. Beilschmied, boticario en Schmieederberg, Silesia, muerto en 1840, tradujo al alemán trabajos de varios botánicos.

Cerca de 230 especies pantropicales desde México al S de Brasil, Nueva Zelanda, Australia, África y Madagascar. En Chile 2 especies.

Belloa Remy 1847. Asteraceae

En honor a Andrés Bello, sabio legista y poeta venezolano que vivió en Chile, muy conocido por la variedad de sus conocimientos y adicto a las ciencias naturales. Fue el primer rector de la Universidad de Chile.

1 especie endémica de los Andes de Argentina y Chile.

Benthamiella Speg. 1883. Solanaceae En honor al gran botánico inglés y explorador de América, George Bentham (1800-1884). La magna obra junto a J.D.Hooker, Genera Plantarum (1862-1883) es aún considerada una obra clásica para la clasificación vegetal. 12 especies endémicas de la Patagonia de Argentina y Chile con 4 especies.

Berberidopsis Hook. f. 1862. BERBERIDOPSIDACEAE Por su parecido al género Berberis.

2 especies: 1 en Australia y 1 en Chile.

Berberis L. 1753. BERBERIDACEAE

Versión latinizada del nombre árabe, aplicado al fruto de estas plantas.

Cerca de 470 especies en Eurasia, norte de África, norte y sur de América. En Chile 47 especies.

Bidens L. 1753. AsteraceAe

Del latín: $b i=$ dos y dens $=$ dientes, bidentado; aludiendo a los aquenios biaristados.

Cerca de 240 especies en todas las regiones templadas y cálidas del mundo. En Chile 7 especies. 
Bipinnula Comm. ex Juss. 1789. Orchidaceae

Del latín bis=doble y pinnula=diminutivo de pinna; dos secciones del cáliz son pinadas, ya que los sépalos son plumosos.

8 especies en las zonas templadas de Sudamérica. En Chile 4 especies.

Blechnum L. 1753. BLECHNACEAE

Antiguo nombre griego para un helecho o según Ateneo para una planta sin gusto.

Cerca de 175 especies subcosmopolitas, Magadascar y Juan Fernández. En Chile 10 especies.

Blennosperma Less. 1832. AsterACEAE

Del griego: blenna y sperma = semilla delgada, por la forma de las semillas.

3 especies: 2 en California y 1 en Chile.

\section{Blepharocalyx Berg 1859. MyrtaCEAE}

Del griego blepharo=pestaña y calyx=cáliz, ya que los lóbulos del caliz, son a veces, fimbriados.

17 especies de las regiones tropicales y subtropicales del Caribe y Sudamérica. En Chile 1 especie.

Blumenbachia Schrader 1825. LOASACEAE

En honor a Johann Friedrich Blumenbach (1752-1840), naturalista alemán, fisiólogo y antropólogo, nacido en Gotha y formado en las universidades de Jena y Gotinga, donde fue catedrático de Medicina desde 1776.

12 especies de Brasil, Uruguay, Paraguay, Argentina y Chile con 3 especies.

\section{Boehmeria Jacq. 1760. URTICACEAE}

En honor a Georg Rudolph Boehmer (1723-1803) nacido en Liegnitz, profesor de Anatomía y de Botánica, autor de Flora Lipsige.

50 especies pantropicales y Juan Fernández, Chile con 1 especie.

Bolax Comm. ex Juss. 1789. APIACEAE

Del griego por el hábito de montículos en cojín.

5 especies de las regiones templadas de Sudamérica. En Chile 2 especies.

\section{Bomarea Mirb. 1804. Alstroemeriaceae}

En honor a Jacques Christopher Valmont de Bomare (17311807), nacido en Rouen, desde 1786 profesor de Ciencias Naturales en París, escribió un Diccionario Universal de Historia Natural.

Cerca de 100 especies de México, Brasil, Bolivia, Perú, Argentina y Chile con 3 especies.

Boopis Juss. 1803. Calyceraceae

Del griego boos=buey y (ojo), ojo de buey o tragaluz, en referencia a sus grandes cabezuelas de flores.

Cerca de 13 especies del S de Brasil y en los Andes de Argentina y Chile con 7 especies.

Boquila Decaisne 1837. LaRdizABalaceAe

Del nombre chileno boqui o voqui, para plantas que se enredan en otras.

Género monotípico endémico de Chile y Argentina.

\section{Bothriochloa Kuntze 1891. POACEAE}

Del griego bothros $=$ orificio y chloe o chloa=pasto, ya que la especie Tipo tiene un orificio en la base de la primera gluma.

35 especies de zonas templadas y subtropicales, trópicos de montaña. En Chile 2 especies.

Botrychium Sw. 1801. Ophioglossaceae

De uva: (rizo, pámpano), por su inflorescencia en forma de racimo.

35 especies de las regiones templadas, polares y trópicos de altura de todo el mundo. En Chile 2 especies.

Bouteloua Lag. 1805. POACEAE

En honor a Claudio Boutelou (1774-1842), horticultor español, que escribió sobre jardinería.

40 especies desde Canadá a Argentina y Chile con 1 especie.

Bowlesia Ruiz \& Pav. 1794. APIACEAE

En honor a William Bowles, irlandés que murió en 1780 en España, escribió Jeografía e Historia Natural de España.

15 especies del S de Norteamérica y Sudamérica. En Chile 7 especies.

Brachyclados Don 1832. Asteraceae Del griego brachy $=$ corto y clados=rama, tallo.

3 especies de las regiones templadas de Sudamérica. En Chile 1 especie.

Brachystele Schlech. 1920. OrCHIDACEAE

Del griego brachy=corta y stele=columna; por la estructura de la flor.

22 especies de las regiones tropicales de Sudamérica, especialmente Brasil. En Chile 1 especie.

Bridgesia Bert. ex Cambess. 1834. SAPINDACEAE

En honor de A. T. Bridges, médico inglés que vivió en Chile entre 1828-1833 y herborizó plantas que luego fueron descritas por varios botánicos.

Género monotípico endémico de Chile.

Bromidium Nees \& Meyen 1843. PoACEAE

Significa pequeño Bromus.

5 especies del $\mathrm{S}$ de Estados Unidos y de las zonas subtropicales de Sudamérica. En Chile 2 especies. 
Bromus L. 1753. PoAceae

Del griego bromos = antiguo nombre para la "avena", por su parecido con esa planta ya que sirve de alimento o forraje.

Cerca de 150 especies de Eurasia, N y S de África, trópicos de altura de Asia, América y Juan Fernández. En Chile 10 especies.

Browningia Britton \& Rose 1920. CACTACEAE

En honor a W. E. Browning, director del Instituto Inglés de Santiago, por su labor educativa y las muestras de amistad para con los norteamericanos que venían a Santiago.

11 especies de Perú, Bolivia y Chile con 1 especie.

Bryantiella Porter 1998. Polemoniaceae

En honor de Susanna Bixby Bryant (1880-1946) fundadora del Rancho Santa Ana Botanic Garden en California.

2 especies del NW de América. En Chile 1 especie.

Buddleja L. 1753. (Buddlejaceae) Scrophulariaceae El género fue dedicado por Linneo al Reverendo Adam Buddle (1665-1715), botánico inglés que fue rector de Farmbridge, en Essex, autor de la obra Herbarium of British Plants.

90 especies en el E de Asia, en la zonas tropicales y subtropicales de América y África. En Chile 3 especies.

\section{Bulbostylis Kunth 1837. CyPERACEAE}

Del latín bulbus=bulbo y stylus=estilo; por la forma bulbosa del estilo.

90 especies de las regiones tropicales y subtropicales del mundo. En Chile 1 especie.

\section{Bulnesia Gay 1845. Zygophyllaceae}

Dedicado al general Manuel Bulnes, vencedor de Yungay en la guerra de la Independencia y Presidente de la República de Chile (1841-1851).

8 especies de Venezuela, Colombia, Brasil, Argentina y Chile con 1 especie.

Caesalpinia L. 1753. (Caesalpiniaceae) FABACEAE

En honor a Andrea Caesalpinio (1519-1603), italiano, profesor de medicina e inspector del Jardín Botánico de Pisa. Fue el primero en clasificar las plantas según sus flores y semillas.

Cerca de 150 especies pantropicales, subtropicales, de Argentina, Madagascar, S de África y Arabia. En Chile 4 especies.

Caiophora Presl 1831. LOASACEAE

Del griego cajo, caio=arder y phora, phorum=llevar, ya que al contacto con la piel, su pilosidad produce un fuerte escozor.

56 especies en las regiones templadas de Sudamérica. En Chile 5 especies.
Calandrinia Kunth 1823. Portulacaceae

En honor a Johann Ludwig Calandrini, botánico suizo del S. XVIII, quien en 1734 escribió "Theses de vegetatione \& generatione plantarum".

13 especies desde el $\mathrm{O}$ de Estados Unidos hasta Chile, con 10 especies.

Calceolaria L. 1771. (Scrophulariaceae) CALCEOLARIACEAE Del latín calceolus, diminutivo de calceus=zapato, pantufla, en relación a la forma del labio inferior de la flor.

Cerca de 300 especies en Centro y Sudamérica. En Chile 59 especies.

Caldcluvia Don 1830. Cunoniaceae

En honor a Alexander Caldcleugh, escocés que viajó por Sudamérica (1819-1825), colectando plantas para el Jardín Botánico Real de Kew, Inglaterra.

11 especies de Filipinas, Sulawesi, Molucas, Nueva Guinea, trópicos de Australia y sur de Argentina y Chile con 1 especie.

Calliandra Benth. 1840. FABACEAE

Del griego kalli $=$ hermoso y andros $=$ masculino. Arbusto de hermosos estambres coloreados.

Cerca de 200 especies de Centro y Sudamérica, África, Madagascar y Asia tropical. En Chile 1 especie.

Callianthemoides Tamura 1992. RANUNCULACEAE Parecido a Callianthemum, que significa hermosas flores. Una especie de Argentina y Chile.

Callitriche L. 1748. (Callitrichaceae) Plantaginaceae Del griego kalos=belleza y thrix=pelo, por la apariencia de las pequeñas y delicadas flores, que parecen un mechón verde que flota en el agua.

17 especies cosmopolitas. En Chile 6 especies.

Calopappus Meyen 1834. Asteraceae

Del griego kalos $=$ hermoso y papus=papo, se refiere a la hermosa corona de páleas blancas en el fruto.

Género monotípico restringido a los Andes de Chile central.

Calotheca Desv. 1810. PoACEAE

Del griego kalos=bonito, hermoso y theca=recipiente; por la hermosa forma de su espiga.

Género monotípico de Argentina, Brasil, Uruguay y Chile.

Caltha L. 1754. RANUNCULACEAE

Del griego: canasta, por la forma de la corola.

15 especies, en el Ártico y regiones templadas del Hemisferio Norte, Nueva Zelanda y Sudamérica templada. En Chile 3 especies. 
Calycera Cav. 1797. Calyceraceae

De calyx=cáliz y keros $=$ cuerno, ya que las divisiones del cáliz son en forma de cuerno.

17 especies en regiones templadas de Sudamérica. En Chile 7 especies.

\section{Calydorea Herbert 1843. IRIDACEAE}

Del griego: $c a l y x=$ envainado, cubierto y dory=lanza, alude a las brácteas lanceoladas envainadas, que cubren las flores antes de la antesis. Otra versión es: $k a l o s=$ hermoso y dorea $=$ regalo.

15 especies en regiones tropicales y subtropicales de América. En Chile 1 especie.

\section{Calystegia R. Br. 1810. Convolvulaceae}

Del griego calyx = cáliz, taza y stegos $=$ cubierta, ya que el cáliz está rodeado por dos brácteas.

25 especies de regiones costeras templadas y frías de casi todo el mundo y Juan Fernández. En Chile 2 especies.

\section{Camissonia Link 1829. OnAGRACEAE}

En honor al distinguido botánico y poeta del romanticismo alemán Adalberto von Chamisso (1781-1838), quien estuvo en Talcahuano y Concepción en febrero de 1816. Fue director del Real Jardín Botánico de Berlín.

62 especies de región NO de América, México y Sudamérica templada. En Chile 1 especie.

\section{Campsidium Reiss. \& Seem. 1862. Bignoniaceae}

Del griego: pequeño Campsis (campylon=curvo) en referencia a la forma curva de los estambres.

Género monotípico endémico de Argentina y Chile.

\section{Cardamine L. 1753. BRASSICACEAE}

Del griego: diminutivo de kardamon o kardamis, palabra usada por Dioscórides para un "berro", la cual vale principalmente para Lepidium sativum L., pero tal vez es más correcta para Eucaria aleppica, debido a su parecido con ella.

Cerca de 200 especies en zonas templadas de ambos hemisferios y Juan Fernández. En Chile 15 especies.

\section{Cardionema A. DC. 1828. Caryophyllaceae}

Del griego: kardia=corazón y nema=filamento, hilo, ya que de una mala disección para su ilustración, los estambres parecen nacer de un órgano acorazonado.

6 especies desde el NO de América hasta la Patagonia austral. En Chile 3 especies.

\section{Carex L. 1753. CyPerACEAE}

Del latín carere $=$ faltar, tener defectos; en algunas especies faltan las semillas en la parte superior de la inflorescencia, porque las espigas son masculinas (característica que antiguamente no se conocía). Otra versión, del griego keiro
= cortar, en alusión a los pequeños dientes del margen de la hoja a menudo capaces de cortar en la mano al tomarlas hacia abajo.

Cerca de 2.000 especies cosmopolitas, especialmente en regiones frías y templadas en las partes altas de los trópicos y Juan Fernández. En Chile 67 especies.

Carpha Banks \& Sol. ex R. Br. 1810. Cyperaceae

Voz griega que significa "brizna de paja", alude a las setas plumosas de las flores.

15 especies de Australia, Tasmania, Nueva Zelanda, trópico y S de África, Madagascar, Japón, Nueva Guinea y Sudamérica templada. En Chile 1 especie.

Carpobrotus N.E. Brown 1926. Aizoaceae

Del griego karpos=fruto y brotus $=$ comestible.

30 especies del S de África, Australia, Tasmania, Nueva Zelanda, California y Chile con 1 especie.

Castilleja Mutis ex L. f. 1781. (Scrophulariaceae) Orobanchaceae

En honor al botánico español Domingo Castillejo (17441793), profesor de botánica en Cádiz, España.

200 especies de Eurasia, E de Norteamérica, Centro y Sudamérica. En Chile 4 especies.

Catabrosa P. Beauv. 1812. PoACEAE

Del griego katabronis=consumir o roer, por ser buen forraje o por sus glumas algo erosas.

4 especies de las zonas temperadas de Eurasia, Norteamérica y Chile con 2 especies.

\section{Cenchrus L. 1753. POACEAE}

Del griego = perforar, ya que las espinitas del involucro penetran y se adhieren al pelaje de los animales.

22 especies de zonas templadas, subtropicales y trópicos montanos. En Chile 3 especies.

\section{Centaurea L. 1753. AsteraceAe}

Nombre dado por Dioscórides, médico, farmacólogo y botánico griego (40-90 a.C.) a una pequeña "centáurea" que curó la herida causada por una flecha de Hércules en el pie del centauro Chirón.

Cerca de 250 especies en Eurasia, N de China, N y trópico de África, Australia, Nueva Zelanda, Norteamérica y Chile con 7 especies.

Centaurium J.Hill 1756 emend. Adans. 1763. GentianaCEAE Del latín centum $=$ cien y aurum $=$ oro, es decir vale cien monedas de oro (florines). Con esto se expresan las grandes virtudes curativas de la planta. Otra versión: de kentaurion, el nombre dado por Dioscórides a Centaurium umbellatum, el cual se dice haber curado la herida del pie del centauro Chirón, causada por la lanza de Hércules. 
Cerca de 60 especies, casi cosmopolitas. En Chile 1 especie.

Centaurodendron Johow 1896. AsTERACEAE

Arbolito parecido al género Centaurea.

Género endémico con 2 especies de las islas Juan Fernández, Chile.

Centella L. 1760. APIACEAE

Del latín: diminutivo de centrum=espina, ya que el fruto posee brácteas blanquizcas en la base.

40 especies pantropicales, especialmente de Nueva Zelanda.

En Chile 1 especie en Juan Fernández.

Centipeda Lour. 1790. AsterACEAE

Del latín: centum $=$ cien y pes $=$ pie, en relación a los numerosos tallos rastreros con los que la planta cubre el suelo.

10 especies de Madagascar, Islas Mascareñas (Reunión y Mauricio), Asia, Australia, Nueva Zelanda, Nueva Caledonia, Tahiti y Chile con 1 especie.

Cerastium L. 1753. CARYophyllaceAe

Del griego: keras $=$ cuerno, en relación a la cápsula que sobresale como un cuerno del cáliz.

Cerca de 100 especies cosmopolitas, la mayoría de Eurasia templada. En Chile 1 especie.

\section{Ceratophyllum L. 1753. Ceratophyllaceae}

Del griego: keras=cuerno y phyllum=hoja, ya que las divisiones ahorquilladas de las hojas se ven como pequeños cuernos.

20 especies cosmopolitas. En Chile 1 especie.

Cestrum L. 1753. Solanaceae

kestron $=$ antiguo nombre griego o punta de hierro, porque los estambres tienen un diente en la base de su filamento.

Cerca de 175 especies en América tropical, en Brasil y en los Andes. En Chile 1 especie.

\section{Chaetanthera Ruiz \& Pav. 1794. AsteraceAe}

Del griego: chaeta=mechón y anthera=antera, ya que las anteras tienen apéndices conectivales ciliados.

29 especies en el S de Perú, Bolivia, Argentina y Chile con 28 especies.

Chaptalia Vent. 1800. AsteraceAe

En honor a Jean-Antoine Conde Chaptal de Chanteloup (1756-1832), quien se preocupó de la medicina y de la química; también fue ministro de Napoleón.

60 especies del $\mathrm{S}$ de Norteamérica y trópicos y subtrópicos de América. En Chile 1 especie.

Chascolytrum Desv. 1810. POACEAE

Del griego: $\quad \operatorname{chasco}=$ puerta y elytron=cubierta; probablemente alude a la forma envolvente de la glumela.
6 especies de Estados Unidos, Centro y Sudamérica. En Chile 1 especie

Cheilanthes Sw. 1806. (Pteridaceae) Adiantaceae De keylos=labios y anthos $=$ flores, en relación a las membranas que cubren las esporas.

Cerca de 150 especies cosmopolitas. En Chile 9 especies.

Chenopodium 1. 1753. CHENOPODIACEAE

Del griego: $c h e n=$ ganso y podion=pie, debido a la forma de las hojas de algunas especies.

125 especies cosmopolitas, Juan Fernández e Islas Desventuradas. En Chile 12 especies.

Chersodoma Phil. 1891 emend. Cabr.1978. AsteraceAe Del latín: in sicuo degens=alterado en estado seco.

9 especies en los Andes de Perú, Bolivia, Argentina y Chile con 3 especies.

\section{Chevreulia H. Cass. 1818. Asteraceae}

En honor a Michel Eugene Chevreul (1786-1889), químico francés "padre del jabón" ya que estableció los procesos de saponificación de las grasas animales; fue profesor del Colegio Real de Carlomagno.

5 especies sudamericanas e Islas Malvinas. En Chile 4 especies.

Chiliotrichum Cass. 1817. AsteraceAe

Del griego: chilios=mil y trichum=pelos, por los numerosos pelos del vilano.

2 especies en los Andes de Chile y Argentina.

Chiropetalum Juss. 1832. EupHORBIACEAE

Del griego: chiro=mano y petalum=pétalo, ya que los pétalos son palmitidivididos.

20 especies de México y Sudamérica. En Chile 4 especies.

Chloraea Lindl. 1829. ORCHIDACEAE

Del griego: $\operatorname{chloros}=$ verdoso, ya que algunas flores son verdosas.

50 especies desde Perú a Tierra del Fuego. En Chile 32 especies.

Chloris Sw. 1788. PoAcEAE

Del griego: chloros=verdoso, ya que algunas flores son verdosas.

55 especies cosmopolitas. En Chile 2 especies.

Chorizanthe R. Br. ex Bentham 1836. PolygOnACEAE

Del griego: chorizo=dividir y anthos=flor; por las divisiones de los tépalos.

50 especies de las zonas áridas y semiáridas del Oeste americano. En Chile 13 especies. 
Chrysosplenium L. 1753. SAXIFRAGaceae

Del griego: chrysos=amarillo oro y splen $=$ bazo, por la creencia popular del valor medicinal de estas plantas. 64 especies de las zonas templadas de Sudamérica, Europa, África del Norte y Asia. En Chile 2 especies.

Chuquiraga Juss. 1789. Asteraceae

Nombre de este arbusto en Perú, donde fue descrito por primera vez.

Cerca de 23 especies en los Andes sudamericanos y en la Patagonia. En Chile 5 especies.

Chusquea Kunth. 1822. POACEAE

Nombre vulgar de estas cañas en Colombia y Ecuador (chusque).

Cerca de 110 especies centro y sudamericanas y en Juan Fernández. En Chile 10 especies.

\section{Cicendia Adans. 1763. Gentianaceae}

Parecida a una Gentiana o un Centaurium.

Género de 2 especies: 1 especie en Europa mediterránea, 1 especie en California y Sudamérica. En Chile 1 especie.

Ciclospermum Lag. 1821. APIACEAE

Del griego $c i c l o=$ círculo y sperma $=$ semilla; porque las semillas son redondeadas.

3 especies de Argentina, Bolivia, Brasil, Chile, Paraguay y Uruguay. En Chile 2 especies.

\section{Cissarobryon Kunze ex Poepp. 1833. Vivianaceae}

Del griego: ciss-cisso $=$ hiedra, por los tallos tendidos con ramas ascendentes.

Género monotípico endémico de Chile.

Cissus L. 1753. VitACEAE

Del árabe qissos=hiedra, debido al hábito de la planta.

Cerca de 200 especies principalmente en los trópicos de todo el mundo incluido Australia. En Chile 1 especie.

Cistanthe Spach 1836. Portulacaceae

De Cistus otro género y del griego anthos $=$ flor, por su parecido en el color rojo de las flores.

42 especies de Norte, Centro y Sudamérica. En Chile 24 especies.

Citronella D. Don 1832. (Icacinaceae) CARDIOPTERIDACEAE Por su aroma y sabor parecido al limón.

Cerca de 20 especies en Malasia, E de Australia, Nueva Caledonia, Fidji, Samoa y Sudamérica. En Chile 1 especie.

Clarkia Pursh 1814. Onagraceae

En honor del capitán William Clark (1770-1838), perteneciente a la expedición transcontinental Lewis-Clark, cuyos miembros fueron los primeros en encontrar la planta.
42 especies de Norteamérica, especialmente en California. 1 especie en Chile y Argentina.

Cleome L.1753. (Capparaceae) Cleomaceae Linneo usó este nombre para un género cercano a Sinapsis que ya Tournefort había llamado Sinapistrum.

Cerca de 275 especies en los trópicos y subtrópicos de América. En Chile 1 especie.

Clinanthus Herb.1821. Amaryllidaceae

Del griego $k$ line $=$ inclinado y anthos $=$ flor, por la disposición de las flores.

22 especies de Perú y en Chile una de ellas.

Clinopodium L. 1753. LAMiACEAE

Del griego kline $=$ cama, inclinado y podium = pequeño pie, refiriéndose a los tallos y flores.

38 especies de zonas templadas y subtropicales, mediterráneas. En Chile 4 especies.

Cliococca Babingt. 1735. Linaceae

Del griego: $c l i o=$ encerrar y $c o c c a=$ grano; las semillas quedan encerradas.

Especie monotípica de las zonas templadas de Sudamérica.

Codonorchis Lindl. 1840. ORCHIDACEAE

Del griego: kodon=campanilla y Orchis otro género de la familia, por la forma acampanada de sus flores.

3 especies de las zonas tropicales y templadas de Sudamérica. En Chile 1 especie.

Colletia Comm. 1789. Rhamnaceae

Commerson lo dedicó a D. Collet, botánico francés, quien era su adversario, lo hizo porque la planta tenía unas espinas colosales.

5 especies sudamericanas. En Chile 2 especies, 1 en Juan Fernández.

Colliguaja Molina 1782. EUPHORBIACEAE

Nombre indígena chileno "colliguay", de la planta.

5 especies sudamericanas, 1 en Brasil, Uruguay y Paraguay. En Chile 3 especies.

Collomia Nutt. 1818. Polemoniaceae

Del griego kolla $=$ mucílago, goma de pegar, por sus semillas que tienen un pegajoso revestimiento de mucosa.

15 especies del NO de América, de Bolivia a la Patagonia. En Chile 1 especie.

Colobanthus Bartl. 1831. CARYophyllaceae

Del griego $c o l o=$ pequeño, y anthos=flor, es decir flores pequeñas.

Cerca de 20 especies en Australia, Tasmania, Nueva Zelanda, Sudamérica e Islas subantárticas. En Chile 3 especies. 
Combera Sandwith 1936. SolanaCeaE

En honor a H. F. Comber, colector de la especie tipo en Argentina en 1926.

2 especies endémicas de los Andes de Chile y Argentina entre 1.700 y $2.300 \mathrm{msnm}$.

Conanthera Ruiz \& Pav. 1802. TeCoPhilaEACEAE

De konos=cono y anthera $=$ antera; las anteras se agrupan formando un cono.

Género endémico de Chile con 5 especies.

\section{Convolvulus L. 1754. Convolvulaceae}

Del latín convolvere $=$ torcer, dar vueltas, debido al crecimiento voluble de varias de estas plantas.

Cerca de 150 especies en las zonas templadas del mundo. En Chile 6 especies.

\section{Conyza Less. 1832. Asteraceae}

De mosquito, pues debido a su viscosidad es apropiada para la captura de insectos.

Cerca de 60 especies de las zonas tropicales y subtropicales de todo el mundo. En Chile 20 especies.

\section{Copiapoa Britton \& Rose 1922. CACTACEAE}

En honor a la ciudad de Copiapó, capital de la III Región de Chile.

Género endémico del norte árido de Chile con aproximadamente 22 especies.

\section{Coprosma Forst. 1776. RUBIACEAE}

De kopros $=$ estiércol y osme $=$ olor, ya que la planta tiene muy mal olor.

Cerca de 90 especies en Malasia, Australia, Nueva Zelanda, Islas del Pacífico, Hawaii y Juan Fernández, Chile con 2 especies.

Cordia L. 1753. BoraginaceAe

En honor a Eurich Cordus (1486-1535) y a su hijo Valerius Cordus (1515-1544), ambos botánicos.

Cerca de 320 especies de las regiones tropicales y subtropicales de todo el mundo. En Chile 1 especie.

\section{Coreopsis L. 1753. Asteraceae}

De koris= chinche y opsis=forma, apariencia, por la forma del aquenio.

Cerca de 70 especies de América tropical y África. En Chile 1 especie.

\section{Coriaria L. 1753. CORIARIACEAE}

Del latín: corium=cuero. Las hojas de este arbusto contienen mucho tanino, que se usa para curtir el cuero.

15 especies de México a Chile, O del Mediterráneo, de Los Himalayas a Japón, Nueva Guinea y Nueva Zelanda. En Chile 1 especie.
Corrigiola L. 1753. CARYoPhyLlaCEAE

Del latín: corrigia $=$ cordón y ésta de corium $=$ cuero; ya que los tallos se extienden por el suelo como cordones de zapatos desatados.

13 especies en los Andes de Sudamérica de Colombia a Chile, Europa, Mediterráneo, África y Madagascar. En Chile 3 especies.

Corryocactus Britton \& Rose 1920. CACTACEAE

En honor a T. A. Corry, ingeniero jefe de ferrocarriles en Perú, quien colaboró con los autores en la búsqueda de cactáceas en ese país.

12 especies de Bolivia, $\mathrm{S}$ de Perú y $\mathrm{N}$ de Chile, con 1 especie.

\section{Cortaderia Stapf 1897. POACEAE}

Nombre vulgar sudamericano por los bordes de sus hojas cortantes al tacto.

Cerca de 25 especies en Sudamérica e Islas Malvinas, Nueva Zelanda y Nueva Guinea. En Chile 6 especies.

Corynabutilon (K.Schum.) Kearney 1949. MaLVACEAE Del griego: koryne $=$ clava, por la forma de los estilos y del árabe abutilon, nombre vernacular de la planta.

Cerca de 7 especies endémicas de Argentina y Chile.

\section{Cotula L. 1753. AsteraceAe}

Del latín: pequeña copa o hueco de la mano, en relación a la base de las hojas amplexicaules.

Cerca de 55 especies en Sudáfrica, Nueva Zelanda, Nueva Guinea, Australia y Sudamérica. En Chile 1 especie.

\section{Crassula L. 1753. Crassulaceae}

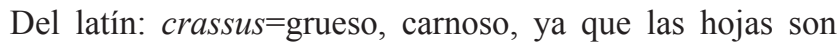
gruesas y jugosas.

Cerca de 200 especies cosmopolitas, especialmente de Sudáfrica. En Chile 7 especies.

Cremolobus DC. 1821. BRASSICACEAE

Del griego: cremo=colgar y lobus=vainas; por la disposición de las semillas en la vaina.

7 especies en los Andes sudamericanos desde Colombia a Chile, con 1 especie.

\section{Cressa L. 1753. Convolvulaceae}

De mujer cretense, es planta nacional de Creta.

5 especies en zonas tropicales y subtropicales. En Chile 1 especie.

Crinodendron Molina 1782. ElaEocarpaceae Del griego: $c r i n o=$ parecido a la azucena y dendron=árbol; significa árbol con flores parecidas a la azucena blanca.

5 especies en Bolivia, $\mathrm{N}$ de Argentina, Brasil y Chile central, con 2 especies. 
Cristaria Cav. 1799. MalvaCeAe

Del latín: crista=peine; el fruto tiene alas que coronan los carpelos.

Cerca de 75 especies de Chile, Argentina, Bolivia, Perú e Islas Desventuradas. En Chile 19 especies.

Croton L. 1753. EupHORBIACEAE

Del griego: kroton=así llamaron los antiguos griegos al árbol egipcio Ricinus communis (higuerilla). También de "garrapata", por el parecido de la semilla con este insecto. Cerca de 1.250 especies en las zonas tropicales y subtropicales de todo el mundo. En Chile 1 especie.

Cruckshanksia Miers ex Hook. \& Arn.1833. RuBiACEAE En honor de Alexander Cruckshanks, viajero inglés que residió en Chile (h.1830) y envió ejemplares a Europa, especialmente al botánico inglés William Jackson Hooker (1785-1865).

7 especies endémicas de Chile y Argentina, en Chile las 7.

Cryptantha Lem. ex G.Don 1833. BoraginaceaE

Del griego: krypthos $=$ oculto y anthos $=$ flor, porque varias especies presentan flores cleistógamas.

Cerca de 100 especies americanas, principalmente en Norteamérica; también en Perú, Bolivia, Chile y Argentina. En Chile 40 especies.

Cryptocarya R.Br. 1810. LAURACEAE

Del griego: krypthos $=$ oculto y carya $=$ núcleo, nuez; porque en varias especies el fruto se ubica en el conducto abayado cerrado de la cubierta de las flores.

Cerca de 230 especies en los trópicos y subtrópicos de todo el mundo. En Chile 1 especie endémica.

Cryptogramma R.Br. 1823. (Pteridaceae) AdiantaCEAE Del griego: $k r y p t h o s=$ oculto y gramma=línea, raya, porque los soros son liniformes y están bajo un indusio.

2 especies de las zonas temperadas de todo el mundo. En Chile 1 especie.

Cuatrecasasiella H.Rob. 1985. AsTERACEAE

En honor de José Cuatrecasas Arumí (1903-1996), botánico español que realizó grandes aportes a la botánica en Colombia.

2 especies de Ecuador, Perú, Chile y Argentina. En Chile 1 especie.

Cuminia Colla 1835. LAMIACEAE

En honor a Hugo Cumini, colector de hongos de Pisa, Italia.

1 especie endémica del Archipiélago de Juan Fernández, Chile.

Cumulopuntia Ritter 1980. CACTACEAE
Del latín: cumulus=montón, por el hábito de la planta. 20 especies de Bolivia, S de Perú y N de Chile. En Chile 2 especies.

\section{Cuscuta L. 1753. Convolvulaceae}

Del árabe: kechout. Theofrasto lo deriva de atar, apretar, en relación al crecimiento de la planta, que es a la vez parasitario.

Cerca de 155 especies cosmopolitas. En Chile 11 especies.

Cynanchum L. 1753. (Asclepiadaceae) APOCYNACEAE Del griego kyon o kynos=perro y anchein $=$ matar; referido al supuesto uso para envenenar perros.

En sentido amplio comprende ca. de 300 especies de regiones templadas, tropicales y subtropicales del mundo, con sus principales centros de diversidad en Madagascar, sur de China y los Andes americanos.

4 especies en Chile. (Otros fueron transferidos al género Diplolepis).

\section{Cynodon Rich. 1805. PoAceaE}

Del griego: $k y n o s=$ perro y odus=diente, porque los rizomas tienen escamas blancas y agudas.

9 especies de zonas tropicales y subtropicales de todo el mundo. En Chile 2 especies.

Cynoglossum L. 1753. BoraginaCeAE

Del griego: $k y n o s=$ perro y glossum=lengua, en relación a la forma y blandura de las hojas.

75 especies de las zonas tropicales y subtropicales de todo el mundo. En Chile 1 especie.

Cyperus L. 1753. CyPeraceae

Esencialmente de "Venus" debido a las cualidades afrodisíacas de la planta, por cuya razón las sabrosas raíces de Cyperus suculentus son usadas en Oriente. Bahuin opina que derivó de "vasija", debido a la forma ovada de la raíz. Cerca de 400 especies de las zonas tropicales, subtropicales, templadas y en la Isla Juan Fernández. En Chile 14 especies.

Cyphocarpus Miers 1848. CAmpanulaceae Del griego: cypho=joroba, protuberancia y carpus=fruto. Género endémico de Chile con 3 especies.

Cystopteris Bernhardi 1806. (Dryopteridaceae) WOOdSIACEAE

Del griego: cystis=vejiga y pteris=helecho; alude a la forma del indusio.

12 especies de zonas templadas, tropicales y en trópicos de altura. En Chile 1 especie.

Dalea L. 1753. FABACEAE

En honor a Samuel Dale (1650-1739), doctor en Bocking, 
Essex, Inglaterra, escribió "Pharmacologia”. Otro botánico, Thomas Dale, escribió en 1723 una disertación médicobotánica sobre la Pereira brava.

Cerca de 165 especies americanas desde Canadá hasta Argentina y Chile con 3 especies.

\section{Danthonia DC. 1805. PoACEAE}

En honor al botánico francés Etienne Danthoine, de comienzos del siglo XVIII.

Cerca de 20 especies de Europa, Cáucaso y América. En Chile 4 especies.

\section{Dasyphyllum Kunth 1820. AsterACEAE}

Del griego: dasy=áspero, peludo y phyllum=hoja, ya que las hojas son peludas por ambos lados, tallos ásperos y espinosos en el ápice y en la axila de ellas.

Cerca de 40 especies sudamericanas. En Chile 2 especies.

\section{Daucus L. 1753. APIACEAE}

Del griego: dauxos=quemar. Para los antiguos los "dauxos" eran plantas que producían excitación. Dioscórides distinguió 3 especies de dauxos, pero nuestra actual especie no es idéntica a ellas.

22 especies cosmopolitas. En Chile 2 especies.

Davallia Sm. 1793. Davalliaceae

En honor al botánico inglés Edmund Davall (1763-1798), que vivió la mayor parte de su vida en Suiza.

Cerca de 90 especies cosmopolitas. En Chile 1 especie.

Dendroseris D.Don. 1832. AsterACEAE

Del griego: dendron=árbol y seris=lechuga, árbol de hábito parecido a las lechugas.

Género endémico con 11 especies del Archipiélago Juan Fernández, Chile.

Dennstaedtia Bernh. 1801. Dennstaedtiaceae

En honor a August W. Dennstaedt, médico y botánico, director del Jardín Belvedere cerca de Weimar, Alemania. Tiene varias obras: Weimar Flora, 1800; Nomenclator Botanicus, 1810; Hortus Belvedereanus, 1818.

45 especies de zonas calurosas y templadas de todo el mundo. En Chile 1 especie.

\section{Deschampsia P.Beauv. 1812. PoAceae}

En honor a J. C. A. Loiseleur Deslongchamps (1774-1849), miembro de la Academia de Medicina de Francia.

35 especies comunes a ambos hemisferios, incluida la Antártica. En Chile 15 especies.

Descurainia Webb \& Berthel. 1836. BRASSICACEAE En honor a François Descuraine (1658-1740), farmacéutico francés, amigo de Antoine Laurent de Jussieu (1748-1836), famoso botánico francés.
Cerca de 40 especies de América e Islas Canarias. En Chile 12 especies.

Desfontainia Ruiz \& Pav. 1794. Desfontainiaceae En honor a Rene Louiche Desfontaines (1750-1833), botánico francés profesor del Jardín de Plantas de París.

Género monotípico desde Costa Rica al Cabo de Hornos.

Desmaria van Tiegh. 1895. LORANTHACEAE

Del griego: desma=ramo; ya que las flores van agrupadas en un denso ramo de cortos pedúnculos.

Género monotípico endémico de Chile.

Deuterocohnia Mez 1894. Bromeliaceae

Del griego: deutero=segundo y Cohnia $=$ otro género de monocotiledóneas.

13 especies sudamericanas. En Chile 1 especie.

Deyeuxia Clarion \& Beauv.1812. POACEAE

En homenaje al célebre químico M. Deyeux, miembro del "Institut de l'Athénée des Arts \& de Plusiers Sociétés Savantes", en París.

42 especies de zonas templadas, subtropicales y trópicos montanos. En Chile 22 especies.

Dichanthelium (A.S.Hitchc. \& Chase) Gould 1974. PoAcEAe

Del griego: dichan $=$ dos y anthele $=$ pequeña flor, por los 2 períodos de floración que tiene la mayoría de las especies. 58 especies en toda América. En Chile 1 especie.

Dichondra J.R.Forst. \& G.Forst. 1776. Convolvulaceae De doble y grano; en cada cápsula con dos lóculos hay dos semillas.

7 especies en trópicos y subtrópicos del mundo y en Juan Fernández. En Chile 2 especies.

Dicksonia L'Hér. 1789. DiCKSONIACEAE En honor a James Dickson (1738-1822), botánico y cultivador inglés.

20 especies de las zonas tropicales de todo el mundo. En Chile 2 especies.

Dicliptera Juss. 1807. ACANTHACEAE

De diklis=doble puerta y pteron=ala (alada); ya que la cápsula es de base bicolumnar y se separa hacia arriba en 2 valvas aladas.

Cerca de 200 especies de los trópicos y subtrópicos de todo el mundo. En Chile 1 especie.

Dielsiochloa Pilger 1943. POACEAE

Dedicado a Friedrich Ludwig Emil Diels (1874-1945) del Museo y Jardín Botánico de Berlín-Dahlem.

Género monotípico de Perú, Bolivia, Argentina y Chile. 
Digitaria Haller 1768. POACEAE

Del latín digitus $=$ dedos, por la disposición de las ramas de la inflorescencia.

220 especies de zonas templadas, subtropicales y trópicos montanos. En Chile 2 especies.

\section{Dinemagonum Juss. 1843. MAlPIGHIACEAE}

Del griego: $d i=$ dos, nema=filamento y agonos=estéril, referido a que de 10 estambres, 2 son estaminodios estériles.

Género monotípico endémico de Chile.

Dinemandra Juss. ex Endl. 1840. MalpighiaceAe

Del griego: $d i=\mathrm{dos}, n e m a=$ filamento y andra $a$ masculino; de 10 estambres sólo 2 tienen anteras.

Género monotípico endémico de Chile.

\section{Dioscorea L. 1753. DioscoreaceAe}

En honor a Pedanio Dioscórides Anazarbeo (Anazarbus), Cilicia, en Asia Menor (c. 40 - c. 90 a.C.), fue un médico, farmacólogo y botánico de la antigua Grecia.

Cerca de 400 especies en las regiones tropicales, subtropicales y templadas de todo el mundo. En Chile 36 especies.

\section{Diostea Miers 1870. Verbenaceae}

Del griego: $d i o=$ dos y $o s t e o=$ hueso, se refiere a las dos nueces duras que produce cada flor.

4 especies en las regiones templadas de Sudamérica. En Chile 1 especie.

Diplazium Sw. 1801. (Dryopteridaceae) WoodsIACEAE Del griego: diplazios $=$ doble, aludiendo al indusio doble de los soros.

Cerca de 300 especies cosmopolitas. En Chile 1 especie.

Diplolepis R.Br. 1809. APocynaCEAe

De diploos=doble y lepis=escama, ya que las flores llevan una corona que rodea los estambres.

6 especies endémicas de Chile y Argentina.

\section{Diplostephium Kunth 1820. Asteraceae}

De diploos=doble y stephan=corona, ya que el papo es doble, erizado por dentro y por fuera.

Cerca de 90 especies en los Andes tropicales desde Colombia al N de Chile; 1 especie en Costa Rica. En Chile 2 especies.

\section{Diposis DC. 1829. APIACEAE}

De (doble) y (novio, marido), ya que las umbelas son de tres flores. La flor del medio es fecunda y las laterales son sólo masculinas.

3 especies en las regiones templadas de Sudamérica. En Chile 1 especie.
Discaria Hook. 1830. RHAMNACEAE

De diskos=disco, ya que el pistilo está rodeado de un disco carnoso en forma de llave.

8 especies de Australia, Nueva Zelanda y Sudamérica. En Chile 2 especies.

Dissanthelium Trin. 1836. POACEAE

Del griego: dissos $=$ doble y anthelion=pequeña flor.

16 especies en California, Bolivia, Perú y Chile con 1 especie.

Distichia Nees \& Meyen 1843. JunCACEAE

Del griego: distichia $=$ doble fila; probablemente por la disposición de las espiguillas.

3 especies de los Andes sudamericanos. En Chile 2 especies.

Distichlis Raf. 1815. POACEAE

Del griego: distichos=en dos hileras, ya que las hojas están dispuestas en dos hileras.

9 especies desde Canadá a Sudamérica. En Chile 3 especies.

Dodonaea L. 1753. SAPINDACEAE

En honor a Rembert Dodonée, Dodonaeus en latín (15181585), belga. Doctor de cámara del Emperador Maximilian II y de Rodolph II y profesor en Leyden.

68 especies en los trópicos y subtrópicos, especialmente en Australia. En Chile 1 especie.

Domeykoa Phil. 1860. APIACEAe

En honor a Ignacio Domeyko (1802-1889), natural de Polonia, que fue contratado por el Gobierno chileno para desempeñarse como profesor de química y mineralogía en el Liceo de Coquimbo y en el Instituto Nacional. Tuvo una participación relevante en la fundación de la Universidad de Chile.

4 especies de Perú y Chile. En Chile 2 especies.

Donatia J.R.Forst. \& G.Forst. 1775. STYLIDIACEAE

En honor a Vitaliano Donati (1713-1762), naturalista italiano, profesor en Turín; autor de la Historia Natural de Turín, su colección de plantas llegó en parte a posesión de Linneo.

2 especies en Tasmania, Nueva Zelanda y región subantártica de Sudamérica. En Chile 1 especie.

Doniophyton Wedd. 1855. Asteraceae

En honor a George Don (1798-1856), botánico escocés, que puso la especie original en el género Chuquiraga. Su obra principal la constituyen cuatro volúmenes de "A General System of Gardening and Botany", que se publicó entre 1832 y 1838.

2 géneros endémicos de los Andes patagónicos de Chile y Argentina. 
Doodia R.Br. 1810. Blechnaceae

Dedicado a Samuel Doody (1656-1706), boticario de Londres, aficionado a estudios botánicos, quien se hizo cargo del Jardín de Plantas Medicinales de Chelsea.

12 especies de Australia, Nueva Zelanda, Nueva Guinea, Islas del Pacífico, Hawai e Isla de Pascua. En Chile 1 especie.

\section{Downingia Torrey 1857. Campanulaceae}

En honor de Andrew Jackson Downing (1815-1852), jardinero paisajista norteamericano y notable pomologista. 11 especies principalmente del O de Norteamérica. En Chile 1 especie.

Draba L. 1753. BRASSICACEAE

Del griego: drabe=acre, picante, aplicado por Dioscórides a algunas crucíferas.

Cerca de 350 especies del Árctico, regiones templadas del Hemisferio Norte, Asia, regiones altas de Centro y Sudamérica. En Chile 8 especies.

\section{Drapetes Banks ex Lam. 1792. ThymelaeACEAE}

Del griego: drapetes=huir, escapar, posiblemente aludiendo a su hábito rastrero.

Género monotípico de las regiones temperadas de Sudamérica, incluido Chile.

Drimys J.R.Forst. \& G.Forst. 1776. WinteraceaE

Del griego: drimys=acre, picante, refiriéndose al sabor de su corteza y de sus hojas. El nombre winteri, de la especie chilena, en honor a William Winter, quien obtuvo algunos ejemplares en 1578 en el viaje de Drake.

11 especies de México, Centro y Sudamérica y Juan Fernández. En Chile 3 especies.

\section{Drosera L. 1753. DROSERACEAE}

Del griego droseros=rociado, aludiendo a que la planta parece estar cubierta de rocío, a causa de las gotitas que se desprenden del ápice de los pelos que cubren sus hojas.

Cerca de 115 especies cosmopolitas, especialmente de Australia, Tasmania y Nueva Zelanda. En Chile 1 especie.

Drymaria Willd. ex Roem. \& Schult. 1819. Caryophyllaceae

De drymos = madera, por el hábitat (bosque de robles o encinas), o nudoso, ya que a menudo salen raíces de estos nudos, las que forman pequeños bosques.

Cerca de 50 especies pantropicales. En Chile 3 especies.

Dryopteris Adans. 1763. DRYOPTERIDACEAE

Del griego: $d r y a d=$ ninfa del bosque o dryos=roble, encina y pteris=helecho; por crecer en estos bosques.

Cerca de 150 especies cosmopolitas. En Chile 1 especie.
Dunalia Kunth 1818. SolanaceaE

En honor a Michel Felix Dunal (1789-1856), francés, profesor de botánica en Montepellier. Escribió: Historie Naturelle des Solanum, 1813, Synopsis Solanorum, 1816 y también sobre algas.

5 especies de los Andes desde Colombia a la Patagonia. En Chile 1 especie.

Dysopsis Baill. 1858. EuPHORBIACEAE

Del griego, poco vistosa.

Género andino de 2 especies de los Andes de Costa Rica, Ecuador, Argentina y Chile, incluso en Juan Fernández.

Dysphania R.Br. 1810, emend. Mosyakin \& Clemants, 2002. Chenopodiaceae

Del griego $d y s=$ con dificultad y phanos $=$ antorcha o phaneros $=$ evidente, conspicuo, visible, y se refiere a las flores muy pequeñas, apenas visibles.

Corresponde a las especies antes tratadas como Chenopodium subgénero Ambrosia, con 32 especies de distribución en todo el mundo. En Chile 4 especies.

Eccremocarpus Ruiz \& Pav. 1798. BignONIACEAE Del griego: ekkremos=colgante y karpos $=$ fruto. 5 especies de Perú, Argentina y Chile con 1 especie.

Echinodorus Rich. \& Engelm. ex A.Gray 1848. Alismataceae

Del latín echino=puerco espín y dorus=botella o recipiente, y se refiere a los frutos espinosos.

26 especies desde EUA a Argentina y Chile, con 1 especie.

Elaphoglossum Schott ex J. Sm. 1814. Dryopteridaceae Del griego: elapho=ciervo y glossum=lengua; por la forma de la fronda.

Cerca de 400 especies de las regiones tropicales y pantropicales, especialmente Madagascar e Isla de Pascua. En Chile 6 especies.

Elatine L. 1753. Elatinaceae

Del griego, nombre del abeto, o del árabe: elatyny.

12 especies de regiones temperadas, tropicales y subtropicales. En Chile 1 especie.

Eleocharis R. Br. 1810. CyPERACEAE

Del griego helos, heleos=pantano y charis=gracia, hermosura; alude al hábitat pantanoso de estas especies.

Cerca de 200 especies cosmopolitas y en Juan Fernández. En Chile 18 especies.

Elodea Ric. 1803. HydrocharitaceAe

Voz griega que alude al hábitat pantanoso de estas especies. 9 especies en toda América templada. En Chile 1 especie. 
Elymus L. 1753. Poaceae

Nombre griego para una clase de mijo, o del griego: envolver; ya que las hojas sirven para gruesos trenzados. También podría ser por Elyma, una ciudad de Macedonia. Cerca de 150 especies de las regiones templadas y subtropicales y en los trópicos montañosos. En Chile 4 especies.

Elytropus Müll.Arg. 1860. ApocynaCeAe Probablemente deriva del griego y alude a la naturaleza voladora de la semilla o tal vez a que el fruto aquillado se retuerce.

Género monotípico endémico de Chile y Argentina.

Embothrium J.R.Forst. \& G.Forst. 1776. PROTEACEAE

Del griego: $\mathrm{em}=\mathrm{en}$ y bothrion=fosa, ya que las anteras están ubicadas en una cavidad de los tépalos.

Género monotípico endémico de Chile y Argentina.

Empetrum L. 1753. (Empetraceae) ERICACEAE

Del griego: $\mathrm{em}=\mathrm{en}$ y petrum=piedra, porque crece entre las rocas.

3 especies en las regiones templadas del Hemisferio Norte, Ártico, Andes sudamericanos, Islas Malvinas y Juan Fernández. En Chile 1 especie.

Encelia Adans. 1763. AsteraceAe

En honor de Christopher Entzelt (1517-1583), naturalista y temprano pastor luterano alemán, que latinizó su apellido a Encelius, y en 1577 escribió "De uva quercina": sobre las agallas de las encinas.

15 especies del SO de Estados Unidos, México, Chile, Perú y Galápagos. En Chile 1 especie.

Enneapogon Desv. ex P.Beauv. 1812. PoACEAE

Del griego: ennea $=$ nueve y pogon=barba; alude a las 9 aristas ciliadas que posee la lemma.

35 especies de las regiones templadas de Europa y en los trópicos y subtrópicos americanos. En Chile 1 especie.

Ephedra L. 1753. EPHEDRACEAE

Del griego, (sobre) y (asiento); por su hábito apoyante.

Cerca de 60 especies en Eurasia y América. En Chile 7 especies.

Epilobium L. 1753. Onagraceae

Del griego, epi=sobre y lobos=vaina, es decir, la flor se ubica en la punta del fruto.

164 especies cosmopolitas. En Chile 12 especies.

Epipetrum Phil. 1862. DiosCoreaceAe

Del griego $e p i=$ sobre y petro $=$ piedra, sobre piedras. Existe un trabajo reciente (Viruel et al. 2010) que las incluye dentro de Dioscorea.

Género endémico de Chile con 3 especies.
Equisetum L. 1753. EquiseTACEAE

Del latín: equus=caballo y seta $=$ cola, por la forma de sus tallos.

30 especies cosmopolitas. En Chile 2 especies.

Eragrostis Wolf 1776. POACEAE

Del griego: eros = amor y agrostis=pasto; otra versión es de era $=$ tierra, ya que es común en praderas.

Cerca de 300 especies de climas templados y tropicales y en Islas Desventuradas. En Chile 8 especies.

Ercilla A.Juss. 1832. PhytolacCaCEAE

En honor al poeta y soldado español Don Alonso de Ercilla y Zúñiga (1533-1593), autor del poema épico La Araucana. Género endémico de Chile con 2 especies.

Erechtites Raf. 1817. AsterACEAE

Nombre mencionado por Dioscórides para una planta presumiblemente hoy referida a Senecio o a otro género relacionado.

5 especies de Norte y Sudamérica. En Chile 1 especie.

Eremocharis Phil. 1860. APIACEAE

Del griego: eremo $=$ desierto y charis $=$ gozo, alegría .

9 especies en los Andes de Perú y Chile con 1 especie.

Eremodraba O.E.Schulz 1924. BRASSICACEAE

Del griego: eremo=desierto y Draba, otro género.

2 especies en los Andes de Perú y Chile. En Chile 1 especie.

Eriachaenium Sch.Bip. 1855. Asteraceae

Del griego, erion=lanoso y achenium= aquenio (el fruto), por la característica de éste.

Género monotípico de la Patagonia Chilena y Argentina.

Erigeron L. 1953. Asteraceae

Del griego: eri=temprano y geron=anciano, haciendo referencia a lo rápido que se marchitan las flores y aparecen los vilanos grises.

Cerca de 400 especies en Eurasia, Norte y Sudamérica, Australia y Juan Fernández. En Chile 17 especies.

Eriochloa Kunth 1816. POACEAE

Del griego erion=lana y chloe o chloa=pasto; por ser un pasto lanoso.

30 especies de zonas templadas y subtropicales. En Chile 1 especie.

Eriosyce Phil. 1872. CACTACEAE

Del griego: erion=lanoso y sykos=higo, en referencia a la lanosidad del fruto.

Género endémico de Chile con 5 especies. 
Erodium L'Hérit. 1787. GeraniaCEAE

De erodius=garza, en relación a la cápsula larga como patas de garza.

75 especies cosmopolitas. En Chile 1 especie.

Errazurizia Phil. 1872. FABACEAE

En honor a Federico Errázuriz Zañartu, Presidente de Chile entre 1871 y 1876 .

4 especies del SO de Norteamérica, México y Chile, con 1 especie.

Eryngium L. 1753. APIACEAE

Del griego: eringion $=$ nombre usado por Teofrasto aplicado a una pequeña planta espinosa.

Cerca de 240 especies cosmopolitas, también en Juan Fernández. En Chile 15 especies.

\section{Escallonia Mutis ex L.f. 1781. EsCALlONIACEAE}

En honor al viajero y botánico español Antonio Escallón, discípulo de José Celestino Mutis (1732-1808), y contemporáneo de Linneo, quien fue el primero en recolectar un ejemplar de este género en Colombia.

40 especies en los Andes sudamericanos, SE de Brasil y Juan Fernández. En Chile 14 especies.

\section{Eucryphia Cav. 1797. CunONIACEAE}

Del griego: $e u=$ verdadera y cryphia $=$ cofia cónica, alude a la naturaleza y forma de los sépalos caliptrados.

6 especies en el SE de Australia, Tasmania y Chile. En Chile 2 especies.

\section{Eudema Bonpl. 1813. BrassiCACEAE}

En honor de Eudemus de Rhodus (325 a.C.), alumno de Aristóteles, que ideó una clasificación notable de las Brassicáceas arrepolladas.

6 especies en los Andes desde Ecuador hasta Chile y Argentina. En Chile 3 especies.

\section{Eulychnia Phil. 1860. CACTACEAE}

Del griego: $e u=$ verdadero y lychnia $=$ candelabro, aludiendo a la ramificación de sus tallos.

Género con 6 especies en Chile y una subespecie en Perú.

\section{Euphorbia L. 1753. EuPHORBIACEAE}

En honor de Euphorbos (54 a.C.), médico de cámara del rey Juba de Mauritania, su nombre significa "el hombre que ordenó las hierbas comestibles", aunque las Euphorbiaceae no son comestibles.

Cerca de 2.000 especies subcosmopolitas, en Chile 23 especies.

Euphrasia L. 1753. (Scrophulariaceae) Orobanchaceae Del griego: $e u=$ bueno, verdadero y phren=ánimo, mente. En relación a las propiedades medicinales de la planta, especialmente para los ojos.

Cerca de 300 especies cosmopolitas. En Chile 15 especies.

Evolvulus L. 1764. Convolvulaceae

Del latín: envolvere $=$ desarrollar; es una hierba tendida o rastrera.

Cerca de 100 especies de regiones tropicales y subtropicales. En Chile 1 especie.

Exodeconus Raf. 1838. SOlAnACEAE

Del griego: exodos $=$ saliendo y konos $=$ cono, por la forma de la flor.

6 especies en Sudamérica y Galápagos. En el N de Chile 3 especies.

Fabiana Ruiz \& Pav. 1794. Solanaceae

En honor de Francisco Fabiano (1719-1801), religioso español, Arzobispo de Valencia, que fue botánico aficionado.

15 especies del S de Perú, Bolivia, Argentina y Chile con 8 especies.

Facelis Cass. 1819. AsterACEAE

Del latín: $f a x=$ antorcha, en relación a la apariencia de la planta, ya que el tallo nudoso termina en una floración espigosa.

4 especies en Sudamérica. En Chile 2 especies.

Fagara L. 1759. RUtACEAE (ver Zanthoxylum)

Fagonia L. 1753. ZyGOPHYLLACEAE

En honor a Guy Crecent Fagon (1638-1718), profesor de botánica francés y médico de cámara de Luis XIV.

Cerca de 30 especies en las regiones templadas de todo el mundo, excepto Australia. En Chile 2 especies y 1 variedad.

Famatina Ravenna 1972. AMARYLLIDACEAE

Conmemora el cordón montañoso de Famatina, provincia de La Rioja en Argentina, donde se encontró la especie tipo.

2 especies de Chile y Argentina.

Fascicularia Mez 1894. Bromeliaceae

Alude a la disposición fasciculada o agrupada de sus hojas. Género monotípico endémico de Chile.

Festuca L. 1753. POACEAE

Del celta: fest=alimento, porque es un buen forraje.

Cerca de 500 especies cosmopolitas. En Chile 25 especies.

Ficinia Schrader 1832. CYPERACEAE

En honor de H.D.A.Ficinus (1782-1857), nacido en Dresden, Alemania, médico y profesor cerca de 1815; escribió Flora de Dresden. 
60 especies del hemisferio sur (Australia, Nueva Zelanda, Santa Helena, San Paul y África sub-Sahara). En Chile una especie.

Fitzroya Hook.f. ex Lindl. 1851. CuPRESSACEAE En honor al ilustre marino británico Robert Fitz Roy (18051865), capitán de la Beagle, barco en el que navegó Charles Darwin, recalando en varios puntos del territorio chileno. Especie monotípica endémica de Chile y Argentina.

Flaveria Juss. 1789. AsteraceAe

Del latín: flavus=amarillo; sus flores de color amarillo son usadas para teñir.

22 especies principalmente americanas, con 1 especie en Australia. En Chile 1 especie.

\section{Flourensia DC. 1836. AsterACEAE}

En honor a Pierre Flourens (1794-1867), médico y biólogo francés contemporáneo de Augustin Pyramus de Candolle (1778 - 1841), quien describió por primera vez este género. 31 especies de América. En Chile 1 especie.

Fonkia Phil. 1859-60. (Scrophulariaceae) Plantaginaceae En honor a Francisco Adolfo Fonck Foveaux (1830-1912), médico y naturalista alemán, que llegó a Chile en 1854 y recolectó numerosas plantas para $\mathrm{R}$. A. Philippi.

Especie monotípica endémica de Chile y Argentina.

Francoa Cav. 1801. (Francoaceae) Melianthaceae En honor a Francisco Franco (siglo XVI), médico valenciano, promotor de la botánica española.

Género monotípico endémico de Chile.

Frankenia L. 1753. FRANKENIACEAE

En honor a J. Franke (1590-1661), botánico sueco; fue el primero que escribió sobre las plantas de su país.

Cerca de 50 especies de las regiones templadas de todo el mundo. En Chile 6 especies.

Fuchsia L. 1753. Onagraceae

En honor a Leonard Fuchs (1501-1566), alemán; defensor de la medicina hipocrática y botánico, escribió: De Historia Stirpium en 1542.

Cerca de 105 especies de Centro y Sudamérica, Nueva Zelanda y Tahiti. En Chile 2 especies.

Fuertesimalva Fryxell 1996. MaLvaceAe

En honor del botánico español Javier Fuertes, y Malva. Fuertes es contemporáneo del autor y ha contribuido al estudio de la familia Malvaceae.

14 especies de México, Andes centrales, Galápagos e Islas Desventuradas. En Chile 3 especies.

Gaimardia Gaudich. 1826. CENTROLEPIDACEAE
En honor a Joseph Paul Gaimard (1796-1858), médico y zoólogo francés, participó en el viaje por el mundo de Freycinet.

3 especies de Nueva Guinea, Nueva Zelanda, Tasmania, Tierra del Fuego e Islas Malvinas. En Chile 1 especie.

Galium L. 1753. RUBIACEAE

Del griego: gala=leche, ya que se usaba la leche de esta planta para la coagulación.

Cerca de 350 especies cosmopolitas, también en Juan Fernández. En Chile 20 especies.

Gamocarpha DC. 1836. CALYCERACEAE

Del griego: gamos=unido y carphos=escama; las 5-6 escamas exteriores están unidas en el medio.

6 especies de las regiones templadas de Sudamérica. En Chile las 6 especies.

\section{Gamochaeta Wedd. 1856. AsterACEAE}

Del griego: gamos=unido y $\operatorname{chaeta}=$ seta; alude a los pelos del vilano, unidos en su base.

Cerca de 65 especies en Norte y Sudamérica y en Juan Fernández. En Chile 24 especies.

Gamochaetopsis Anderb. \& Freire 1991. AsterACEAE Del género Gamochaeta y del griego: opsis=apariencia; por su parecido al primer género.

Género monotípico del S de Argentina y Chile.

Gaultheria L. 1753. ERICACEAE

En honor a Jean Francoise Gaulthier (1708-1756), botánico canadiense, de Quebec, médico del Rey alrededor de 1750. Cerca de 140 especies semicosmopolitas. En Chile 10 especies.

Gavilea Poepp. \& Endl. 1840. OrchidaceAe

De gavilú, el nombre araucano de la planta.

15 especies de las regiones templadas de Sudamérica, incluida Juan Fernández. En Chile 12 especies.

Gayophytum Juss. 1832. OnAGRACEAE

En honor a Claudio Gay (1800-1873) y previo a su gran obra sobre Chile; su profesor en Francia, Adrien de Jussieu dice: "para recordar el nombre de Monsieur Gay quien la recolectó en las montañas de la provincia de Santiago".

9 especies de las regiones templadas de América. En Chile 2 especies.

Gentiana L. 1753. Gentianaceae

En honor a Gentius, rey de Illyria en el año 500 a.C., quien recomendó la Gentiana amarilla como remedio para la peste.

Cerca de 360 especies de las regiones templadas del mundo, excepto África. En Chile 1 especie. 
Gentianella Moench. 1794. Gentianaceae

De pequeña Gentiana.

Cerca de 256 especies de las regiones templadas del mundo, excepto África. En Chile 5 especies.

\section{Geoffroea Jacq. 1760. FABACEAE}

En honor al farmacéutico, botánico y químico francés Claudio José Geoffroy (1685-1752).

3 especies en Sudamérica. En Chile 1 especie.

Geranium L. 1753. GeraniaCEAE

Del griego: geranos=grulla, debido al parecido de los frutos de estas plantas con la cabeza y el pico de esta ave.

Cerca de 400 especies cosmopolitas, especialmente en las regiones templadas y en los trópicos de altura. En Chile 5 especies.

\section{Gethyum Phil. 1873. Alliaceae}

Del griego, una especie de cebollín o ajo.

Género endémico de Chile con 2 especies.

Geum L. 1754. RosACEAE

Del latín: gaeum=de buen sabor, en relación a la raíz. Otra versión dice: antiguo nombre griego según Plinio.

Cerca de 50 especies de regiones templadas y del Ártico. En Chile 7 especies.

Gevuina Molina 1782. ProteaceAe

De "gevuín", nombre que le dan los mapuches al fruto.

3 especies de Nueva Guinea, Australia, Chile y Argentina.

En Chile 1 especie endémica.

Gilia Ruiz \& Pav. 1794. Polemoniaceae

Dedicado a don Felipe Luis Gil (1756-1821), botánico español, quien junto a Gaspar Xuárez (1731-1804) publicaron Observationes phytologicas de nonnullis plantis exoticis 1789.

25 especies del NO de Norteamérica y Sudamérica. En Chile 3 especies.

Gilliesia Miers ex Lindl. 1826. Alliaceae

En honor al médico escocés John Gillies (1747-1836), quien vivió varios años en Mendoza, Argentina y también en Chile donde herborizó plantas y publicó una Flora de Chile y Argentina.

4 especies en Chile, una de ellas también en Argentina.

Glandularia Gmel. 1791. VerbenACEAE

De glándula; porque los estambres superiores llevan un apéndice glanduloso.

Cerca de 100 especies en América. En Chile 12 especies.

Glinus L. 1753. Molluginaceae

Del griego: glinos=jugo dulce; algunas especies son medicinales.

9 especies de regiones pantropicales. En Chile 1 especie.

Glyceria R.Br. 1810. POACEAE

Del griego: $g l y k y s=$ dulce (pasto de sabor dulce).

Cerca de 45 especies de regiones templadas y subtropicales, excepto África. En Chile 1 especie.

Glycyrrhiza L. 1753. FABACEAE

Del griego: $g l y k y s=$ dulce y rhiza=raíz. Llamada también "regaliz".

Cerca de 20 especies de Eurasia, Australia, Norteamérica y regiones templadas de Sudamérica. En Chile 1 especie.

Gnaphalium L. 1753. AsterACEAE

Del griego: gnaphalon=lana, fieltro, en relación al revestimiento lanoso de toda la planta.

Cerca de 80 especies cosmopolitas. En Chile 27 especies.

Gochnatia Kunth 1820. AsteracEAe

En honor a Frédéric Charles Gochnat de Strassburg, botánico francés que escribió sobre las Cichoriaceae en 1808.

Cerca de 60 especies en el S de Norteamérica, SE de Asia y América tropical y subtropical. En Chile 1 especie.

Gomortega Ruiz \& Pav. 1794. GomortegaceAe

En honor a Casimiro Gómez Ortega (1741-1818), primer profesor del jardín botánico de Madrid.

Género monotípico endémico de Chile.

Gomphrena L. 1754. Amaranthaceae

Nombre usado por Plinio para Amaranthus tricolor, planta parecida a la Gomphrena.

Cerca de 100 especies de regiones tropicales y subtropicales de América, África, Indochina y Australia. En Chile 2 especies.

Grabowskia Schltdl. 1832. SolAnACEAE En honor al farmacéutico alemán H. E. Grabowski (fallecido en 1842), intermediario de la Flora de Silesia.

4 especies en México, regiones templadas de Sudamérica y Galápagos. En Chile 1 especie.

Grammitis Sw. 1801. (Polypodiaceae) Grammitidaceae Del griego: gramme=línea; alude a los soros alargados de algunas especies.

Cerca de 400 especies en regiones templadas de todo el mundo excepto Europa y África. En Chile 3 especies.

Gratiola L. 1753. (Scrophulariaceae) Plantaginaceae Diminutivo de gratia=gracia, debido al efecto curativo de la planta.

25 especies de las regiones templadas y subtropicales; también en trópicos de altura. En Chile 1 especie. 
Greigia Regel 1864. Bromeliaceae

En honor a Samuel Alexeivich Greig (1827-1887), presidente de la Sociedad de Horticultura Rusa en 1865.

27 especies de Centro y Sudamérica y Juan Fernández. En Chile 4 especies.

Grindelia Willd. 1807. Asteraceae

En honor de David Hieronymus Grindel (1776-1836), químico y médico de Riga, Letonia, rector de la Universidad de Tartú.

Cerca de 70 especies de América. En Chile 3 especies.

\section{Griselinia G.Forst. 1786 GriselinIACEAE}

En honor al botánico veneciano Francesco Griselini (17171787).

6 especies de Nueva Zelanda, Paraguay, S de Brasil y Chile con 5 especies.

Guindilia Gillies ex Hook. 1833. SAPINDACEAE Del nombre común "guindillo", por el fruto rojizo. 3 especies de Chile y Argentina. En Chile 1 especie.

Gunnera L. 1767. GUNNERACEAE

En honor de Johann Ernst Gunner (1718-1773), religioso y botánico sueco autor de Flora Norvegica (1766-1772).

Cerca de 40 especies semicosmopolitas. En Chile 11 especies.

Gutierrezia Lag. 1816. AsteraceAe

En honor al noble español Pedro Gutiérrez, botánico del Jardín Botánico de Madrid, fundado por el rey Carlos III. 16 especies de la región $\mathrm{O}$ de Norteamérica y del $\mathrm{S}$ de Sudamérica. En Chile 6 especies.

Guynesomia Bonifacino \& Sancho 2004. Asteraceae Dedicado al botánico norteamericano Guy L. Nesom, contemporáneo de los autores, $\mathrm{y}$ que ha trabajado extensamente en Asteraceae.

Género monotípico y endémico de Chile.

Gymnachne Parodi 1938. POACEAE

Del griego: gymnos $=$ desnudo y achne $=$ glumela.

Género monotípico endémico de Chile.

Gymnophyton Clos 1847. APIACEAE

Del griego: gymnos $=$ desnudo y phyton=planta; alude a los tallos sin hojas.

6 especies de los Andes de Chile y Argentina. En Chile 5 especies.

Gypothamnium Phil. 1860. AsteraceAe

Del griego: gyps, gypos=jote y thamnium=arbusto; por el nombre vernáculo 'palo del jote'.

Género monotípico endémico del $\mathrm{N}$ de Chile.
Haageocereus Backeb.1934. CACTACEAE

En honor de Walter Haage (1899-1992), cultivador alemán de cactus.

20 especies de Perú y Chile. En Chile 2 especies.

Habenaria Willd. 1805 OrChiDACEAE

De habena (correa, rienda), en relación al órgano con forma de hebra en la base de la antera, lo que no debe confundirse con filamentos estériles.

Cerca de 600 especies en regiones pantropicales y subtropicales. En Chile 1 especie.

Habranthus Herb. 1824. AmaRYLlidaCEAE

Del griego habros=tierno, débil y anthos $=$ flor.

30 especies en EUA, México, Argentina y Chile con 1 especie.

Halerpestes Greene 1900. RanunCulaceae

Del griego hals, halos $=$ sal, mar y erpo, herpo $=$ arrastrar; por el hábito de algunas especies.

10 especies de Asia templada, N y S América; en Chile 2 especies.

Haloragis J.R.Forst. \& G.Forst.1776. HALORAGINACEAE Del griego: $h a l o=$ mar y ragis $=$ racimo.

27 especies de Australia, Nueva Caledonia, Nueva Zelanda, Isla de Pascua y Juan Fernández. En Chile 2 especies

Hamadryas Commers. ex Juss. 1789. RanunCulaceae De la mitología griega, Hamadríade, ninfa de los bosques que nacía con un árbol y moría con él, ya que la planta se encuentra en los bosques.

5 especies de las regiones antárticas de Sudamérica. En Chile 4 especies.

Haplopappus Cass. 1828. Asteraceae

Del griego: $h a p l o=$ simple, sencillo y pappus=papus; el papo está en una o más filas y consta de cerdas idénticas.

75 especies en América. En Chile 54 especies.

Haplorhus Engl. 1881. AnACARdiACEAE

Del griego: haplos=simple, único y Rhus otro género.

Género monotípico endémico de Chile y Perú.

Hebe Juss. 1789. (Scrophulariaceae) Plantaginaceae En la mitología griega, Hebe (en griego antiguo Hêbê) era la personificación de la juventud, descrita como hija de Zeus y Hera. Según La Ilíada, Hebe era la ayudante de los dioses: llenaba sus copas con néctar. Alude a la hermosura de estas plantas.

Cerca de 80 especies de Nueva Guinea, Australia, Tasmania, Nueva Zelanda, regiones templadas de Sudamérica e Islas Malvinas. En Chile 2 especies. 
Helenium L. 1753. Asteraceae

Del griego: helios=sol; por la forma de las flores. También de Helena, Helane=luz brillante como el sol, nombre que se hizo famoso por el personaje Helena de Troya.

30 especies de América. En Chile 7 especies.

\section{Heliotropium L. 1753. Boraginaceae}

Del griego: helios $=$ sol y tropium=virar; pues en algunas especies, las flores giran con el sol.

Cerca de 260 especies cosmopolitas. En Chile 22 especies.

\section{Helogyne Nutt. 1844. Asteraceae}

Del griego (clava, joroba) y gyne $=$ femenino; los estigmas tienen ápices redondeados y romos.

8 especies de Perú, Bolivia, Argentina y Chile con 2 especies.

\section{Herbertia Sweet 1827. IRIDACEAE}

En honor del sacerdote y botánico inglés Warren Herbert $(+1825)$. Escribió sobre las plantas bulbosas.

5 especies del SE de EEUU, y regiones templadas de Sudamérica (Argentina, Paraguay, Uruguay, Brasil y Chile). En Chile 1 especie.

Herreria Ruiz \& Pav. 1794. (Liliaceae) AsparagaceAe En honor al eclesiástico español Gabriel Alfredo Herrera (1576-1639), profesor en Salamanca.

8 especies de Brasil, Uruguay, Paraguay, Argentina y Chile con 1 especie.

\section{Heterosperma Cav. 1794. Asteraceae}

Del griego: hetero $=$ diferente y sperma $=$ semilla; las semillas son de diferentes formas.

7 especies de América. En Chile 2 especies.

Heterozostera (Setch.) Hartog 1970. ZosteraceAe Del griego: hetero=diferente y Zostera otro género. Género monotípico de las costas templadas de Australia, Tasmania y Norte de Chile.

Hieracium L. 1753. AsterACEAE Del griego: hierax=halcón; supuestamente se creía que el halcón tomaba su jugo para agudizar su vista.

Cerca de 200 especies de las regiones templadas y trópicos de altura, excepto Australasia. En Chile 4 especies.

Hippuris L. 1753. (Hippuridaceae) Plantaginaceae De caballo y cola, en relación a las ramas u hojas delgadas y a la apariencia total de la planta.

Género monotípico circumboreal de Sudamérica, incluido Chile y Australia.

Histiopteris Agardh ex J.Smith 1875. Dennstaedtiaceae Del griego: histion $=$ tejido o vela y pteris $=$ helecho.
5 especies pantropicales, especialmente en Madagascar. En Chile 1 especie.

Hoffmannseggia Cav. 1792. FABACEAE En honor a John Centurius Duque de Hoffmannsegg (17661849). Viajó por Portugal y escribió "Flora Portugaise".

28 especies del SO de Norteamérica, Chile y Argentina. En Chile 8 especies.

Hollermayera O.E.Schultz 1928. BRASSICACEAE

Dedicada al sacerdote y misionero capuchino alemán Atanasio Hollermayer (1860-1945), quien trabajó con los mapuches y reunió un valioso herbario; publicó varios trabajos sobre flora chilena.

Género monotípico endémico de Chile.

Homalocarpus Hook. \& Arn. 1833. APIACEAE Del griego: homalo=igual y carpus=fruto; probablemente por los frutos de partes iguales unidas por el dorso plano. Género endémico de Chile con 6 especies.

Hordeum L. 1753. POACEAE

Del latín: hordus=pesado, difícil; porque el pan que se prepara con este grano es muy pesado y firme.

30 especies de las regiones templadas y subtropicales y trópicos de altura. En Chile 9 especies.

Huanaca Cav. 1801. ApIACEAE

Nombre autóctono americano.

4 especies endémicas de Chile y Argentina.

Huidobria Gay 1842. LOASACEAE

Don Claudio Gay se lo dedicó a su amigo chileno Francisco García de Huidobro, "persona tan recomendable por sus virtudes y modestia, como por sus buenos conocimientos en las ciencias naturales"; él tomó la dirección del Museo de Ciencias Naturales cuando Gay regresó a Francia en 1842. Género endémico de Chile con 2 especies.

Huperzia Bernh. 1874. Lycopodiaceae

En honor de Johan Peter Huperz (+1816), horticultor alemán, dedicado a los helechos.

Cerca de 350 especies subcosmopolitas y Madagascar. En Chile 2 especies.

Hybanthus Jacq. 1760. VioLACEAE

De hyba=joroba y anthos=flor; del cáliz de 5 hojuelas dos son recurvadas, las otras tres están reunidas en la base a modo de joroba.

Cerca de 130 especies de las regiones tropicales y subtropicales de todo el mundo. En Chile 1 especie.

Hydrangea L. 1753. HydrangeaceAe

Del griego: hydor=agua y aggeion=vasija; porque el fruto es 
una cápsula con forma de copa.

29 especies de los Himalayas, Asia, Filipinas, Norte y Centroamérica, en los Andes hasta Chile con 1 especie.

Hydrocotyle L. 1753. APIACEAE

Del griego: $h y d r o=$ agua y cotyle $=$ copa; alude a la forma de las hojas de algunas especies.

130 especies cosmopolitas. En Chile 8 especies.

Hymenoglossum C.Presl 1843. HymenophyllaceAe

Del griego hymen=membrana y glossum=lengua; por la forma de las frondas.

Una especie de Chile y Argentina.

Hymenophyllum Sm. 1793. Hymenophyllaceae

Del griego: hymen $=$ membrana y phyllon $=$ hoja, aludiendo a las láminas delgadísimas de estos helechos.

Cerca de 250 especies de regiones tropicales y temperadas de Europa, Japón, Madagascar y Juan Fernández. En Chile 19 especies.

Hypericum L. 1753. HyPeriCACEAE

De hyper $=$ sobre y (maleza) (antiguo nombre griego usado por Dioscórides); porque crece en medio de la maleza y se eleva sobre ella. Otra versión dice de hyper $=$ sobre y eikon= cuadro, por la costumbre de poner estas flores en las casas, junto a una imagen, para ahuyentar los malos espíritus.

Cerca de 370 especies de las regiones temperadas y en trópicos de altura. En Chile 2 especies.

Hypochaeris L. 1753. Asteraceae

Del griego: hypo=debajo y chaeris=cerdo; porque los cerdos se comen la raíz.

Cerca de 55 especies de las regiones templadas de Sudamérica, Eurasia mediterránea y $\mathrm{N}$ de África. En Chile 31 especies.

Hypolepis Bernh. 1806. Dennstaedtiaceae

De hypo=debajo y lepis=escama, ya que los soros están en la parte de debajo del corte o diente del fronde y tienen una cubierta marginal continua.

40 especies en las regiones tropicales y subtropicales de todo el mundo y Madagascar. En Chile 1 especie.

\section{Imperata Cirillo 1792. POACEAE}

En honor a Ferrante Imperato (1550-1631), farmacéutico italiano que escribió una Historia Natural.

9 especies en regiones tropicales, subtropicales y templadas de todo el mundo. En Chile 2 especies.

Ipomoea L. 1753. ConvolvulaceAe

Del griego: $y p s=$ nombre de una enredadera y omoios $=$ semejante.

Cerca de 650 especies de las regiones pantropicales de todo el mundo. En Chile 1 especie.

Ipomopsis Michx. 1803. Polemoniaceae

Parecida a Ipomoea (otro género).

26 especies del $\mathrm{O}$ de Norteamérica y Florida. 1 especie en Argentina y Chile.

Islaya Backeb. 1934. CACTACEAE

Por la provincia de Islay, departamento de Arequipa, Perú. 4 especies de Perú y Chile.

Isoëtes L. 1753. IsOETACEAE

Del griego: isos=igual y etos=años; las plantas tienen el mismo aspecto todo el año.

150 especies cosmopolitas, principalmente en Madagascar. En Chile 2 especies.

Isolepis R.Br. 1810. CYPERACEAE

Del griego isos=igual y lepis=escama, y se refiere a las glumas de la flor.

70 especies de la región del Cabo en Sudáfrica, Australasia, Sudamérica y Norteamérica templada; en Chile 4 especies.

Ivania O.E.Schulz 1933. BRASSICACEAE

En honor a Ivan Murray Johnston (1898-1960), profesor de botánica norteamericano, que publicó varios importantes trabajos sobre la flora del desierto de Chile.

Género monotípico endémico del $\mathrm{N}$ de Chile.

Jaborosa Juss. 1789. Solanaceae

Del árabe: yaboroch=mandrágora, debido a la similitud con la especie Mandragora officinalis.

23 especies de las regiones templadas de Sudamérica. En Chile 11 especies.

Jarava Ruiz \& Pav. 1794 emend. Peñail. 2002. POACEAE En honor de Juan Jaravae, noble, médico y filósofo español, que escribió sobre Historia y Dioscórides en 1557.

59 especies sudamericanas. En Chile 19 especies.

Jovellana Ruiz \& Pav. 1798. (Scrophulariaceae) CAlceolariaceae

Está dedicado al ilustre gijonés Gaspar Melchor de Jovellanos (1744-1811), quien ostentaba el cargo de ministro de Gracia y Justicia en los días en que los botánicos Hipólito Ruiz y José Pavón estudiaban los ejemplares que habían recolectado durante los años de expedición botánica a Perú y Chile. 5 especies de Nueva Zelanda y Chile. En Chile 3 especies.

Juania Drude 1878. ARECACEAE

Por el nombre del Archipiélago Juan Fernández, Chile, donde vive la planta.

Género monotípico endémico de Chile. 
Jubaea Kunth 1816. ARECACEAE

En honor de Juba, rey de Numidia (85-46 a.C.), capturado de niño por César, pero educado cuidadosamente y que fue devuelto a su reino por Augustus. Escribió sobre botánica y geografía.

Género monotípico endémico de Chile.

Juncus L. 1753. JUNCACEAE

Del griego: jungere=atar, juntar; en relación al uso del tallo y las hojas.

Cerca de 275 especies cosmopolitas, Juan Fernández e Isla de Pascua. En Chile 22 especies.

Junellia Moldenke 1940. VerBENACEAE

En honor de S. Junell, botánico sueco, quien realizó estudios sobre morfología sistemática de la familia Verbenaceae en 1934.

38 especies en Perú, Bolivia, Chile y Argentina. En Chile 24 especies.

Kageneckia Ruiz \& Pav. 1794. RosACEAE

En honor al conde Friedrich von Kageneck, embajador alemán en Madrid en el siglo XVIII y promotor de la botánica.

4 especies en Perú, Bolivia, Chile y Argentina. En Chile 2 especies.

Koeleria Pers. 1805. PoACEAE

En honor a Georg Ludwig Koeler (1765-1807), alemán, profesor de historia natural en Maguncia; fue uno de los primeros agrostólogos y escribió: "Descriptio graminum in Germania et Gallie sponte nascentium”, 1802.

Cerca de 45 especies en regiones templadas, subtropicales y trópicos de altura. En Chile 3 especies.

\section{Krameria Loef. 1758. KrAmERIACEAE}

En honor a Johannes Georg Heinrich Kramer (1684-1744), médico militar austro-húngaro, buscó cambiar el sistema de plantas de Rivinus y Tournefort.

18 especies del SO de Norteamérica, México, Ecuador, Brasil, Argentina y Chile con 2 especies.

Kurzamra Kuntze 1891. LAMIACEAE

En honor del botánico alemán Federico Kurtz (1854-1920), que vivió varios años en Córdoba, Argentina, donde ocupó la cátedra de botánica en la Universidad Nacional de dicha ciudad. Kurtz es autor de numerosos estudios relacionados con la flora argentina.

Género monotípico endémico de Chile y Argentina.

Kyllinga Rottb. 1773. CyPerACEAE

En honor al botánico danés Peder Lauridsen Kylling (16401696), quien escribió: “Viridarium daricum”, 1628.

Cerca de 40 especies pantropicales. En Chile 1 especie.
Lachemilla (Focke) Rydberg 1908. RosACEAE

Anagrama de Alchemilla L., cuyo nombre es por el uso que daban los alquimistas al rocío de sus hojas para descubrir la piedra filosofal.

80 especies desde México a los Andes de Argentina y Chile: con 3 especies.

Lactoris Phil. 1865. LACTORIDACEAE

Philippi anota Lactoris es el nombre antiguo de una planta que ya no se conoce; en el diccionario latín dice $=$ planta llena de leche que provoca el vómito. Curioso el nombre de Philippi porque la planta de Juan Fernández no tiene látex. Otra versión sería que aumenta la leche al ser comida por las cabras.

Género monotípico endémico de Juan Fernández, Chile.

Laennecia Cass. 1822. Asteraceae

En honor del médico francés René Théophile Hyacinthe Laennec (1781-1826), profesor de medicina clínica e inventor de lo que hoy es el estetoscopio.

3 especies de Bolivia, Argentina y Chile: 1 especie.

Lagenophora Cass. 1818. AsterACEAE

Del griego: lagenos=botella y pherein=llevar; en relación a la forma del aquenio, con gollete pronunciado.

14 especies semicosmopolitas, excepto Europa y África. En Chile 3 especies.

Lampaya Phil. 1891. VerbenACEAE

Nombre vernáculo de la planta.

3 especies de Bolivia, Chile y Argentina. En Chile 2 especies.

Landoltia Les \& D.J.Crawford 1999. LemnACEAE

En honor del Dr. Elias Landolt por sus contribuciones a la sistemática y biología de las Lemnáceas en sus más de 45 años de investigación en plantas acuáticas.

1 especie monotípica cosmopolita, incluido Chile.

Lapageria Ruiz \& Pav. 1802. Philesiaceae

En honor de Josefina Tascher de Beauharnais de La Pagerie (1763-1814), primera esposa de Napoleón Bonaparte, egregia cultora de la botánica y protectora de naturalistas.

Género monotípico endémico de Chile.

Lardizabala Ruiz \& Pav. 1794. LardizabalaceAe En honor de Miguel Lardizábal y Uribe (1744-1824) político español y protector de la botánica.

Género monotípico de Chile.

Laretia Gillies \& Hook. 1830. APIACEAE Del nombre vernáculo en Chile "llareta". Género monotípico de Chile y Argentina. 
Larrea Cav. 1800. ZYGophylLACEAE

En honor de Juan Antonio Hernández de Larrea, clérigo español, propulsor de las artes y las ciencias.

5 especies en Norteamérica y Sudamérica. En Chile 2 especies.

\section{Lastarriaea J.Remy 1849. Polygonaceae}

En honor al ilustre escritor y profesor chileno don José Victorino Lastarria (1817-1889), autor de varias obras de mérito sobre Chile.

3 especies de California y Chile. En Chile 1 especie.

Lasthenia Cass. 1834. AsteraceAe

Del griego antiguo donde Lasthenia era una pupila de Platón que vestía de hombre.

18 especies del SW de Estados Unidos de América, Argentina y Chile con 1 especie.

\section{Lathyrus L. 1753. FABACEAE}

Del griego: lathyros, el nombre de un guisante o legumbre. Cerca de 155 especies cosmopolitas. En Chile 13 especies.

Latua Phil. 1858. Solanaceae

Del nombre vernáculo latua o latue.

Género monotípico endémico de Chile.

Laurelia Juss. 1809. (Monimiaceae) AtherospermataceAe De laurus; árbol chileno cuyas hojas fragantes se asemejan al "laurel de comer".

2 especies de Nueva Zelanda y Chile: con 1 especie.

Laureliopsis Schodde 1983. (Monimiaceae)

AtHEROSPERMATACEAE

El nombre alude a la semejanza del hábito, hojas e inflorescencia con el género Laurelia.

Género monotípico endémico de Chile y Argentina.

Lebetanthus Endl. 1841. ERICACEAE

Del griego: lebes, lebetos $=$ caldera y anthos $=$ flor.

Género monotípico endémico de la Patagonia (Argentina y Chile).

Lecanophora Speg. 1926. MaLvaceae

Del griego: lecanos $=$ plato y phora $=$ llevar.

7 especies de Chile y Argentina. En Chile 1 especie.

Legenere McVaugh 1943. Campanulaceae

Anagrama de Eduard Lee Greene (1843-1915), norteamericano, descubridor de la especie tipo Howellia limosa Greene en 1890, que MacVaugh pasó al género Legenere en 1943.

2 especies: 1 endémica de California y 1 endémica de Chile.
Legrandia Kausel 1944. MyrtaCEAE

En honor al Dr. Diego Legrand (1901- 1982), uruguayo, importante estudioso de las mirtáceas sudamericanas.

Género monotípico endémico de Chile.

Lemna L. 1754. LeMnACEAE

Del griego limnos=laguna o pantano, alude a la forma o al hábito de estas plantas.

14 especies cosmopolitas. En Chile 3 especies.

Lenzia Phil. 1863. Portulacaceae

En honor del naturalista y zoólogo alemán Dr. Harold Ottmar Lenz (1798-1870), autor de un trabajo mundial sobre culebras.

Género monotípico endémico de Chile y Argentina.

Leontochir Phil. 1873. Alstroemeriaceae

Derivado del nombre vernáculo, traducido al griego leon=león y tochir=garra, "garra de león".

Género monotípico endémico de Chile.

\section{Lepechinia Willd. 1806. LAMIACEAE}

En honor de Iván Lepechin (1740-1802), naturalista, botánico y explorador ruso, describió algunas plantas del norte de Rusia.

40 especies de Norte y Sudamérica. En Chile 3 especies.

Lepidium L. 1753. BRASSICACEAE

Del griego: lepis=escama, en relación a la forma del fruto: la siliqua, que era considerada remedio para la piel.

180 especies cosmopolitas. En Chile continental y también en Islas Desventuradas, 18 especies, de las cuales 7 son endémicas.

Lepidoceras Hook. f. 1846. SANTALACEAE

Del griego lepido=escama y ceras $($ cerato $)=$ cuerno; en atención a la escama que supera a las hojas.

2 especies del S de Perú y Chile con 1 especie.

Lepidophyllum Cass. 1816. Asteraceae

Del griego lepido=escama y phyllum=hojas, por la apretada disposición de las hojas sobre el tallo.

Género monotípico, endémico de la Patagonia chilena y argentina.

Lepidothamnus Phil. 1860. Podocarpaceae

Del griego lepido=escama y thamnus=arbusto, por sus ramas formadas por escamas.

3 especies, 2 endémicas de Nueva Zelanda y 1 en el S de Chile y Argentina.

Leptinella Cass. 1822. AsterAceAe

De leptos=delgado, se refiere probablemente a las divisiones de las hojas. 
33 especies de Nueva Guinea, Australia, Nueva Zelanda, Sudamérica e Islas subantárticas.

En Chile 1 especie.

Leptocarpha DC. 1836. AsteraceAe

De leptos=delgado y carpha=fruto, se refiere a los aquenios planos de la planta.

Género monotípico endémico de Chile.

Leptochloa P.Beauv. 1812. POACEAE

Del griego leptos $=$ delgado, grácil y chloa=gramínea, pasto. 17 especies en las regiones tropicales y subtropicales de todo el mundo. En Chile 1 especie.

Leptophyllochloa C.E.Calderón 1978. POACEAE

Del griego leptos=delgado, grácil, phyllon=hoja y chloa $=$ gramínea

Género monotípico endémico de Argentina y Chile, incluido Juan Fernández.

Leptosiphon Benth. 1833. Polemoniaceae

Del griego leptos=delgado, angosto y siphon=tubo; probablemente por el tubo de la flor.

31 especies de WN América y Chile: con 1 especie.

Leptostigma Arn. 1841. RUBIACEAE

Del griego leptos $=$ delgado, fino y stigma $=$ estigma

6 especies del SE de Asia, Nueva Zelanda y O de Sudamérica. En Chile 1 especie.

Lepuropetalon Elliot 1812. (Saxifragaceae) CELASTRACEAE Del griego lepuro $=$ piel, vaina y petalon $=$ pétalo.

Género monotípico del SE de Estados Unidos de América, México, Chile, Argentina y Uruguay.

Leucheria Lag. 1811. AsterACEAE

Del griego leuco (leukeres)=blanco; las hojas de algunas especies están cubiertas de vellosidad blanca.

46 especies de Perú, Bolivia, Chile y Argentina, incluidas las Islas Malvinas. En Chile 42 especies.

Leucocoryne Lind. 1830. Alliaceae

Del griego leuco (leukos)=blanco y coryne=mazo; alude a la forma y color de los estaminodios.

Género endémico de Chile con 14 especies.

Leunisia Phil. 1864-65. AsterACEAE

En honor de Johannis Leunis, amigo de R.A. Philippi, autor de "Synopsis trium naturae regnorum sermone germanico", 1844.

Género monotípico endémico de Chile central.

Leymus Hochst. 1848. POACEAE

Anagrama de Elymus, nombre griego para los granos de cereales.

30 especies de regiones templadas, en Chile 1 especie.

Libertia Spr. 1825. IRIDACEAE

En honor a Marie-Anne Libert (1782-1865), belga que se dedicó al estudio de los líquenes en Europa.

10 especies de Nueva Guinea, E de Australia, Nueva Zelanda, Andes sudamericanos y Juan Fernández. En Chile 6 especies.

Ligaria Tiegh. 1895. LORANTHACEAE

De ligar=unir, juntar, ya que estas plantas se pegan al huésped.

2 especies de Perú, Bolivia, Chile, Uruguay, Argentina y Brasil. En Chile 1 especie.

Lilaea Bonpl. 1801. JunCAGINACEAE

En honor al botánico y médico francés Alire RaffeneauDelile (1778-1850), quien acompañó a Napoleón a Egipto y fue profesor de botánica en Montpellier (1819-1850).

Género monotípico de la costa del Pacífico, de Canadá a Chile.

Lilaeopsis Greene 1891. APIACEAE

Del griego Lilaea, otro género y opsis=parecido, ya que tiene un parecido en sus tallos.

13 especies de Canadá a Tierra del Fuego, Australia y Nueva Zelanda. En Chile 1 especie.

Limonium Miller 1752. Plumbaginaceae

Del griego leimon=pradera húmeda, aludiendo al hábitat de muchas de las especies del género.

Cerca de 250 especies cosmopolitas. En Chile 1 especie.

Limosella L. 1753. SCROPHULARIACEAE

Del latín limosus=barro, lodo; alude al lugar donde viven estas pequeñas plantas.

15 especies cosmopolitas, especialmente de Madagascar. En Chile 1 especie.

Lindernia Allioni 1755. (Scrophulariaceae) LINDERNIACEAE En honor a Franz Balthasar Lindern (1682-1755), botánico y médico en Strasburgo, Alemania.

100 especies de regiones tropicales, subtropicales y templadas, especialmente en Madagascar. En Chile 1 especie.

Linum L. 1753. LiNACEAE

Del celta $l i n=$ hilo, en relación al uso como tejido.

200 especies de regiones templadas y subtropicales de todo el mundo. En Chile 5 especies.

Lippia L. 1753. VerbenACEAE

En honor del Dr. Agostino Lippi (1678-1705), naturalista 
francés; escribió varios textos sobre botánica e historia natural.

Cerca de 200 especies de América tropical y África. En Chile 2 especies.

Lithrea Miers ex Hook. et Arn. 1833. Anacardiaceae Por el nombre vernáculo de la planta "lithri" o "llithri". 4 especies de Sudamérica. En Chile 1 especie.

Littorella P.J.Bergius 1768. Plantaginaceae

Del latín littus $=$ costa, orilla, porque crece a orillas del agua, especialmente salada.

3 especies, 1 de Norteamérica, 1 de Europa y 1 de Sudamérica, incluido Chile.

\section{Llagunoa Ruiz \& Pav. 1794. SAPINDACEAE}

En honor a don Eugenio de Llaguno y Amirola (1724-1799), español, amigo y defensor de la botánica.

3 especies de los Andes tropicales de Sudamérica. En Chile 1 especie.

Loasa Adans. 1763. LOASACEAE

Según Wittstein (1856): del nombre vernáculo americano. NOTA: Esta afirmación es curiosa porque Adanson no da la etimología y además se basa en la obra de Feuillée de 1714 previa a la nomenclatura binominal y allí sólo se le llama "ortiga". Recién en Jussieu (1804) aparece una mención a Loxa, un lugar en Colombia, donde crecen Loasas, hoy pertenecientes a otros géneros.

36 especies de Chile y Argentina, 1 especie en Perú.

\section{Lobelia L. 1753. CAMPANULACEAE}

En honor al botánico y médico flamenco Matthias de Lobel (1538-1616), cuyo trabajo botánico estaba enfocado a la farmacología de las plantas.

Cerca de 330 especies de las regiones tropicales y subtropicales de todo el mundo. En Chile 8 especies.

\section{Lobivia Britton \& Rose 1922. CACTACEAE}

Anagrama de Bolivia, ya que la mayoría de las especies de este género viven en ese país. 24 especies de los Andes de Perú, Bolivia, Argentina y Chile: con 2 especies.

\section{Lomatia R.Br. 1810. ProteACEAE}

Del griego lomato=ribete, ya que el ala de la semilla es orillada o ribeteada.

12 especies de Australia, Tasmania y Sudamérica. En Chile 3 especies.

Lophopappus Rusby 1894 emend. Cabrera 1953. Asteraceae

Del griego lophos=cresta y pappus=papo, se refiere a los pelos crestados del papo.
6 especies de Perú, Bolivia, Argentina y Chile con 3 especies.

Lophosoria C.Presl 1847. (Lophosoriaceae) DiCKSONIACEAE Del griego: lophos $=$ cresta, por las divisiones de las hojas. 1 especie de las regiones tropicales de Sudamérica, incluido Chile.

Lucilia Cass. 1817. AsterACEAE

Del latín: lucidus=brilloso, resplandeciente; aludiendo al involucro escarioso de la planta.

11 especies de los Andes de Argentina, Perú y Chile: con 3 especies.

Luciliocline Anderb. \& Freire 1991. AsteraceAe

De Lucilia, otro género de la familia y del griego cline $=$ soporte, cama; porque los involucros que sostienen las flores son como en Lucilia.

13 especies de los Andes de Argentina, Perú y Chile: con 3 especies.

Ludwigia L. 1753. ONAGRACEAE

En honor a Christian Gottlieb Ludwig (1709-1773), botánico alemán.

81 especies cosmopolitas. En Chile 4 especies.

Luma A.Gray 1854. Myrtaceae

Del nombre vernáculo "luma".

4 especies de Chile y Argentina. En Chile 2 especies.

Lupinus L. 1753. FABACEAE

Del latín: lupus=lobo; porque vive en terrenos pobres, como el lobo. Otra versión: nombre latino usado por Virgilio y Plinio; se dice que proviene de lupus=lobo, ya que se creyó que los lupinos destruyeron la fertilidad del suelo.

Cerca de 220 especies de Norte y Sudamérica, Mediterráneo, trópicos de altura y E de África. En Chile 6 especies.

Luzula DC. 1805. JUNCACEAE

Del italiano: luciola $=$ brillar, resplandecer; o lucciola $=$ luciérnaga, haciendo referencia a las hojas e inflorescencia pilosas, brillantes con las gotas de rocío.

75 especies cosmopolitas y en Juan Fernández. En Chile 7 especies.

Luzuriaga Ruiz \& Pav. 1802. LuZuRiAgaceAe En honor a don Ignacio María Ruiz de Luzuriaga (17631822), español, botánico y doctor en medicina y cirugía.

3 especies, 1 en Nueva Zelanda y las 3 en Chile y Argentina hasta Tierra del Fuego.

Lycapsus Phil. 1870. Asteraceae

Del griego: lycapsus=nombre de una planta ahora ignorada. 
1 especie de las Islas Desventuradas, Chile.

Lycium L. 1753. SOlAnACEAE

De Lycien, cerca de Xanthos, Anatolia antigua en Asia Menor, donde crece normalmente la planta.

80 especies de Norteamérica, Sudamérica templada, Eurasia, Sudáfrica, Australia e Isla de Pascua. En Chile 11 especies.

\section{Lycopodium L. 1753. LyCOPODIACEAE}

Del griego lykos= lobo y podium= pie; en referencia al ligero parecido a la pata de un lobo.

55 especies de los trópicos templados. En Chile 6 especies.

\section{Lysimachia L. 1754. PrimulaceAe}

En honor a Lysimachus, estratega de Alejandro el Grande, quien según Plinio pudo haber descubierto esta planta.

150 especies cosmopolitas. En Chile 1 especie.

\section{Machaerina Vahl 1806. CyPERACEAE}

Del griego: machaira= daga, espada corta.

45 especies de las regiones tropicales, especialmente Australia, también en Juan Fernández. En Chile 1 especie.

\section{Macrachaenium Hook.f. 1845. AsteraceAE}

Del griego: macro=grande y achaenium=aquenio; por los frutos.

Género monotípico de Patagonia y Tierra del Fuego, Chile.

Madia Molina 1782. AsteraceAe

De "madi" nombre vernáculo de la planta en Chile.

10 especies del $\mathrm{O}$ de Norteamérica, Chile y Argentina. En Chile 2 especies.

Maihuenia (Phil. ex Weber) Schumann 1898. CACTACEAe De "maihuén" nombre vernáculo chileno.

2 especies, en Chile y Argentina.

\section{Maihueniopsis Speg. 1925. CACTACEAE}

Parecido a Maihuenia.

16 especies de los Andes de Perú, Bolivia, Chile y Argentina. En Chile 13 especies.

\section{Maireana Moq. 1840. Amaranthaceae}

Dedicado al naturalista francés Charles Antoine Lemaire (1800-1871), especialista en la familia Cactáceas, y editor de L'Horticulteur universel, París, entre 1839 y 1845.

58 especies principalmente de Australia y Chile, con 1 especie.

Malacothrix DC. 1838. ASTERACEAE

Del griego malakos=suave, delicado y trichum=pelo; algunas de estas hierbas están provistas de pelos blancos largos y suaves.

21 especies en el O Norteamericano y Chile, con 1 especie.
Malesherbia Ruiz \& Pav. 1794. MalesherbiaceAe

En honor a Guillaume-Chrétien de Lamoignon de Malesherbes (1721-1793), francés, quien escribió trabajos sobre agricultura e historia natural.

24 especies de los Andes de Perú, Chile y Argentina. En Chile 16 especies.

Malvella Jaub. \& Spach 1895. Malvaceae

Significa pequeña Malva.

5 especies, 3 en el O de Norteamérica, 1 de Perú a Uruguay, 1 especie del mediterráneo de Europa. En Chile 1 especie.

Mancoa Wedd. 1857. BrassicaceAe

Probablemente basado en Manco Cápac (quechua: Manqu Qhapaq) o Ayar Manco, que según algunos cronistas fue el primer gobernador de la etnia inca en Cusco (¿inicios siglo XIII?).

4 especies en México y 4 de los Andes de Perú, Bolivia, Argentina y Chile, con 1 especie.

\section{Margyracaena (ver x Margyracaena)}

\section{Margyricarpus Ruiz \& Pav. 1794. RoSACEAE}

Del griego: argyron=plata y karpos=fruto; ya que los frutos son brillantes como perlas.

3 especies en Brasil, Juan Fernández y en los Andes sureños de Chile con 2 especies.

Marsilea L. 1753. MarsileACEAE

En honor de Aloys (Alesinus) Marsili, botánico italiano del siglo XVIII.

70 especies de las regiones tropicales y templadas, y Madagascar. En Chile 1 especie.

\section{Marsippospermum Desv. 1808. JUNCACEAE}

Del griego: marsippo $=$ limadura y spermum $=$ semillas. 3 especies de Nueva Zelanda, $\mathrm{S}$ de Sudamérica, Tierra del Fuego e Islas Malvinas. En Chile las 3 especies.

\section{Marticorenia Crisci 1974. Asteraceae}

En honor al botánico chileno Profesor Clodomiro Marticorena de la Universidad de Concepción, quien ha hecho importantes contribuciones en estudios de polen y en el conocimiento de la flora chilena.

Género monotípico endémico de Chile.

Mastigostyla I.M.Johnst. 1928. IRIDACEAE

Del griego: mastigo=flagelo, cola y $s t y l o=$ estilo; ya que las 3 ramas del estilo son divididas y los 6 lóbulos resultantes producen un apéndice flagelado subapical.

16 especies de Perú, Argentina y Chile con 1 especie.

Mathewsia Hook. \& Arn. 1833. Brassicaceae

En honor a A. P. Mathews viajero inglés que recolectó 
plantas vivas y para herbarios; murió en Perú en 1841.

7 especies de Perú y Chile con 5 especies.

Maytenus Molina 1782. Celastraceae

De "maytén" nombre vernáculo en Chile.

Cerca de 200 especies de las regiones tropicales y subtropicales de todo el mundo. En Chile 4 especies.

Mecardonia Ruiz \& Pav. 1797. (Scrophulariaceae) Plantaginaceae

Dedicado a don Antonio de Meca y Cardona, marqués de Cintadella (Menorca), quien donó generosamente un terreno para el Jardín Botánico.

10 especies del S de Norteamérica hasta Argentina y Chile con 1 especie.

Megalachne Steud. 1854. PoACEAE

Del griego: $m e g a=$ grande y $a c h n e=$ arista; alude a la longitud de ellas.

Género endémico con 2 especies del Archipiélago de Juan Fernández, Chile.

Megalastrum Holttum 1986. DRYOPTERIDACEAE

Del griego: $m e g a=$ grande, con el sufijo latino astrum, que indica una similitud incompleta, es helecho grande pero no tanto como arborescente.

40 especies de los trópicos de América, 1 especie en África, Madagascar y Juan Fernández. En Chile 2 especies.

Melica L. 1753. POACEAE

Del griego: meli=dulce, la médula de los tallos sabe dulce como la miel.

80 especies de las regiones templadas y trópicos de altura. En Chile 8 especies.

Melosperma Benth. 1846. (Scrophulariaceae) Plantaginaceae Del griego: $m e l o s=$ negro, oscuro y sperma $=$ semilla.

2 especies endémicas de Chile y Argentina.

Menodora Bonpl. 1809. Oleaceae

Del griego: menos=agradable y doro=regalo, ofrenda; porque da fuerza a los animales.

25 especies de las regiones tropicales y subtropicales de América y Sudáfrica. En Chile 1 especie.

Menonvillea DC. 1821. BRASSICACEAE

En honor a Nicolás Joseph Thiéry de Ménonville (17361780) botánico francés, quien viajó a América a estudiar las "cochinillas" que describió y cultivó.

26 especies de Chile y Argentina. En Chile 19 especies.

Mentzelia L. 1753. LoASACEAE

En honor a Christian Mentzel (1622-1701), médico y botánico alemán que escribió "Centuria plantarum circa
Gedanum nascentium".

80 especies desde Canadá hasta el Caribe, Argentina y Chile con 3 especies.

Metharme Phil. ex Engler 1891. ZygophyllaceaE

En la mitología griega, reina de Chipre. Metharme era hija de Pygmalion, esposa de Cinyras y madre de Adonis y Myrrha.

Género monotípico endémico del $\mathrm{N}$ de Chile.

Microlepia C.Presl 1863. DennStaedtiaceae

Del griego: micro=pequeño y lepis=escama.

45 especies de regiones paleotropicales, Madagascar, Japón y Nueva Zelanda. 1 especie en África y 1 especie en Chile.

Microphyes Phil. 1860. Caryophyllaceae

Del griego: mikros=pequeño y phyo, phye=crecimiento; por su hábito pequeño.

Género endémico de Chile con 3 especies.

Micropsis DC. 1836. AsteraceAe

De $m i k r o s=$ pequeño y (apariencia); es muy parecido al género Micropus y mide sólo una pulgada de alto.

8 especies de Brasil, Argentina, Uruguay y Chile con 1 especie.

Microseris D.Don 1832. Asteraceae

De mikros=pequeño y seris=lechuga; planta pequeña parecida a la Lactuca (lechuga).

14 especies del $\mathrm{O}$ de Norteamérica, Nueva Zelanda, 1 especie en Australia y 1 especie en Chile.

Microsorum Link 1833 emend. Copel 1929.

Polypodiaceae

Del griego: mikros $=$ pequeño y sorus $=$ soro.

40 especies de las regiones tropicales y cálidas y Madagascar. En Chile 1 especie en Isla de Pascua.

Microsteris Greene 1896-98. Polemoniaceae

Del griego: mikros=pequeño y sterizo=soporte; quizás alude al pedúnculo de la flor.

Otra versión dice: $m i k r o s=$ pequeño y aster $=$ estrella.

Género monotípico del oeste de Norte y Sudamérica, incluido Chile.

Miersia Miers ex Lindl. 1826. Alliaceae

En honor al inglés John Miers (1789-1879), quien vivió algunos años en Chile y escribió "Travels in Chile and La Plata", Londres 1826.

Género endémico de Chile con 4 especies.

Mikania Willd. 1804. Asteraceae

En honor a Johann Christian Mikan (1769-1844), profesor de botánica en la Universidad de Praga que recorrió Brasil. 
400 especies de las regiones pantropicales de todo el mundo. En Chile 2 especies.

Mimulus L. 1753. (Scrophulariaceae) Phrymaceae Del latín, diminutivo de mimo, bufón, por el aspecto y colorido de la flor.

150 especies de Sudáfrica, Madagascar, este de Asia, América y Juan Fernández. En Chile 7 especies.

Minuartia L. 1753. CARYophyllaCeaE

En honor a Juan Minuart (1693-1768), farmacéutico y botánico español.

120 especies de las regiones árticas y templadas, México, Etiopía e Himalayas. En Chile 1 especie.

Miqueliopuntia Frić ex F.Ritter 1980. CACTACEAE

En honor del Dr. Friedrich A. W. Miquel (1818-1871), médico y botánico holandés, director del Jardín Botánico de Rotterdam, luego de Amsterdam y finalmente de Utrecht y Opuntia, otro género.

Género monotípico endémico de Chile.

Mirabilis L. 1753. NyCTAGINACEAE

Del latín: mirari=maravillarse, sorprenderse, ya que las flores se abren sólo en la noche y huelen muy agradablemente.

54 especies de los Himalayas, China y América tropical. En Chile 5 especies.

Misodendrum Banks ex DC. 1830. Misodendraceae Del latín: miso=odio y dendron=árbol; ya que la planta es un parásito que perjudica los árboles en que se aloja.

8 especies en Argentina y Chile, bajo los $33^{\circ}$, asociados al género Nothofagus. En Chile las 8 especies.

Mitraria Cav. 1801. GesneriaceAe

Del latín, mitra o gorro, por la forma de las brácteas que rodean el cáliz.

Género momotípico endémico de Argentina y Chile.

Mniodes A.Gray ex Benth. \& Hook.f. 1873. Asteraceae

Del griego: mniodes, mniaros $=$ musgoso, ya que forma cojines.

4 especies de Perú y Chile con 2 especies.

Monnina Ruiz \& Pav. 1798. Polygalaceae

En honor de José Moñino (1728-1808) conde de Floridablanca y Primer Ministro de Carlos III y Carlos IV de España.

130 especies americanas, desde SW Estados Unidos de América a Chile: con 2 especies.

Montia L. 1753. Portulacaceae

En honor al italiano Giuseppe Monti (1682-1770), profesor de botánica e historia natural en Bologna, en la primera mitad del siglo XVIII.

20 especies en las regiones templadas de Eurasia, Mediterráneo, trópicos de altura, África, Australia, Centro y Sudamérica. En Chile 1 especie.

Montiopsis Kuntze 1898. Portulacaceae

De Montia, otro género de la familia y del griego opsis=parecido.

18 especies de Perú, Bolivia, Argentina y Chile con las 18 especies.

Monttea Gay 1849. (Scrophulariaceae) Plantaginaceae

En honor a "nuestro digno amigo, ilustre presidente de la cámara de diputados, don Miguel Montt, ex Ministro de Instrucción Pública y uno de los más sabios lejistas de Chile".

3 especies, 2 en Argentina, 1 en Chile.

Morella Lour. 1790. MYrICACEAE

Del griego: mora, por el fruto parecido a ésta.

40 especies de los Andes de Ecuador, Perú y Chile, África, E de Asia, Filipinas y Malasia. En Chile 1 especie.

Moscharia Ruiz \& Pav. 1794. AsteraceAe

De $m o s c h o s=$ almizcle, por su olor almizclado.

Género endémico de Chile con 2 especies.

Moschopsis Phil. 1865 (el original dice Moschopis). CAlyceraceae

Del griego: moschos=almizcle y ops, opiscarr=poder, fuerza.

8 especies de Perú y Patagonia de Chile y Argentina. En Chile 5 especies.

Mostacillastrum O.E.Schulz 1924. BrassicaCeAE

Del nombre común español "mostacilla" para Sisymbrium officinale y astrum=parecido.

17 especies del sur de Perú y Bolivia hasta el sur de América en la Patagonia argentina y chilena. En Chile 8 especies.

Muehlenbeckia Meisn. 1841. Polygonaceae

En honor a H.G. Muehlenbeck (1798-1847), médico y botánico suizo en Mühlhausen, Elsass. Su obra principal fue "La flora criptogámica de Elsass".

25 especies de Nueva Guinea, Australia, Tasmania, Nueva Zelanda y O de Sudamérica. En Chile 2 especies.

Muhlenbergia Schreb. 1789. POACEAE

En honor al botánico norteamericano Gotthilf Henry Ernest Muhlenberg (1753-1815).

150 especies de la regiones templadas y subtropicales de América y Asia. En Chile 3 especies.

Mulguraea N.O’Leary \& P.Peralta 2009. VerBenACEAE 
En honor a M.E. Múlgura del Instituto Botánico Darwinion, Argentina, quien ha estudiado Verbenaceae por más de 20 años y es gran especialista en Junellia, del cual derivaron las especies del nuevo género.

11 especies de Argentina, Perú y Chile.

\section{Mulinum Pers. 1805. APIACEAE}

Anagrama parcial de Selinum, el género bajo el cual se descubrió su primera especie.

20 especies del S de los Andes. En Chile 5 especies.

\section{Munroa Torrey 1856. POACEAE}

En honor al inglés general William Munro (1816-1880), que hizo su carrera militar en India, Crimea e Indias Orientales. Recolectaba plantas y su afición botánica lo llevó a ser una autoridad en gramíneas.

5 especies, 4 en el $\mathrm{SO}$ de Sudamérica, 1 en el $\mathrm{O}$ de Norteamérica. En Chile 3 especies.

\section{Mutisia L.f. 1781. AsteraceAe}

En honor al médico español José Celestino Mutis (17321809). Profesor de anatomía en Madrid, llegó a Nueva Granada (hoy Colombia) como médico del Virrey Don Pedro Musia de la Corda. Creó un jardín botánico en Santa Fe de Bogotá y envió muchas plantas al joven Linneo para su clasificación.

Cerca de 62 especies desde Colombia a Chile y Argentina. En Chile 23 especies.

\section{Myoschilos Ruiz \& Pav. 1794. Santalaceae}

Del griego myos=ratón, coypu y $k y l o=$ comida; ya que a los ratones les gusta comer sus frutos.

Género monotípico de Chile y Argentina.

\section{Myosotis L. 1753. BoraginaceAe}

Del griego $m y o s=$ ratón y otis=oreja; en relación a la forma de sus hojas.

Cerca de 100 especies de Eurasia, trópicos de altura, Sudáfrica, Nueva Guinea, Australia y Nueva Zelanda. En Chile 2 especies.

\section{Myosurus L. 1754. RanunCulaceae}

Del griego myos=ratón y ouro=cola; en relación a la forma del tálamo donde van los frutos.

15 especies de las regiones templadas de ambos hemisferios. En Chile 2 especies.

Myrceugenia O.Berg 1856. MyrtaCEAE

Combinación del nombre de los géneros Myrcia y Eugenia, (Myrtaceae).

Cerca de 40 especies en el SE de Brasil, Argentina y Chile con 13 especies.
Myrcianthes O.Berg 1955-56. MyrtaCEAE

De Myrcia, otro género de Mirtáceas.

Cerca de 50 especies de América tropical, Andes, Brasil y el Caribe. En Chile 1 especie.

\section{Myriophyllum L. 1753. HaloragaCeAe}

Del griego: myrio=innumerable y phyllum=hoja; las hojas son recortadas semejando pelos.

60 especies subcosmopolitas. En Chile 2 especies.

Myrteola O.Berg 1856. Myrtaceae

Un pequeño mirto.

3 especies de Colombia a Chile, incluido Juan Fernández. En Chile 1 especie.

Nama L. 1753. BoraginaceAe

De nama=agua fluyente; en relación a su hábitat.

Cerca de 45 especies en toda América, Caribe y Hawai. En Chile 2 especies.

\section{Nanodea Banks 1807. Santalaceae}

Del griego: nanos=pequeño; por el tamaño de la planta.

Género monotípico endémico de las regiones templadas de Sudamérica, incluido Chile.

Nardophyllum Hook. \& Arn. 1836. AsteracEAe

Del latín: hoja con forma de nardo; tiene las hojas lateralmente enrolladas como el género Nardus L.

7 especies en Bolivia, Argentina y Chile, con 4 especies.

Nasa Weigend 1997. LOASACEAE

Significa $N$-orth $A$-ndean Loa-sa, ya que esta parte del antiguo género Loasa está principalmente restringido a los Andes del Norte.

Cerca de 100 especies en Centro y Sudamérica. En Chile 1 especie.

Nassauvia Comm. ex Juss. 1789. Asteraceae

En honor al príncipe alemán Joseph Moritz von NassauSiegen, quien acompañó al conde Louis Antoine de Bougainville (1729-1811), militar y navegante francés en su viaje por el mundo (1766-69).

39 especies de Bolivia, Argentina y Chile con 23 especies.

Nassella (Trin.) Desv. 1853. PoACEAE

Diminutivo del latín: nassus=nariz; porque el antecio es generalmente giboso.

79 especies de Centro y Sudamérica. En Chile 28 especies.

Nastanthus Miers ex Lindl. 1860. CAlyceraceae

Del griego: nastic=amontonado y anthos $=$ flor; alude a las apretadas cabezuelas de flores.

9 especies de Chile, Argentina e Islas Malvinas. En Chile 5 especies. 
Navarretia Ruiz \& Pav. 1794. Polemoniaceae

En honor a Francisco Fernando Navarrete, primer doctor del rey de España, que escribió sobre la historia natural del Reino de Granada.

30 especies del O de Norteamérica, Argentina y Chile con 1 especie.

Neoporteria Britton \& Rose 1922. CACTACEAE

En honor al entomólogo y naturalista chileno Carlos Porter, fundador de la Revista Chilena de Historia Natural. El prefijo neo se debe a que existía con anterioridad un género Porteria, denominado por Hooker, que correspondía a plantas de la familia Valerianáceas, y no pueden coexistir dos géneros con el mismo nombre.

Género endémico de Chile con 6 especies.

\section{Neowerdermannia Fric 1930. CACTACEAE}

Del griego: $n e o=$ nuevo y Werdermannia en honor al botánico alemán Dr. Erich Werdermann (1892-1959), del Museo Botánico de Berlín, explorador y observador de las plantas de América y autor de muchas descripciones de cactus.

2 especies de Perú, Bolivia, Argentina y Chile con 1 especie.

Nertera Banks \& Sol. ex Gaertner 1788. RuBIACEAE

Del griego: nerteros=humilde, bajo, aludiendo al hábito rastrero de estas plantas.

13 especies de Madagascar, SE de Asia, Malasia, Australia, Nueva Zelanda, Hawai, Sudamérica y Juan Fernández. En Chile 1 especie.

Nesocaryum I. M. Johnst. 1927. BoraginaceAe Del griego: $n e s o s=$ isla y karyon $=$ nuez (el fruto), por el hábitat de la especie.

Género monotípico endémico de Islas Desventuradas (Chile).

Neuontobothrys O. E. Schulz 1924. BrassicACEAE

Del griego: nevon=colgante y bothrys=racimo.

11 especies de Perú, Chile y Argentina. En Chile 8 especies.

Nicandra Adans. 1763. SolAnACEAE

Por Nicandro, poeta de Colofón, Asia Menor, quien escribió sobre plantas, alrededor del año 100 a.C.

Género monoespecífico de Perú, Argentina, sur de Brasil y Chile.

Nicotiana L. 1753. SolanaCEAE

En honor a Jean Nicot (1530-1600), embajador francés en la corte portuguesa, en 1560; llevó la semilla de esta planta a Francia y en 1564 implantó la moda de fumar las hojas. 67 especies desde Estados Unidos de América a Chile,Australia, Nueva Caledonia, Namibia y Chile con 14 especies.
Nierembergia Ruiz \& Pav. 1794. SolanACEAE

En honor a Juan Eusebio Nieremberg y Otin (15951658), jesuita español de ascendencia alemana, enseñó Humanidades y Ciencias Naturales en el Colegio Imperial de la Compañía en Madrid, escribió entre otros: "Historia Naturae" y "Maxime Peregrinae".

20 especies desde México a Argentina y Chile con 1 especie.

Nitrophila S. Watson 1861. AmARANTHACEAE

Del griego: nitron=carbonato de sodio y phylos=amante; ya que son plantas que crecen en suelos alcalinos.

8 especies en Estados Unidos, México, Argentina y Chile con 1 especie.

Noccaea Moench 1802. BrassicaCeAe

En honor al botánico y clérigo italiano Domenico Nocca (1758-1841), prefecto del Jardín Botánico de Pavia.

20 especies en regiones templadas del hemisferio norte, en Sudamérica unas pocas especies. En Chile 1 especie.

Nolana L. 1762. SolAnACEAE

Del latín: nola=campana; en relación a la forma de la flor. 89 especies de Perú, Galápagos y Chile con 44 especies.

Notanthera (DC.) G. Don 1834. LoranthaceaE

Del griego: notos=dorso y anther=antera; las anteras están fijas por su dorso al filamento, por lo tanto oscilan.

Género monotípico endémico de Chile continental y Juan Fernández.

Nothofagus Blume 1850. Nothofagaceae

Del griego: nothos=falso y fagus=haya; refiriéndose a su semejanza con el haya europea.

37 especies de Nueva Guinea, Australia, Tasmania, Nueva Zelanda, Nueva Caledonia y regiones templadas de Sudamérica. En Chile 10 especies.

Notholaena R. Br. 1810. Pteridaceae

Del griego: nothos=falsa y chlaina=capa; porque el margen de la lámina de la hoja no es reflejo como en Cheilanthes, un género semejante.

40 especies de las regiones cálidas y tropicales de Sudamérica, SO de Estados Unidos de América, México, Madagascar y Juan Fernández. En Chile 1 especie.

Nothomyrcia Kausel 1948. MyrTACEAE

Del griego nothos=falso y Myrcia, otro género de la misma familia y que es nombre de la mitología identificada con Venus.

Género monotípico con una especie de Juan Fernández.

Nothoscordum Kunth 1843. Alliaceae

Del griego: nothos=falso y skorodon, skordon= ajo.

26 especies americanas. En Chile 5 especies. 
Noticastrum DC. 1836. AsteraCEAE

Del griego: noto $=$ sur, austral y astrum=estrella; casi como Aster, otro género de la familia.

19 especies de Ecuador, Brasil, Perú, Bolivia, Chile y Argentina. En Chile 5 especies.

Notopappus Klingenberg 2007. AsteraceAe

Del griego noto=sur y pappus=vilano; para separar las plantas del género Haplopappus de distribución austral.

5 especies de Argentina y Chile con 4 especies.

Nototriche Turcz. 1863. MALVACEAE

Del griego: notos $^{=}$dorso y trichos $=$pelo; alude a los frutos con largos pelos en el dorso.

100 especies de Ecuador, Perú, Bolivia, Chile y Argentina. En Chile 24 especies.

Ochagavia Phil. 1856. Bromeliaceae

En honor a don Silvestre Ochagavía Errázuriz (1820-1883);

Ministro de Justicia e Instrucción Pública en Chile, entre 1853 y 1854.

Género endémico de Chile con 4 especies, incluido Juan Fernández.

Ochetophila Poepp. \& Endl. 1840. RHAMnACEAE Del griego: ochetion $=$ canal, drenaje y phila $=$ gustar.

2 especies de Chile y Argentina.

Ocyroe Phil. 1890. Asteraceae

Nombre de la mitología: Ocyroe era la hija del centauro Chiron y de la náyade Chariclo. Aparentemente Ocyroe tenía pelo de color dorado-rojizo.

Género monotípico que se distribuye principalmente en Argentina, aunque llega también a Bolivia y penetra levemente en territorio chileno bien al N.

Odontorrhynchus M.N.Correa 1953. ORCHIDACEAE

Del griego odontos $=$ diente y rhynchos $=$ cuerno, pico, por la forma del rostelo.

5 especies de Sudamérica templada, Argentina y Chile: con 4 especies.

Oenothera L. 1753. Onagraceae

Del griego, oeno=vino y ther $a=$ coger, atrapar, ya que la raíz de una especie se usaba como aditivo de sabor para el vino. 121 especies de las regiones templadas y subtropicales de América. En Chile 14 especies.

Oldenlandia L. 1753. RUBIACEAE

En honor de Heinrich Bernhard Oldenland, médico alemán del siglo XVII, que vivió en Sudáfrica y realizó el jardín Company's Garden que existe hasta hoy.

250 especies de Asia tropical, Malasia y Juan Fernández; en Chile 2 especies.
Olsynium Raf. 1836. IRIDACEAE

Del griego, ol=entero, syn=juntos, ium=característico de, alude a los filamentos de los estambres unidos en un tubo.

20 especies del NO de Norteamérica y regiones andinas templadas de Sudamérica. En Chile 10 especies.

Ombrophytum Poepp. ex Endl. 1836. Balanophoraceae Del griego: ombro $=$ sombra y phytum=planta; es decir planta que ama la sombra ya que es casi subterránea.

4 especies de Perú, O de Brasil, N de Argentina y Chile con 1 especie.

Onuris Phil. 1872. BrassicaceAe

Nombre antiguo griego de una planta que ya no se conoce.

5 especies endémicas de la Patagonia chilena y argentina.

Ophioglossum L. 1753. Ophioglossaceae

Del griego: $o p h i=$ serpiente y glossum=lengua; en relación a la espiga que termina en una delgada punta. También tiene esta planta una singular hoja, larga y angosta.

26 especies subcosmopolitas, Madagascar y Juan Fernández. En Chile 5 especies.

Ophryosporus Meyen 1834. Asteraceae

Del griego: Ophrys=planta que tiñe de negro y sporus =semilla; los aquenios de algunas especies son casi negros.

37 especies de regiones tropicales y subtropicales de Sudamérica, incluido Brasil. En Chile 8 especies.

Oreobolus R.Br. 1818. CyPeraceae

Del griego: oreos $=$ montaña; ya que esta planta crece en forma de cojines en las zonas montañosas.

15 especies en Malasia, Australia, Tasmania, Nueva Zelanda, Hawai, regiones tropicales y templadas de América, Tierra del Fuego, Islas Malvinas y Juan Fernández. En Chile 1 especie.

Oreocereus (A. Berger) Riccob. 1909. CACTACEAE

Del griego: oreos=montaña y Cereus, otro género de Cactáceas; significa cactus de montaña.

7 especies andinas de Perú, Bolivia, Argentina y Chile con 4 especies.

Oreomyrrhis Endl. 1839. APIACEAE

Del griego: oreos=montaña y Myrrhis, otro género; por el hábitat de algunas especies.

23 especies del E de Asia, Borneo, Nueva Guinea, SE de Australia, Nueva Zelanda, México, Centroamérica, Andes, Tierra del Fuego e Islas Malvinas. En Chile 1 especie.

Oreopolus Schltdl. 1856. RuBiaceAe

Del griego: oreos=montaña y polus=mucho, muchos. 
Género monotípico endémico de la Patagonia de Chile y Argentina.

Oriastrum Poepp. \& Endl. 1842. Asteraceae

Del griego: oreos $=$ montaña y astrum=estrella, porque las flores liguladas parecen estrellas, en las montañas muy altas de Chile.

18 especies del altiplano y zonas andinas de Perú, Bolivia, Argentina y Chile. En nuestro país: 14 especies (entre grados $11^{\circ}$ y $\left.35^{\circ}\right)$.

\section{Orites R.Br. 1810. Proteaceae}

Del griego: orites $=$ habitante de las montañas.

9 especies; 6 especies en las regiones templadas del E de Australia y 3 especies en los Andes sudamericanos. En Chile 1 especie.

\section{Orobanche L. 1753. OROBANCHACEAE}

Del griego: orobos=nombre de una especie de "veza" (una especie de algarroba) y anche=ahogar, estrangular: haciendo referencia al parasitismo de estas plantas sobre ciertas leguminosas, aunque también parasitan plantas de otras familias.

130 especies preferentemente de las regiones templadas y subtropicales del Hemisferio Norte. En Chile 2 especies.

Ortachne Nees ex Steud. 1854. PoACEAE

Del griego: orto=regular, normal, recto y achne=gluma.

2 especies endémicas de Chile y Argentina.

\section{Osmorhiza Raf. 1819. APIACEAE}

Del griego: $o s m o=$ olor y $r h i z a=$ raíz; ya que la raíz huele a anís.

10 especies de Norteamérica, E de Asia y regiones templadas de Sudamérica. En Chile 4 especies.

Otholobium C.H.Stirt. 1981. FABACEAE

Del griego: otho=empujar y lobium=legumbre; por la forma en que ella es presionada hacia fuera del cáliz.

36 especies del E y S de África y de las regiones templadas de Sudamérica. En Chile 2 especies.

Ourisia Comm. ex Juss. 1789. (Scrophulariaceae) Plantaginaceae

En honor a un señor Ouris, gobernador de las Islas Malvinas en el S. XVIII, de quien Commerson obtuvo la planta. 25 especies de Tasmania. Nueva Zelanda y Andes sudamericanos. En Chile 11 especies.

Ovidia Meisn. 1857. Thymelaceae

En honor al poeta romano Publius Ovidius Nason (43 a.C.17 ó 18 d.C.), último de la década de Augusto.

Género monotípico de los bosques subantárticos de Chile y Argentina.
Oxalis L. 1753. OxALIDACEAE

Del griego: oxus=ácido, agudo; las especies de este género saben ácidas o agrias, ya que contienen agrios concentrados de oxalatos alcalinos.

Cerca de 700 especies cosmopolitas. En Chile 53 especies.

Oxychloë Phil. 1860. JunCACEAE

Del griego: oxys=agudo y chloe= $=$ grama, pasto, alude a que es un cojín punzante.

6 especies de los Andes sudamericanos. En Chile 3 especies.

Oxyphyllum Phil. 1860. AsterACEAE

Del griego: oxys=punzante, agudo y phyllum=hoja; alude a las hojas lineares, punzantes.

Género monotípico endémico del $\mathrm{N}$ de Chile.

Oxytheca Nutt. 1847. Polygonaceae

Del griego: oxys=punzante y theca=receptáculo; alude al involucro espinoso.

7 especies del $\mathrm{O}$ de Norteamérica, Argentina y Chile con 1 especie.

Oziroë Raf. 1836. (Hyacinthaceae) AsPARAGACEAE Nombre de la mitología: ortografía diferente para Ocyroe que era la hija del Centauro Chirón y de la náyade Chariclo. Aparentemente Ocyroe tenía pelo de color dorado-rojizo. 5 especies de Perú, Bolivia, Paraguay, Argentina y Chile con 4 especies.

Pachylaena D. Don ex Hook. \& Arn. 1835. Asteraceae Del latín: pachy=grueso y laena=vestido, capa; ya que las brácteas del involucro que rodean las flores son coriáceas. 2 especies endémicas del $\mathrm{N}$ andino de Chile y Argentina; en Chile una de ellas.

Palaua Cav. 1785. Malvaceae

En honor a Anton Palov y Verdera, profesor de botánica en Madrid en la segunda mitad del siglo XVIII.

15 especies de la costa de Perú y Chile con 4 especies.

Panicum L. 1753. POACEAE

Ya sea de (falso pelo de peluca), porque la inflorescencia se ve con numerosos pelos, o de panis (pan), en relación al antiguo uso de la semilla para hornear pan.

Cerca de 600 especies de las regiones templadas, subtropicales y tropicales de todo el mundo. En Chile 3 especies.

Parastrephia Nutt. 1841 emend. Cabrera 1954. AsteraceAe De (extraño); esta planta tiene la particularidad que las lígulas del borde son masculinas y las del medio femeninas.

3 especies de los Andes de Perú, Bolivia, Argentina y Chile con las 3 especies. 
Parietaria L. 1753. URticaceae

De paries (pared, muro) en relación a los lugares en que crecen.

15 especies subcosmopolitas, Juan Fernández e Islas Desventuradas. En Chile 1 especie.

\section{Paronychia Miller 1754. CARYophyllaceae}

De (al lado, contra) y (uña); se usa como remedio para ciertas enfermedades de las uñas y dedos.

Cerca de 100 especies de las regiones templadas de ambos hemisferios. En Chile 6 especies.

Pasithea D.Don 1832. (Hemerocallidaceae) XANTHORRHOEACEAE En honor a Pasithea, una Nereida, una de las tres Gracias, hija de Júpiter y Eurinomo.

Género monotípico endémico de Perú y Chile.

Paspalum L. 1759. POACEAE

Del griego paspalos = nombre griego para el mijo, ya que es cercano al género Milium "mijo" que es una planta que produce harina. Otra versión: de "almorejo", una Poácea según Hipócrates, que viene de (completo) y (harina), ya que ésta posee granos harinosos.

Cerca de 330 especies de las regiones templadas y tropicales de todo el mundo, también en Isla de Pascua. En Chile 8 especies.

Passiflora L. 1789. Passifloraceae De passio $=$ pasión y floris $=$ flor. Los botánicos del siglo XVI le atribuyeron la idea de caracterizar la Pasión de Cristo: el cáliz externo se rodea de espinas y recuerda la corona de Jesús y el resto de la flor los otros elementos de la Crucifixión.

Cerca de 525 especies de las regiones tropicales y subtropicales de América, Madagascar, E de Asia, Malasia, Australia y Nueva Zelanda. En Chile 1 especie.

Patosia Buchenau 1890. JunCACEAE

Nombre derivado de Los Patos, localidad andina de la Región de Coquimbo, Chile, de donde procede la especie tipo.

Género monotípico de los Andes de Bolivia, Argentina y Chile.

Pectocarya DC. ex Meisn. 1840. Boraginaceae

Del griego: pecto=peinado y carya $=$ nuez; los aquenios están sobrepuestos en la orilla como un peine.

13 especies del O de Norteamérica y Sudamérica. En Chile 3 especies.

Pellaea Link 1841. (Pteridaceae) AdiantaCeAe

Del griego: pellos $=$ oscuro; alude a los estípites de algunas de las especies.

35 especies de las regiones tropicales y cálidas, Madagascar. En Chile 2 especies.
Pelletiera A. St.-Hil. 1822. Primulaceae

En honor a Pierre-Joseph Pelletier(1788-1842), farmacéutico francés. Fue catedrático de historia natural en la Escuela Superior de Farmacia de París.

2 especies, 1 en Macronesia y 1 en las regiones subtropicales de Sudamérica, incluido Chile.

Pennellia Nieuwl. 1918. Brassicaceae

En honor de Francis W. Pennell (1886-1952) botánico norteamericano de la Academia de Ciencias Naturales de Filadelfia, especialista principalmente en Scrophulariaceae, quien en 1925, colectó en Chile y Perú.

9 especies de Estados Unidos de América, México, Costa Rica, Guatemala, Colombia, Bolivia, Argentina y Chile con 2 especies.

Pennisetum Rich. 1805. POACEAE

Del latín: penna $=$ pluma y seta $=$ cerda; las espigas están envueltas en cerdas dentadas que se encuentran en la base de cada flor.

115 especies de las regiones tropicales y templadas de todo el mundo. En Chile 1 especie.

Peperomia Ruiz \& Pav. 1794. Piperaceae

Es una derivación del género Piper por peperi=pimienta y omorios $=$ similar.

Cerca de 1.000 especies de las regiones tropicales y cálidas, especialmente de Sudamérica, Hawai y Juan Fernández. En Chile 7 especies.

Perezia Lag. 1811. Asteraceae

En honor a Juan Pérez Pastor de Murcia, España, quien envió al autor (Lagasca) muestras de trigo, judías y otras semillas, especialmente de la costa de Granada.

32 especies de los Andes de Colombia a Chile y en el SE de Brasil. En Chile 20 especies.

Perityle Benth. 1844. Asteraceae

Del griego: peri $=$ alrededor y tyle $=$ callo; alude al margen calloso del fruto.

65 especies principalmente del SO de Norteamérica, en Chile y Perú 1 especie.

Persea Mill. 1754. Lauraceae

Nombre original de un árbol etiope, cultivado en Grecia y Egipto.

120 especies de las regiones tropicales y subtropicales de América, Asia y Macronesia. En Chile 1 especie.

Peumus Molina 1782. Monimiaceae

Del nombre vernáculo del árbol, "peumo". Género monotípico endémico de Chile. 
Phacelia Juss. 1789. Boraginaceae

Del griego: phakelos=manojo, racimo; alude a las flores en racimo de la especie original.

200 especies del O de Norteamérica y Sudamérica. En Chile 6 especies.

Phalaris L. 1753. POACEAE

De (resplandeciente, brillante, blanco); por sus semillas lustrosas. Otra versión: antiguo nombre griego para un pasto.

20 especies de las regiones templadas de Eurasia y América.

En Chile 2 especies.

Philesia Comm. ex Juss. 1789. Philesiaceae

Del griego: $p$ hileo $=$ amar, vivir; sus flores ofrecen un vivo y hermoso aspecto.

Género monotípico endémico de Argentina y Chile.

\section{Philibertia Kunth 1818. APOCYNACEAE}

En honor a J. C. Philibert, francés, que escribió: "Notions élementaires de la Botanique et Introduction á l'étude de la Botanique", en 1799.

40 especies de los Andes de Perú, Bolivia y Argentina y Chile con 2 especies.

\section{Philippiella Speg. 1897. CARYophyllaceae}

En honor al sabio naturalista doctor Rodulfo Amando Philippi (1808-1904), que vivió gran parte de su vida en Chile desde 1851. Llegó a ser director del Museo Nacional de Historia Natural, institución cultural que tuvo prestigio universal; Philippi describió más de 3.700 especies de plantas nuevas para la ciencia.

Género monotípico endémico de la Patagonia de Argentina y Chile.

Phleum L. 1753. Poaceae

Según el filósofo griego Teofrastro (327-287 a.C.), pleus=fluir, en relación a su uso contra la supuración del oído.

15 especies de las regiones templadas de Eurasia y América. En Chile 1 especie.

Phragmites Adans. 1763. POACEAE

Del griego phragma $=$ cerca, valla; por su forma de crecer a lo largo de los ríos.

4 especies cosmopolitas. En Chile 1 especie.

\section{Phrodus Miers 1849. Solanaceae}

Del griego phroudos=evanidus=que se desvanece, pobre; por el hábito de la planta, achaparrado y pobre.

Género monotípico endémico del $\mathrm{N}$ de Chile (Atacama y Coquimbo).

Phycella Lindl. 1825. Amaryllidaceae Del griego: pintado de rojo.
6 especies endémicas de Chile y Argentina, en Chile las 6.

Phyllachne J.R. Forst. \& G. Forst. 1776. Stylidiaceae Del griego phylla $=$ hoja y achne $=$ paja; la planta tiene hojas pequeñas, pajosas o aleznadas a lo largo de los tallos.

4 especies de Tasmania, Nueva Zelanda y regiones templadas de Sudamérica. En Chile 1 especie.

Phylloscirpus C.B.Clarke 1908. CyPeraceAe

Del griego phyllos=hojas y Scirpus, otro género; por las brácteas que rodean la densa cabezuela de espiguillas.

3 especies endémicas de Argentina, Bolivia y Chile, con las 3 especies.

Phytolacca L. 1753. Phytolaccaceae

Del griego phyto=planta y del latín lacca=barniz; porque el fruto es de un hermoso color rojo brillante.

25 especies de las regiones tropicales y cálidas del mundo. En Chile 2 especies.

Picrosia D.Don. 1830. Asteraceae

Del griego picros=amargo; ya que la planta sabe muy amarga.

2 especies de las regiones subtropicales de Sudamérica. En Chile 1 especie.

Pilea Lindl. 1821. Urticaceae

Del latín: pileus=sombrero, gorra; ya que uno de los tres lóbulos de los perigonios femeninos es muy grande y en forma de gorro.

Cerca de 250 especies de las regiones tropicales y cálidas del mundo, excluido Australasia. En Chile 3 especies.

Pilgerodendron Florin 1930. CuPRESSACEAE

En honor a Robert Pilger (1876-1950), importante botánico alemán especialista en coníferas y dendron=árbol.

Género monotípico endémico de Argentina y Chile.

Pilostyles Guill. 1834. RAFFLESIACEAE

Del griego pileus=gorra y tylo=columna, aludiendo a la forma que adopta el androceo.

25 especies en América desde Estados Unidos a Magallanes, Asia, 2 en el $\mathrm{O}$ de Australia.

En Chile 1 especie.

Pilularia L. 1753. MarsileaceAe

Del latín pilula=pequeña bola, por la forma de los esporocarpos en la base de los pecíolos.

6 especies de Europa, Australia, Nueva Zelanda, Etiopía y O de Sudamérica. En Chile 1 especie.

Pinguicula L. 1753. Lentibulariaceae

Del latín pinguiculus=grasilla; hace referencia a las glándulas de las hojas que de lejos parece grasa acumulada 
en el haz. Las hojas de la pinguícula parecen una lengua, son planas y están cubiertas de minúsculas gotas de líquido "pega" (como en las droseras). Los insectos que caen, en general muy pequeños, quedan pegados a la hoja.

Cerca de 85 especies de América, Mediterráneo y regiones circumboreales. En Chile 2 especies.

Pintoa Gay 1845. Zygophyllaceae

En honor al general don Francisco Antonio Pinto, Presidente de Chile (1827-1829).

Género monotípico endémico de Chile.

Piptochaetium J.Presl 1830. POACEAE

Del griego: pipto $=$ caer y chaeta $=$ cerda, las aristas caen pronto.

30 especies desde Estados Unidos de América hasta Chile y Argentina y Juan Fernández. En Chile 7 especies.

Pitavia Molina 1810. Rutaceae

Del nombre vernáculo de la planta, pitao.

Género monotípico endémico de Chile.

Pitraea Turcz. 1862. Verbenaceae

En honor al botánico ruso Adolf Pitra (1830-1889).

Género monotípico endémico de Perú, Argentina y Chile.

Pityrogramma Link 1833. Pteridaceae

Del griego: pityro o pituron=afrecho, cáscara, deshecho y gramma=línea; probablemente por las glándulas de las hojas que producen una harina blanca.

16 especies de África, Madagascar y América tropical desde el S de Estados Unidos hasta Chile, con 1 especie.

Placea Miers ex Lindl. 1841. AmaryllidaceAe

Presumiblemente del latín, deleitar, agradar.

Género endémico de Chile con 5 especies.

Plagiobothrys Fisch. \& Meyer 1835. BoraginaCEAE

De plagios=diagonal, oblicuo y bothros=hueco, fosa; los aquenios presentan una cicatriz.

Cerca de 70 especies del E de Asia, Australia, O de Norteamérica y Sudamérica. En Chile 17 especies.

\section{Plantago L. 1753. Plantaginaceae}

Del latín: planta=planta del pie y agere=guiar: debido al parecido de las hojas apretadas contra el suelo, a la huella de un pie. Linneo entrega otra etimología : el mismo prefijo y tangere $=$ afectar; es decir, una planta que se palpa suave y blanda.

270 especies cosmopolitas, Juan Fernández e Islas Desventuradas. En Chile 23 especies.

Plazia Ruiz \& Pav. 1794. Asteraceae

En honor a Juan Plaza, médico y profesor valenciano nacido hacia 1525 , fue uno de los primeros botánicos que creó un jardín de plantas medicinales en la universidad, tuvo contacto con el gran naturalista flamenco Charles de l'Escluse (Clusius).

3 especies de Perú, Bolivia, Argentina y Chile con 2 especies.

Pleocarphus D.Don 1830. Asteraceae

Del griego: pleion=muchos y carphus=paja; el receptáculo tiene brácteas anchas que rodean las flores.

Género monotípico endémico del $\mathrm{N}$ de Chile.

Pleopeltis Humb. \& Bonpl. ex Willd. 1810. PolyPODIACEAE Del griego: pleion $=$ muchos, lleno y peltis $=$ escudo; los soros son numerosos, en forma de escudos, cubiertos de escamas pajosas.

10 especies de las regiones tropicales de América, India, Sri Lanka, 1 especie en África y Madagascar. En Chile 2 especies.

Pleurophora D.Don 1831. Lythraceae

Del griego: pleuron=nervio y phorein=llevar; ya que el cáliz tiene nervios notorios.

9 especies de Sudamérica. En Chile 3 especies.

Pleurosorus Fée 1850-52. Aspleniaceae

Del griego: pleuro $=$ nervio, costado y sorus $=$ soros; porque los soros se presentan al lado de las nervaduras.

4 especies de España, Marruecos, Australia, Tasmania, Nueva Zelanda, Argentina y Chile con 1 especie.

Pluchea Cass. 1817. Asteraceae

En honor al francés Noel Antoine Pluche (1688-1761), quien escribió "Spectacle de la nature", París, 1732.

Cerca de 80 especies de Asia, África Australia, Norte y Sudamérica. En Chile 1 especie.

Plumbago L. 1753. Plumbaginaceae

Del latín: plumbum=plomo, ya sea por el color de las flores de algunas especies o porque en un tiempo se suponía que la planta era un antídoto para el envenenamiento por plomo.

20 especies de las regiones tropicales, cálidas y templadas del mundo. En Chile 1 especie.

Poa L. 1753. Poaceae

De (pastar) nombre genérico del griego y latín para "pasto, forraje"

Cerca de 350 especies de regiones templadas, frías y trópicos de altura. En Chile 42 especies.

Podagrostis Scribner \& Merr. 1910. POACEAE

Del griego: $p o d o=p i e$ y agros $=$ campo, tierra; alude probablemente a la raquilla prolongada.

4 especies de Canadá, Estados Unidos de América, Argentina y Chile con 1 especie. 
Podanthus Lag. 1816. Asteraceae

Del griego: $p o d o=$ pie y anthus $=$ flor; alude a los pedúnculos de las inflorescencias.

Género endémico de Chile con 2 especies.

Podocarpus L'Hér. ex Pers. 1807. Podocarpaceae Del griego: podo=pie y carpon=fruto; por el arilo carnoso que lleva la semilla en la base, considerado erróneamente un fruto.

Cerca de 100 especies de Asia, África, Madagascar, Australia, Tasmania, Nueva Zelanda, México, Caribe, Centro y Sudamérica. En Chile 2 especies.

Podophorus Phil. 1856. PoACEAE

Del griego: podo=pie y phorus $=$ llevar.

Género monotípico endémico de Juan Fernández, Chile.

\section{Polemonium L. 1753. Polemoniaceae}

Según Plinio de: riva (guerra), pues fue motivo de peleas entre los países que se disputaban la planta por sus propiedades medicinales. Otra versión: nombre usado por Dioscórides para una planta.

Cerca de 40 especies de las regiones templadas de Eurasia, Norteamérica y Chile con 1 especie.

Polyachyrus Lag. 1811. Asteraceae

Del griego: poly=muchos y achyrus=pajitas o aristas; alude al vilano o papo paleáceo de algunas especies.

7 especies de Perú y Chile con las 7 especies.

Polycarpon Löfl. 1758. CARYophyllaceae

Del griego; poly $=$ muchos y carpon=fruto.

16 especies cosmopolitas. En Chile 1 especie.

Polygala L. 1753. Polygalaceae

Del griego: poly=muchos y gala=leche; ya que estas especies ayudan a aumentar la producción de la leche en las vacas.

Cerca de 500 especies subcosmopolitas. En Chile 7 especies.

Polygonum L. 1753. Polygonaceae

Del griego: poly=muchos y gonum=rodillas, nudos; debido a las numerosas articulaciones del tallo.

Cerca de 90 especies cosmopolitas. En Chile 5 especies.

Polylepis Ruiz \& Pav. 1794. Rosaceae

Del griego: poly=muchos y lepis=escama; porque la corteza se desprende en tiras.

15 especies de los Andes desde Venezuela hasta Argentina y Chile con 2 especies.

Polypogon Desf. 1798. Poaceae

Del griego: poly=muchos y pogon=barba; porque las glumas son aristadas.
13 especies cosmopolitas. En Chile 8 especies.

Polypsecadium O.E.Schulz 1924. Brassicaceae

Del griego: poly=muchos y psecadios $=$ granuloso, en referencia a las numerosas semillas.

14 especies de Colombia hasta la Patagonia argentina y chilena. En Chile 3 especies.

Polystichum Roth. 1799. DrYoPTERIDACEAE

Del griego: poly=muchos y stichum=filas; ya que los soros forman muchas filas.

Cerca de 160 especies cosmopolitas, Madagascar e Isla de Pascua. En Chile 6 especies.

Porlieria Ruiz \& Pav. 1794. Zygophyllaceae

En honor a don Antonio Porlier Marquéz de Baxamar (1722-1813), embajador español en India y mecenas de la botánica.

5 especies del S de Estados Unidos de América, México y Sudamérica. En Chile 1 especie.

Portulaca L. 1753. PortulacaceAe

Probablemente del latín (puertecita), por la abertura del fruto.

Cerca de 40 especies de las regiones tropicales, subtropicales y templadas. En Chile 1 especie.

Potamogeton L. 1753. Potamogetonaceae

Del griego: potamos=río y geiton=vecino, allegado; debido a que estas plantas crecen junto a los ríos.

Cerca de 95 especies cosmopolitas. En Chile 7 especies.

Potentilla L. 1753. RosACEAe

Del latín, diminutivo de potens $=$ potente, poderoso, por las propiedades medicinales de algunas especies.

500 especies de $\mathrm{N}$ y Sudámérica, Eurasia templada. En Chile 1 especie (antes llamada Fragaria chiloensis).

Pouteria Aublet 1775. SAPOTACEAE

Forma latinizada de su nombre nativo en Guyana "pourama pouteri”.

Cerca de 200 especies en los trópicos americanos, África, Asia, Australia, Nueva Zelanda y Nueva Caledonia. En Chile 1 especie.

Pozoa Lag. 1816. Apiaceae

En honor al botánico español don José Manuel Pozo.

2 especies endémicas de los Andes de Chile y Argentina.

Primula L. 1753. Primulaceae

Del latín: primus=primero; ya que es la primera planta que florece en primavera.

Cerca de 400 especies del Hemisferio Norte, Asia tropical y Sudamérica templada. En Chile 1 especie. 
Prosopis L. 1767 emend. Burkart 1976. FABACEAE Nombre griego dado a otra planta y que por razones desconocidas fue dado a este género.

44 especies de las regiones tropicales y subtropicales de América, África y O de Asia. En Chile 7 especies.

Proustia Lag. 1811. Asteraceae

En honor al químico francés Joseph Louis Proust, profesor en el Seminario de Vergara en el Colegio de Artillería de Segovia y en el Real Laboratorio de Madrid.

3 especies en Bolivia, Chile, Argentina y Perú. En Chile las 3 especies.

Prumnopitys Phil. 1860. Podocarpaceae

Del griego: prumno=baya y pitys=piña del pino; ya que la semilla está rodeada por un arilo carnoso que semeja uva.

8 especies de Nueva Caledonia, Nueva Zelanda y E de Australia y América desde Costa Rica hasta Chile, con 1 especie.

Psilocarphus Nutt. 1841. Asteraceae

Del griego: $p$ silos=desnudo, liso y carphus=paja, pálea, porque las flores del disco no están rodeadas por brácteas.

8 especies del $\mathrm{O}$ de Estados Unidos de América y regiones templadas de Sudamérica. En Chile 2 especies.

Psilotum Sw. 1801. Psilotaceae

Del griego $p$ silos=desnudo, lampiño; alude a que el tallo y ramas son generalmente sin hojas.

2 especies de las regiones pantropicales, Hawaii, Australia, Nueva Zelanda, Madagascar e Isla de Pascua. En Chile 1 especie.

Pteris L. 1753. Pteridaceae

Del griego pteris=ala; debido a sus grandes hojas, finas y delicadamente pinnadas, parecen las alas abiertas de un ave. Cerca de 280 especies cosmopolitas, Madagascar y Juan Fernández. En Chile 3 especies.

Pterocactus K.Schum. 1897. CACTACEAE

Del griego pteris $=$ ala y cactus $=$ cacto; se refiere a las semillas aladas de estas especies.

9 especies de la Patagonia argentina y en Chile con 2 especies.

Puccinellia Parl. 1848. POACEAE

En honor al profesor y botánico italiano Benedetto Puccinelli (1808-1850), Director del Jardín Botánico de Lucca.

Cerca de 80 especies de las regiones templadas de Asia, Norteamérica, Sudáfrica, Australia y Sudamérica. En Chile 8 especies.

Puya Molina 1782. Bromeliaceae

Nombre mapuche de esta planta, en Chile.
Cerca de 190 especies de Centro y Sudamérica. En Chile 8 especies.

Pycnophyllum J.Remy 1846. CARYOPHYLLACEAE

Del griego pycno=apretado y phyllum=hojas; por las hojas apretadas sobre el tallo.

17 especies de los Andes de Perú, Bolivia, Argentina y Chile con 5 especies.

Pycreus P.Beauv. 1807. Cyperaceae

Es un anagrama de Cyperus, con las mismas letras se formó este nombre.

Cerca de 70 especies pantropicales. En Chile 3 especies.

Pyrrhocactus A.Berger 1936. CACTACEAe

Del griego $p y r=$ fuego, por el colorido rojo oscuro del tallo de varias de estas especies.

27 especies de Argentina y Chile; en Chile 20 especies.

Quillaja Molina 1782. (Rosaceae) QuillaJACEAE

De "quillai" nombre vernáculo y éste del mapudungun quillean=lavar o cullumn = lavar la cara; ya que la corteza contiene saponina.

2 especies de las regiones templadas de Brasil, Perú, Argentina y Chile con 1 especie.

Quinchamalium Juss. 1789. SANTALACEAE

Del nombre vernáculo mapuche quinchamali=niñas agrupadas, por las inflorescencias amarillas.

25 especies de los Andes de Perú, Bolivia, Argentina y Chile con 14 especies.

Ranunculus L. 1754. RanUnCUlaCeAe

Antiguo nombre utilizado por Plinio, derivado de rana, ya que como las ranas viven en los pantanos o lugares húmedos.

Cerca de 500 especies cosmopolitas. En Chile 18 especies.

Raukaua Seem. 1866. AraliaCEAE

Nombre maorí de una de las especies ( $R$. edgerleyi), cuyas hojas son utilizadas por los maoríes para producir un aceite perfumado.

10 especies de Tasmania, Nueva Zelanda y Chile, con 2 especies. Antes pertenecían al género Pseudopanax.

Reicheella Pax 1900. CARYophyllaceae

En honor al Dr. Carlos Reiche (1869-1929), que llegó a Chile contratado por el Supremo Gobierno en 1889 como profesor del entonces recién fundado Liceo de Hombres de Constitución; publicó "Estudios Críticos sobre la Flora de Chile", en 6 tomos. Reiche, además, es autor de numerosos y muy útiles estudios relacionados con la flora y vegetación chilenas.

Género monotípico y endémico de Chile. 
Relchela Steud.1854. Poaceae

Anagrama de Lechlera, en honor de Willibald Lechler (1814-1857), farmacéutico alemán que llegó a Chile en 1850, colectó plantas en el sur, Magallanes y Tierra del Fuego; luego las envió a Europa y fueron descritas por los principales botánicos de su época.

Género monotípico endémico de Argentina y Chile.

Retanilla Brongn. 1827. RHAMNACEAE

Nombre vernáculo peruano.

4 especies de Argentina y Chile, con 3 especies.

Reyesia Gay 1849. SOLANACEAE

En honor a don Antonio García Reyes (1817-1855), ex Secretario de la Sociedad de Agricultura, miembro de la Universidad de Chile y profesor en el Instituto Nacional.

4 especies endémicas de Argentina y Chile.

Rhamnus L. 1753. RHAMNACEAE

Nombre griego para varios arbustos espinosos.

Cerca de 160 especies del Hemisferio Norte, Sudáfrica y Sudamérica. En Chile 1 especie.

\section{Rhaphithamnus Miers 1870. Verbenaceae}

Del griego rhaphis=aguja y thamnium=arbusto; por las espinas de los tallos.

2 especies de Argentina y Chile, incluido Juan Fernández. En Chile 2 especies.

\section{Rhodophiala C.Presl 1844. Amaryllidaceae}

Del griego rhodo=rojo y phiala=copa; por la forma de la flor.

30 especies de Brasil, Bolivia, Argentina y Chile, con 27 especies.

Rhombolytrum Link 1833. POACEAE

Del griego rhombos $=$ rombo y elytron= cobertura: alude a la forma de la lemma.

2 especies del S de Brasil, Uruguay y Chile, con 1 especie.

Rhynchospora Vahl 1805 (sub Rynchospora) emend. Willd. 1809. CYPERACEAE

Del griego $r$ ynnchos $=$ pico y spora $=$ semilla, por la forma del fruto provisto de un pico o rostro.

Cerca de 250 especies cosmopolitas. En Chile 1 especie.

Ribes L. 1753. Grossulariaceae

Nombre árabe para una planta de sabor agrio.

Cerca de 150 especies del Hemisferio Norte, N de África y América desde Canadá a Tierra del Fuego. En Chile 10 especies.

Robinsonia DC. 1833. Asteraceae

Denominado así en recuerdo del navegante Alejandro
Selkirk, el "Robinson Crusoe" de la famosa obra homónima de Daniel Defoe.

Género endémico con 8 especies del Archipiélago de Juan Fernández, Chile. Existe un trabajo reciente que lo inserta dentro de Senecio (Pelser et al. 2010).

Rorippa Scopoli 1760. BRASSICACEAE Latinización de Rorippen, nombre vulgar sajón proveniente del E de Alemania.

75 especies cosmopolitas del Hemisferio Norte, Sudáfrica y Sudamérica. En Chile 3 especies.

Rostkovia Desv. 1808. JUNCACEAE

En honor al médico de Halle (Sajonia), Friedrich Wilhelm Gottlieb Rostkovius, autor de varios estudios sobre Juncáceas.

2 especies de Nueva Zelanda, S de Sudamérica en Tierra del Fuego e Islas Malvinas. En Chile 1 especie.

Rostraria Trin. 1820. POACEAE

Del griego rostrum=pico; ya que los antecios llevan 2 dientes en el ápice.

2 especies de Estados Unidos de América, México, Caribe, Perú, Uruguay, Argentina y Chile con 1 especie.

Rubus L. 1754. ROSACEAE

Del latín ruber=rojo; en relación al color rojo del fruto de varias especies.

Cerca de 500 especies cosmopolitas y en Juan Fernández. En Chile 2 especies.

\section{Rumex L. 1753. Polygonaceae}

Del latín, según Plinio, nombre latín clásico para una hierba salada. Otra versión (como flecha) en relación a la forma sagitada o alabardada de las hojas en varias especies.

Cerca de 200 especies cosmopolitas. En Chile 10 especies.

\section{Rumohra Raddi 1819. DRYopteridACEAE}

En honor al experto en arte, escritor y patrono de la botánica, Karl Friedrich Ludwig Felix von Rumohr (1785-1843).

7 especies circumaustrales, Madagascar y Juan Fernández. En Chile 2 especies.

\section{Ruppia L. 1753. RUPPIACEAE}

En honor a Heinrik Bernhard Ruppius, originario de Giessen, Alemania, murió en 1719; escribió una Flora de Jena, 1718.

10 especies cosmopolitas. En Chile 2 especies.

Rytidosperma Steud. 1855. POACEAE

Del griego rytidos=rugoso y sperma $=$ semilla, porque el autor confundió una larva de insecto con la semilla.

28 especies de Australia, Nueva Zelanda, Argentina y Chile, incluida Isla de Pascua, con 6 especies. 
Sagina L. 1753. CARYOPHYLLACEAE

Del latín sagina=forraje, cebadura, grasa; es decir, es un buen forraje.

25 especies de las regiones templadas del Hemisferio Norte, del E de África, Asia, Nueva Guinea, Australia, Nueva Zelanda y los Andes de América. En Chile 2 especies.

\section{Sagittaria L. 1753. AlismataCeAe}

Del latín sagitta=flecha; en relación a la forma de la hoja.

25 especies cosmopolitas. En Chile 2 especies.

Salix L. 1753. SALICACEAE

Nombre en latín del sauce o mimbre.

Cerca de 450 especies de las regiones templadas del Ártico y Sudamérica, pocas en los trópicos, 1 especie en Sudáfrica. En Chile 1 especie.

\section{Salpichroa Miers 1845. SolanACEAE}

Del griego salpin $x=$ trompeta y chroa=piel; alude al aspecto de la flor.

15 especies de Sudamérica. En Chile 2 especies.

Salpiglossis Ruiz \& Pav. 1797. Solanaceae

Del latín salpis=tubo y glossis=lengua; ya que el pistilo forma una lengua tubular.

2 especies endémicas de Argentina y Chile.

Salvia L. 1753. LAMIACEAE

Del latín salvare=sanar; en relación a sus propiedades medicinales.

Cerca de 900 especies cosmopolitas. En Chile 5 especies.

\section{Samolus L. 1753. Primulaceae}

Del celta $s a n=$ curativo y $m o s=$ cerdo; los antiguos galos usaban la planta contra las enfermedades de los cerdos y ganado.

12 especies cosmopolitas, incluida Isla de Pascua. En Chile 3 especies.

Sanctambrosia Skottsb. 1947. CARYoPHYLLACEAE

Por la isla de San Ambrosio de donde es originaria esta planta.

Género monotípico endémico de Islas Desventuradas (San Félix y San Ambrosio), Chile.

\section{Sanicula L. 1753. APIACEAE}

Del latín sanare=sanar; se usó mucho como vulnerario (remedios capaces de curar las llagas y heridas).

40 especies subcosmopolitas, excluidos Australia y Nueva Zelanda. En Chile 2 especies.

Santalum L. 1742. SANTALACEAE

Del nombre común "sándalo".

25 especies de Indomalasia a Australia, Hawai y en Juan
Fernández, Chile, con 1 especie endémica, hoy extinta.

Sarcocornia (Duval-Jouve ex Moss) A.J. Scott 1977. Amaranthaceae

Del griego sarkós=carne y cornia $=$ cuerno; alude probablemente a la forma y consistencia de las hojas.

16 especies de Eurasia, África, Australia, Tasmania, Nueva Zelanda, Norte y Sudamérica y Juan Fernández. En Chile 4 especies.

Sarcodraba Gilg \& Muschl. 1909. BRASSICACEAE Del griego sarkós=carne y Draba, otro género; alude probablemente a la consistencia carnosa de las hojas.

4 especies principalmente en la Patagonia argentino-chilena. En Chile 1 especie.

Sarmienta Ruiz \& Pav. 1794. Gesneriaceae

En honor al insigne botánico español Martín Sarmiento (1695-1772), también filólogo y estudioso de la Historia Natural.

Género monotípico endémico de Chile.

Saxegothaea Lindl. 1851. PodocarpacEAe

En honor al príncipe Alberto von Sacksen Koburg-Gotha, esposo de la Reina Victoria de Inglaterra.

Género monotípico endémico de Argentina y Chile.

Saxifraga L. 1753. SAXIFRAGACEAE

Del latín saxum=piedras, rocas y frango=quebrar; deshacer, porque las raíces de algunas especies penetran en las grietas de las rocas provocando su ruptura o por el supuesto efecto de romper las piedras de la vejiga.

Cerca de 350 especies de las regiones temperadas de Eurasia, Norteamérica y los Andes Sudamericanos. En Chile 1 especie.

Saxifragella Engl. 1891. SAXIFRAGACEAE

Pequeña Saxifraga.

1 especie en la región antártica de Sudamérica, incluido Chile.

Saxifragodes D.M.Moore 1969. SAXIFRAGACEAE

Del griego oides, odes=parecido; por el parecido a la Saxifraga.

Género monotípico endémico de Tierra del Fuego de Argentina y Chile.

Schinus L. 1753. ANACARDIACEAE

Nombre griego del lentisco, otro arbolito de esta misma familia.

27 especies de México a Argentina y Chile con 11 especies.

Schizaea Sw. 1793. Schizaeaceae

Del griego schizo=cortar, hender; la fronda es mayormente 
cortada, dicótoma o flabeliforme.

30 especies de las regiones tropicales y australes, Norteamérica y Madagascar. En Chile 1 especie.

Schizanthus Ruiz \& Pav. 1794. SolanaceaE

Del griego $s c h i z o=$ cortar, hendida y anthos=flor; alude a las divisiones de los pétalos.

12 especies endémicas de Argentina y Chile.

Schizeilema (Hook.f.) Domin 1908. APIACEAE

Del griego $s c h i z o=$ cortar, hender, separar y eilema=brácteas; alude a una especie con brácteas fimbriadas.

13 especies: 11 en Nueva Zelanda, 1 en Australia y 1 en el S de Sudamérica, incluido Chile.

Schizopetalon Sims 1823. BRASSICACEAE

Del griego $s c h i z o=$ cortar, hendidura y petalon=pétalo; los pétalos son pinnatífidos.

10 especies endémicas del norte y centro de Argentina y Chile.

Schkuhria Roth 1797. AsterACEAE

En honor a Christian Schkuhr (1741-1811), ilustrador y botánico alemán. Como jardinero sigue estudios en la Universidad de Wittenberg, donde continúa su trabajo de jardinero. Se perfecciona en dibujo y grabado. Partidario del sistema de Linneo, se consagra al estudio de la flora de Wittenberg.

6 especies de las regiones tropicales y subtropicales de América. En Chile 2 especies.

Schoenoplectus (Rchb.) Palla 1888. CyPeraceAe Del griego: schoinos=junco,caña y plektos=torcido

80 especies cosmopolitas; en Chile 3 especies.

Schoenus L. 1753. CYPerACEAE

Del griego: schoinos=junco, caña, cordel; por el uso de las hojas para trenzados y amarras.

100 especies subcosmopolitas. En Chile 4 especies.

Scirpus L. 1753. CyPERACEAE

Del celta: sirs $=$ junco y scirpare=amarrar, trenzar.

200 especies en las regiones templadas de todo el mundo, Isla de Pascua y Juan Fernández. En Chile 5 especies.

Scutellaria L. 1753. LAMIACEAE

Del latín: scutella, pequeña vasija; en relación a la forma del cáliz, que es parecida a una taza con oreja.

Cerca de 360 especies cosmopolitas. En Chile 3 especies.

Scyphanthus D.Don 1828. LOASACEAE

De $s k y p h o s=$ cúpula y anthos=flor; tiene 5 pétalos en forma de gorro.

Género endémico y monotípico de Chile.
Selkirkia Hemsley 1884. BoraginaCEAE

En honor al célebre marino escocés Alejandro Selkirk, quien inspiró al escritor Daniel Defoe para su novela "Robinson Crusoe".

Género monotípico endémico del Archipiélago Juan Fernández, Chile.

Selliera Cav. 1799. GoOdEnIACEAE

En honor a Natale Sellier, francés, grabador e ilustrador botánico, en obras de A.J. Cavanilles.

2 especies de Australia, Nueva Zelanda y Chile con 1 especie.

Senecio L. 1753. Asteraceae

Del latín senex=viejo, anciano; probablemente por el papus o vilano blanco de sus frutos.

Cerca de 1250 especies cosmopolitas. En Chile 224 especies.

Senna Miller 1754. FABACEAE

Del nombre árabe de la planta.

Cerca de 300 especies pantropicales. En Chile 10 especies.

Serpyllopsis Bosch 1861. HyMENOPHYLLACEAE

Parecido a Serphyllum o Thymus serphyllum el "tomillo" con hojas semejantes a estas plantas.

Género monotípico de Argentina, Islas Malvinas y Juan Fernández, Chile.

Setaria P.Beauv. 1812. PoAcEAE

Del latín saeta = cerda, seta, y la terminación aria; aludiendo a las cerdas que rodean las espiguillas.

110 especies tropicales, subtropicales y de regiones templadas; en Chile 1 especie.

Sibara Greene 1896. BRASSICACEAE

Anagrama de Arabis, otro género de Brassicaceae.

12 especies que muestran disyunción anfitropical, 6 en California y 6 en el norte de Chile y en Mendoza y Patagonia en Argentina (antes tratadas como Werdermannia).

Sicyos L. 1753. CucurbitaceAe

Del griego sicyos=pepino.

Cerca de 50 especies de Australia, Tasmania, Nueva Zelanda, Hawai, Norte y Sudamérica e Islas Desventuradas. En Chile 1 especie.

Siegesbeckia L. 1753. AstERACEAE

En honor a Johann Georg Siegesbeck (1686-1755), académico y director del jardín botánico de San Petesburgo. Escribió: "Primitiae florae Petropol, 1736"y "Botanosophia, 1737'".

8 especies de las regiones tropicales y subtropicales del mundo. En Chile 1 especie. 
Silene L. 1753. CARYophyllaceae

En honor a Sileno, padre adoptivo y preceptor de Dionisos o Baco, siempre representado con vientre hinchado, similar a los cálices de las especies.

Cerca de 600 especies de las regiones templadas y mediterráneas y S de África. En Chile 8 especies.

\section{Sisyrinchium L. 1753. IRIDACEAE}

Nombre empleado por Teofrasto y Plinio, que significa comida y trompa de cerdo; las raíces de algunas especies son comidas por estos animales.

60 especies de América. En Chile 18 especies.

\section{Skytanthus Meyen 1834. ApocynaCeae}

Del griego (cuero) y (flor); la corola es coriácea.

3 especies de Brasil y Chile con 1 especie.

\section{Solanum L. 1753. SolANACEAE}

De solamen=consuelo, tranquilidad; en relación al efecto calmante del dolor y adormecedor de varias especies.

Cerca de 1.700 especies subcosmopolitas, Juan Fernández, Islas Desventuradas e Isla de Pascua. En Chile 44 especies.

\section{Solaria Phil. 1857-58. Alliaceae}

En honor a Don Francisco de Borja Solar (1807-1891), ingeniero civil y ex director del Instituto Nacional de Santiago de Chile; fue hombre público chileno y profesor universitario y miembro de la Facultad de Ciencias Matemáticas y Físicas de la Universidad de Chile.

1 especie de Argentina y Chile.

\section{Solenomelus Miers 1842. IRIDACEAE}

Del griego soleno=tubo y melus $=$ miembros; ya que los estambres y estigmas van unidos en un tubo.

2 especies endémicas de Argentina y Chile.

Solidago L. 1753. AsteraceAe

De solidus $=$ firme y agere=llevar; planta que posee una gran fuerza para la curación de heridas.

Cerca de 100 especies de las regiones templadas de Eurasia, Macronesia y América. En Chile 2 especies.

Soliva Ruiz \& Pav. 1794. Asteraceae

En honor al Dr. Salvador Soliva (1750-1793), médico y botánico de la corte española en la segunda mitad del siglo XVIII.

8 especies de Norteamérica, Australia y Sudamérica. En Chile 2 especies.

\section{Sophora L. 1753. FABACEAE}

Del árabe sophera, para una planta con flores amariposadas. 47 especies de los trópicos y abundante en las regiones templadas del Hemisferio Norte, Juan Fernández e Isla de Pascua. En Chile 5 especies.
Spartina Schreb. 1789. POACEAE

Del griego spartine $=$ cuerda, cordel, por ser hierba utilizada para amarrar.

20 especies del O de Europa, NO de África y América. En Chile 1 especie.

Speea Loes. 1927. Alliaceae

En honor al almirante Maximilian Graff von Spee (18611914), jefe de la escuadra alemana en el Pacífico durante la Primera Guerra Mundial. Vencedor en la batalla de Coronel, Chile. Muere junto a sus hijos, también oficiales, derrotado en la batalla de Las Malvinas.

Género monotípico y endémico de Chile.

Spergula L. 1753. CARYophyllaceae

Del latín spargere o spargo= esparcir; porque sembraban semillas como forraje tempranero en Europa.

5 especies de Europa y Patagonia; en Chile 4 especies.

Spergularia J.R.Presl \& C.Presl 1819. CARYOPHYLlaCeAE De Spergula, otro género de la misma familia. De spergere $=$ esparcir, porque los tallos y panojas divergen hacia todos lados.

30 especies cosmopolitas, Juan Fernández e Islas Desventuradas. En Chile 10 especies.

Sphaeralcea A.St.-Hill. 1825. MaLvaCeaE

Del griego sphaera=esfera, bola, y alcea $=$ malva; es una malvácea con cápsula esférica.

60 especies del $\mathrm{O}$ de Norteamérica, México y regiones templadas de Sudamérica. En Chile 2 especies.

Spilanthes Jacq. 1760. AsteraceAe

Del griego spilo=mancha y anthos=flor; las flores de color claro tienen manchas negras que son causadas por el polen oscuro de las anteras.

6 especies de las regiones tropicales del mundo. En Chile 1 especie.

Sporobolus R.Br. 1810. PoACEAe

Del griego sporos $=$ semillas y ballum=arrojar; las semillas se esparcen fácilmente.

Cerca de 160 especies de Asia, África, América y Europa, con 1 especie. En Chile 2 especies.

Stachys L. 1753. LAMiACEAE

Del griego: stachys=espiga; porque las flores van dispuestas en forma de espiga.

Cerca de 300 especies en las regiones tropicales, subtropicales y templadas del mundo, excepto Australasia. En Chile 11 especies.

Stangea Graebn. 1906. VAlerianaceae

En honor a la familia Stange, de donde provenía la esposa 
del autor del género.

5 especies de Perú, Argentina y Chile, con 1 especie.

Stellaria L. 1753. CARYOPHYLLACEAE

Del latín stella=estrella; en relación a la corola, semejante a una estrella.

Cerca de 150 especies cosmopolitas. En Chile 9 especies.

Stemodia L. 1759. (Scrophulariaceae) Plantaginaceae

Del griego stemon $=$ estambre y dia $=$ doble; aludiendo a las tecas separadas por un conectivo notable.

45 especies de las regiones tropicales y subtropicales del mundo, Madagascar. En Chile 1 especie.

Stenandrium Nees 1836. AcAnthaCEAE

Del griego $s t e n o=$ estrecho y andrum=elemento masculino, estambre; las anteras son lineales.

40 especies desde el $\mathrm{S}$ de Estados Unidos de América al centro de Chile, con 1 especie.

Stevia Cav. 1797. AsteraceAe

En honor a don Pedro T. Esteve, español, doctor y profesor de botánica en el S. XVI; dejó un catálogo de plantas del Reinado de Valencia.

Cerca de 230 especies desde el S de Estados Unidos de América a Chile, con 2 especies.

Sticherus C.Presl 1836. GleicheniaCEAe

Del griego: stichus=en hilera; ya que los soros se disponen en dos hileras.

65 especies pantropicales, Madagascar y Juan Fernández; en Chile 5 especies.

Stipa L. 1753. POACEAE

Del latín (estopa), en relación a las largas aristas plumosas.

Cerca de 50 especies de las regiones templadas del Hemisferio Norte, trópicos de altura e Isla de Pascua. En Chile 1 especie.

Stuckenia Börner 1912. Potamogetonaceae

En honor del botánico alemán Wilhelm Adolf Stucken (18601901), cuyos ejemplares por él recolectados se conservan en el Ubersee Museum, Bremen.

6 especies subcosmopolitas. En Chile 3 especies.

\section{Suaeda Forsk. 1775. AmaranthaCeAe}

Nombre árabe para la planta.

Cerca de 100 especies cosmopolitas, Islas Desventuradas.

En Chile 4 especies.

Symphyotrichum Nees 1832. AsterACEAE

Del griego symphysis= nacen o crecen juntos y trichos o trichinos $=$ pelo o pelo simple.

92 especies de Norteamérica y Sudamérica; en Chile 4 especies (antes incluía los Aster).

Synammia C.Presl 1836. PolyPOdiACEAE

Del griego: $s y n=e n l a c e$, fusión; ya que la venación secundaria de la fronda sube hacia el ápice y forma como un engrosamiento.

3 especies de Argentina, Chile y Juan Fernández; en Chile las 3 especies.

Tagetes L. 1753. AsteraceAe

En honor a Tages, una divinidad etrusca, quien se tenía por un hermoso adolescente; por la belleza de sus flores.

Cerca de 50 especies de Norte y Sudamérica. En Chile 3 especies.

Tapeinia Comm. ex Juss. 1789. IrIDACEAE

De tapeinos=bajo; la planta es muy pequeña, no más de dos pulgadas de alto.

Género monotípico endémico de Argentina y Chile.

Tarasa Phil. 1891. MaLvaceae

Del nombre vernáculo de una planta.

30 especies, 2 en México, el resto desde Perú a Argentina y Chile con 10 especies.

Taraxacum Hall. 1768. AsterACEAE

De (agitar); por ser una planta laxante, estimulante del intestino. Otra versión: derivado del latín medieval tarasacon, del árabe tarakhsshagog o del persa talkh chakok, y que significa hierba amarga.

Cerca de 60 especies de las regiones templadas del Hemisferio Norte, Nueva Zelanda, Sudamérica y Juan Fernández. En Chile 3 especies.

Tecoma Juss. 1789. BignoniaCEAE

Abreviación de su nombre vernáculo en México: tecomaxochitl.

12 especies de América tropical desde Arizona a Chile, con 1 especie. También 1 especie en Sudáfrica y probablemente en Australia.

Tecophilaea Bertero ex Colla 1836. Tecophilaeaceae En honor a Tecophila Billoti, hija del botánico italiano A. Colla y que estuvo de novia con el malogrado botánico Carlos Bertero, que dedicó a ella esta hermosa planta primaveral chilena.

Género endémico de Chile con 2 especies.

Tepualia Griseb. 1854. MyrTACEAE

Por el nombre vernáculo tepual, usado para denominar las agrupaciones de estos árboles.

Género monotípico endémico de Argentina y Chile.

Tessaria Ruiz \& Pav. 1794. AsteraceAe 
En honor a Luis Tessari, profesor italiano de botánica en Ancona, Italia.

4 especies de Sudamérica. En Chile 1 especie.

Tetilla DC. 1830. (Francoaceae) Melianthaceae

Nombre vernáculo de la planta por sus pecíolos hinchados de agua.

Género monotípico y endémico de Chile.

Tetrachondra Petrie ex Oliv. 1892. (Lamiaceae) TETRACHONDRACEAE

Del griego tetra $=$ cuatro y chondros $=$ grano; alude al fruto dividido en 4 partes.

2 especies, 1 en Nueva Zelanda y 1 en Patagonia y Tierra del Fuego, Chile.

\section{Tetraglochin Poepp. 1783. Rosaceae}

Del griego tetra=cuatro y glochin=puntas, ángulo; el cáliz de la flor masculina es de 4 lóbulos o anchas aletas.

8 especies de Perú, Argentina y Chile con 3 especies.

Tetragonia L. 1753. AIzOACEAE

Del griego tetra $=$ cuatro y gonia=ángulo, esquina; el fruto es de 4 esquinas y cubierto con el resto del cáliz, que acaban en las esquinas en cuernos o aletas.

Cerca de 70 especies en África, SE de Asia, Australia, Tasmania, Nueva Zelanda, Polinesia, Perú y Chile con 8 especies.

Tetroncium Willd. 1808. JunCaginaceae

Del griego tetra $=$ cuatro y gonia $=$ esquina; tiene 4 pistilos elongados, que dan origen a cápsulas de 4 ángulos.

Género monotípico de las regiones templadas de Sudamérica y Magallanes. En Chile 1 especie.

Teucrium L. 1753. LAmiaceAe

Por Teucer, príncipe troyano que fue el primero en recomendar el empleo de esta planta.

Cerca de 250 especies cosmopolitas. En Chile 2 especies.

Thamnoseris Phil. 1875. Asteraceae

Del griego thamnium=arbusto y seris=lechuga; por el hábito y hojas de la planta.

Género monotípico endémico de Islas Desventuradas, Chile.

\section{Thelocephala Y.Itô 1957. CACTACEAE}

Del griego thele $=$ tubérculo $\mathrm{y}$ kephale $=$ cuerpo; probablemente por los tubérculos que cubren los cuerpos globosos de estas especies.

Género endémico de Chile con 6 especies.

Thelypteris Schmidel 1763. TheLypteridaceae

Del griego thelys $=$ hembra y pteris $=$ helecho.
Cerca de 800 especies de las regiones tropicales y subtropicales del mundo y Madagascar. En Chile 2 especies.

Thyrsopteris Kunze 1835. (Dicksoniaceae) THYRSOPTERIDACEAE Del griego thyrsus $=$ inflorescencia racemosa y pteris $=$ helecho; alude a las pinnas fértiles del helecho.

Género monotípico endémico de Juan Fernández, Chile.

Tigridia Juss. 1789. IRIDACEAE

De tigre, porque la flor es manchada como la piel del tigre.

35 especies de México, Guatemala, Brasil, Perú, Bolivia y Chile, con 1 especie.

Tillandsia L. 1753. BROMELIACEAE

En honor a Elias Tillands (1640-1693), médico y botánico sueco, profesor de Medicina en Albo.

Cerca de 540 especies de las regiones tropicales y subtropicales de América. En Chile 5 especies.

Tiquilia Pers. 1805. Boraginaceae

Del nombre vernacular tiquil-tiquil, de la especie tipo. Probablemente deriva de la palabra quechua t'ika, que significa flor.

27 especies de las regiones áridas de Norte y Sudamérica. En Chile 5 especies.

Traubia Moldenke 1963. AmaryllidaCEAE

En honor de Hamilton P. Traub (1890-1983), botánico norteamericano, estudioso de la familia Amaryllidaceae y otras bulbosas, fundador de la American Plant Life Society. Género monotípico endémico de Chile.

Trevoa Miers ex Miers 1829. RhamnaceaE

Del nombre vernáculo "trevo".

Género monotípico endémico de Chile.

Tribeles Phil. 1864. EsCALloniaceAe

Del griego: $t r i=$ tres, triacuminado; aludiendo a la forma de la hoja.

Género monotípico endémico de Chile y Tierra del Fuego.

Trichocereus (A. Berger) Riccob. 1909. CACTACEAE

Del griego tricho=pelo, por las areolas pilosas de la flor y Cereus otro género de Cactáceas. El término latino Cereus significa de cera, y de allí deriva el término Cirio.

25 especies de Argentina, S de Perú y Chile: con 7 especies.

Trichocline Cass. 1817. AsteraceAE

Del griego tricho=pelo y cline $=$ lecho, cama; el tálamo es peludo-flocoso.

22 especies sudamericanas, 1 en el O de Australia. En Chile 5 especies. 
Trichomanes L. 1753. HymenophyllaCEAE

Del griego tricho=pelo y manos=delgado, esponjoso; tiene delgadas y delicadas ramas y tallos. Según Plinio, se usaba contra la caída del cabello.

Cerca de 80 especies pantropicales, Madagascar y Juan Fernández. En Chile 3 especies.

Trichoneura Andersson 1853 (1855). POACEAE

Del griego thrix $=$ pelo y neuron $=$ nervio; alude a los nervios ciliados de la lemma.

7 especies de Arabia, África tropical, S de Estados Unidos de América, Perú y Chile, con 1 especie.

Trichopetalum Lindl. 1832. (Laxmanniaceae) AsParAGACEAE Del griego tricho=pelo y petalum $=$ pétalo; los tres tépalos interiores de la flor son flocosos, en forma de barba.

2 especies de Argentina y Chile, con 1 especie.

\section{Trifolium L. 1754. FABACEAE}

Del griego: tri=tres y folium=hoja, ya que las hojas están divididas en tres folíolos.

Cerca de 250 especies de las regiones templadas y subtropicales del mundo, excluido Australia. En Chile 10 especies.

Triglochin L. 1754. JunCAGINACEAE

Del griego: tries=tres y glochin=punta; el fruto se abre en la base en tres puntas aleznadas.

12 especies subcosmopolitas. En Chile 3 especies.

Triodanis Raf. ex Greene 1836. CAmpanulaceae

Del griego: $t r i=$ tres y odons=diente; por el ápice de los frutos en dientes desiguales.

8 especies de Norteamérica, México, Guatemala y Mediterráneo. En Chile 1 especie.

Tripogon Röem. \& Schult. 1817. PoACEAE

Del griego: tri=tres y pogon=barba, refiriéndose a los pelos en la base de las lemas.

30 especies de las regiones tropicales y subtropicales. En Chile 2 especies.

Triptilion Ruiz \& Pav. 1794. Asteraceae

Del griego: $t r i=$ tres y ptilon=ala, pluma. Por las cerdas del papo, plumosas en la parte superior.

7 especies de Chile central y Argentina.

Trisetum Pers. 1805. POACEAE

Del griego tri=tres y setum $=$ cerdas; la glumela tiene dos aristas en la punta y una en el dorso.

Cerca de 70 especies de las regiones frías y templadas de los trópicos de altura y Juan Fernández. En Chile 15 especies.

Tristagma Poepp. 1833. Alliaceae
Del griego tri=tres y stagma $=$ gota; el pistilo tiene arriba tres poros llenos de néctar.

14 especies de Uruguay, Argentina y Chile, con 6 especies

Tristerix Mart. 1830. LoRANTHACEAE

Del griego tri=tres y sterix=apoyo; porque cada flor lleva tres brácteas en la base.

11 especies de los Andes desde Colombia a Chile, con 3 especies.

Triumfetta L. 1753. MALVACEAE

En honor al botánico italiano Giovanni Baptista Triumfetti (1656-1708), quien escribió sobre la vida de las plantas o por su hermano Laelius Triumfetti quien fue profesor de botánica en Roma.

Cerca de 70 especies pantropicales. 1 especie en Isla de Pascua, Chile.

Trixis P.Browne 1756. AsteraceAE

Del griego: trixos=triple; se refiere a las hendiduras en el ápice de las lígulas externas.

Cerca de 50 especies desde el SO de Norteamérica hasta Chile con 1 especie.

Tropaeolum L. 1753. TRopaeolaceae

Del griego; tropeion=trofeo; ya que la flor tiene la forma de una especie de yelmo o casco.

50 especies de México a Chile, con 18 especies.

Tropidocarpum Hook. 1836. BRASSICACEAE

Del griego tropis=quilla y karpos=fruto; alude a las silicuas aquilladas.

4 especies de California y Chile, con 1 especie.

Tunilla D.R.Hunt \& Iliff 2000. CACTACEAE

El nombre deriva de "tuna" nombre común de los frutos de varias Opuntias.

9 especies de los Andes de Perú, Bolivia, Argentina y Chile, con 2 especies.

Tweedia Hook. \& Arn. 1834. Apocynaceae

En honor al botánico y viajero inglés J. Tweedie, quien descubrió esta planta.

6 especies de Bolivia, Uruguay, Argentina y Chile con 3 especies.

Typha L. 1753. Typhaceae

De "tupn" de los pueblos antiguos, supuestamente (pantano), en relación a su hábitat; o de (humo, quemar) porque el espádice se ve fumoso, oscuro.

13 especies cosmopolitas. En Chile 2 especies.

Ugni Turcz. 1848. Myrtaceae

Del nombre vernáculo "uñi” en Chile. 
10 especies desde México hasta Chile y Juan Fernández. En Chile 3 especies.

Uncinia Pers. 1807. CyPeraceAe

Del latín uncinus=ganchos, en la base del pistilo existe una arista en forma de gancho, que sobresale de la flor.

Cerca de 60 especies de Malasia, Pacífico, Australia, SE de Asia, Centro y Sudamérica y Juan Fernández. En Chile 18 especies.

\section{Urmenetea Phil. 1860. Asteraceae}

En honor a don José Tomás Urmeneta García (1808 - 1878), hombre público y acaudalado industrial chileno, dueño de minas y de industrias en Coquimbo y Santiago. Urmeneta invitó en 1864 a R. A. Philippi a un viaje a Juan Fernández, donde R. A. Philippi reunió numerosas plantas nuevas para la ciencia.

Género monotípico endémico del NO de Argentina y del N de Chile.

Urocarpidium Ulbr. 1916. MALVACEAE

Del griego ouro $=$ cola y carpidium $=$ fruto, ya que es un mericarpo aristado.

Género monotípico de Perú y Chile.

\section{Urtica L. 1753. URTICACEAE}

Del latín urere=quemar; porque los pelos de las hojas producen un dolor quemante a su contacto con la piel.

75 especies subcosmopolitas de las regiones templadas. En Chile 10 especies.

\section{Utricularia L. 1753. LENTIBULARIACEAE}

Del latín utriculus=pequeña vejiga; refiriéndose a los utrículos o pequeñas trampas para insectos que posee la planta.

Cerca de 200 especies cosmopolitas. En Chile 1 especie.

Vahlodea Fr. 1842. POACEAE

En honor del botánico danés Jens Laurentius Moestue Vahl (1796-1854), colector de plantas, viajero y bibliotecario.

1 especie de Argentina, Canadá, Chile y Estados Unidos de América.

\section{Valdivia J.Remy 1847. EsCALloniaCeAE}

En honor al conquistador español de Chile, don Pedro de Valdivia (1500-1553).

Género monotípico endémico de Chile.

Valeriana L. 1753. VALERIANACEAE

Del latín valere $=$ ser saludable y fuerte; en relación al poder curativo de la planta.

Cerca de 230 especies en las regiones templadas del $\mathrm{N}$ de Eurasia, S de África y Andes sudamericanos. En Chile 44 especies.
Vasconcellea A.St.-Hill. 1837. CARICACEAE

En honor del P. Simón de Vasconcellos, a quien tanto debe la historia de Brasil y que en "Noticias curiosas y necesarias de las cosas del Brasil" (alrededor de 1660), diera a conocer las plantas más útiles de ese imperio.

20 especies de México a Chile, con 1 especie.

\section{Verbena L. 1753. VerBENACEAE}

Supuestamente del celta ferfaen, compuesto de fer=viajar, llevar, guiar y faen=piedra; se usaba como remedio para los cálculos vesiculares. Más cercana es del latín: verbum=palabra; ya que se juraba sobre esta planta. Según Plinio también se usaba para sacrificios.

Cerca de 225 especies de las regiones templadas y tropicales de América, pocas en Eurasia. En Chile 10 especies.

Verbesina L. 1753. AsteraceAe

Por su parecido en las hojas al género Verbena.

Cerca de 300 especies en las regiones tropicales y subtropicales de América y el Caribe. En Chile 3 especies.

Veronica L. 1753. (Scrophulariaceae) Plantaginaceae Nombrado así por Santa Verónica, la mujer que pasó a Jesús un pañuelo para enjugar su cara camino al Calvario, y se llaman así porque los dibujos de algunas especies parecen aquellas del sagrado pañuelo.

270 especies cosmopolitas; en Chile 1 especie.

Vestia Willd. 1809. Solanaceae

En honor a Lorenz V. Vest, profesor de botánica en Grätz, Alemania. Escribió "Manuale Botanicum".

Género monotípico endémico de Chile.

Vicia L. 1753. FABACEAE

Derivada de vincire $=$ amarrar, envolver: en relación a los zarcillos que tiene la planta.

Cerca de 140 especies de las regiones templadas del Hemisferio Norte, Mediterráneo, pocas en África tropical, Hawai y Sudamérica. En Chile 19 especies.

Viguiera Kunth 1920. AsteraceAe

En honor de L. G. A. Viguier (1790-1867), doctor y botánico en Montpellier, Francia. Autor de una historia natural de las Adormideras (Papaveráceas).

Cerca de 140 especies de las regiones tropicales y subtropicales de América y el Caribe.

En Chile 4 especies.

Villanova Lag. 1816. AsteraceAe

En honor a don Tomás Villanova, botánico español del siglo XIV que escribió "De virutatibus plantarum".

10 especies de México a Chile, con 2 especies. 
Viola L. 1753. ViolaceaE

Nombre clásico de estas plantas.

Cerca de 430 especies cosmopolitas. En Chile 72 especies.

Vittaria Sm. 1793. (Pteridaceae) Vittariaceae

Del latín vitta=cinta; en relación a la forma de las frondes, que son lineares y muy largas.

Cerca de 70 especies pantropicales. En Chile 1 especie.

Viviania Cav. 1804. VivianiaCEAE

En honor al doctor italiano Doménico Viviani (1772-1840), profesor de botánica en Génova. Autor de la Flora de Córcega.

6 especies del S de Brasil, Argentina y Chile, con 3 especies.

Vulpia Gmel. 1805. POACEAE

En honor a J. S. Vulpius (1760-1846), farmacéutico en Pforzheim, Alemania, autor de "Spicilegium florae Stuttgardiensis".

25 especies del $\mathrm{N}$ de África, Asia Media y Norte y Sudamérica. En Chile 3 especies.

Wahlenbergia Schrad. 1814. CAMPANULACEAE

En honor al profesor de medicina y botánica sueco Göran (Georg) Wahlenberg (1780-1851). Escribió "Flora lapponica", "Flora upsaliensis" y "Flora suecica".

Cerca de 260 especies del Hemisferio Sur, Europa y SE de Asia. En Chile 6 especies.

Weberbauera Gilg \& Muschl. 1909. BRASSICACEAE En honor del botánico alemán Augusto Weberbauer (18711948), que hizo una de las contribuciones científicas más grandes al Perú del siglo XX con su obra cumbre "El Mundo Vegetal de los Andes Peruanos", 1945.

18 especies de los Andes de Perú, Bolivia, Argentina y Chile con 6 especies.

Wedelia Jacq. 1760. AsterACEAE

En honor a Georg Wolfgang Wedel (1645-1721), de Golssen, Alemania. Físico agrícola y profesor de medicina; escribió, entre otros, sobre las plantas de los pueblos antiguos.

Cerca de 100 especies pantropicales y O de Australia. En Chile 1 especie.

Weinmannia L. 1759. CUNONIACEAE

En honor a Johannes Wilhelm Weinmann (1683-1741), farmacéutico en Regensburg, Alemania, autor de "Phytanthosa iconographia".

Cerca de 160 especies de Madagascar, Australasia, México, Centro y Sudamérica. En Chile 1 especie.

Werneria Kunth 1820. AsteraceAe

En honor a Abraham Gottlieb Werner (1849-1817) alemán, especialista en minerales, profesor en la Escuela de Minas de Freiberg. Fue alumno dilecto de Humboldt.

30 especies de los Andes de Ecuador a Chile, con 8 especies.

Wolffia Horkel ex Schleid. 1839. (Lemnaceae) ARACEAE En honor al botánico y médico alemán Johann Friedrich Wolff (1778-1806).

11 especies cosmopolitas. En Chile 1 especie.

Wolffiella Hegelm. 1895. (Lemnaceae) ARACEAE

Diminutivo del género Wolffia.

10 especies de las regiones tropicales y cálidas de América y 1 especie en el S de África. En Chile 1 especie.

Woodsia R.Br. 1810. (Dryopteridaceae) WoODSIACEAE En honor a Joseph Woods (1776-1864), arquitecto y botánico inglés, quien escribió sobre estos temas y de geología. 25 especies de las regiones templadas y frías de Eurasia, África y América. Excluida Australia. En Chile 1 especie.

Xenophyllum V.A.Funk 1997. AsteraceaE

Del griego $x e n o=$ extraño y $p h y l l u s=$ hojas; por sus hojas que cubren los tallos.

21 especies de los Andes de Colombia al N de Argentina y Chile con 5 especies.

Xerodraba Skottsb. 1916. BRASSICACEAE

Del griego xeros $=$ seco y Draba, otro género de Brassicáceas.

6 especies del S de Argentina y Chile con 2 especies.

X Margyracaena Bitter 1921. RosACEAE

Híbrido entre los géneros Margyricarpus y Acaena.

Género monotípico endémico de Juan Fernández, Chile.

Yunquea Skottsb. 1929. AsteraceAe

Por el nombre del cerro El Yunque de Más a Tierra, en el Archipiélago de Juan Fernández.

Género monotípico endémico de Juan Fernández, Chile.

Zameioscirpus Dhooge \& Goetghebeur 2003. CyPERACEAE Del griego $z a=$ muy, meion=comparativo de micros: pequeño y Scirpus otro género; porque son especies perennes, pequeñas, cespitosas.

3 especies de Bolivia, Argentina y Chile con las 3 especies.

Zannichellia Mich. ex L. 1753. (Zannichelliaceae) Potamogetonaceae

En honor de Gian G. Zannichelli, médico, farmacéutico y botánico veneciano (1662-1729).

5 especies cosmopolitas. En Chile 1 especie. 
Zanthoxylum L. 1753. RUTACEAE

Del griego $x a n t h o s=$ amarillo y $x y l o n=$ madera.

Cerca de 250 especies de África, Asia, América y Juan

Fernández, en Chile 2 especies.

\section{Zephyra D.Don 1832. Tecophilaeaceae}

De Céfiro, dios griego del viento dulce y suave del oeste. La planta tiene hermosas y aromáticas flores celestes.

Género monotípico endémico de Chile.

\section{Zoellnerallium Crosa 1975. AlliaceAe}

En honor al botánico de origen alemán Otto Zöllner Schorr (1909-2007). Llegó a Chile en 1935. Fue profesor y director del Colegio Alemán de Quilpué y profesor de botánica de la Universidad de Valparaíso, Chile.

2 especies endémicas de Argentina y Chile.

\section{AGRADECIMIENTOS}

Agradecemos la gentileza de la Dra. Charlotte Taylor, quien me contactó con la Dra. Stiffler, bibliotecaria del Missouri Botanical Garden y al Dr. Bonifacino, quienes pudieron consultar el "World Dictionary of Plant Names" para enviarme el significado de algunos nombres. Al Dr. Kuijt (Desmaria, Ligaria, Notanthera, Ombrophytum), a la Dra. Guaglianone (algunas monocotiledóneas), al Dr. AlShehbaz (Mostacillastrum, Neuontobothrys, Polypsecadium y Sibara), al Dr. Anderberg (Luciliocline), al Dr. Spooner (Lycopersicon), al Dr. Zuloaga (Dichanthelium), al Dr. Eggli (Cactaceae), a P. Hechenleitner (Vahlodea), al Dr. Weigend (Nasa), al Dr. Luebert (Stuckenia, Vasconcellea, Loasa y Dicliptera). A Alicia Marticorena del herbario CONC por su colaboración en la revisión del manuscrito y su aporte en bibliografía por las dudas en los géneros. Muy especialmente al Dr. Roberto Rodríguez, de la Universidad de Concepción, por la dedicada revisión del manuscrito.

\section{LITERATURA CITADA Y PERTINENTE}

Al-Shenbaz, I. 2006. The genus Sisymbrium in South America, with synopsis of the genera Chilocardamum, Mostacillastrum, Neuontobotrys, and Polypsecadium (Brassicaceae). Darwiniana 44: 341-358.

Al-Shenbaz, I. 2010. A synopsis of the South American Lepidium (Brassicaceae). Darwiniana 48: 141-167.

Al-Shenbaz, I. 2010. A synopsis of the genus Sibara (Brassicaceae). Harvard Papers in Botany 15(1): 139-147.

Al-Shehbaz, I. A. \& R. A. Price. 2001. The Chilean Agallis and Californian Tropidocarpum (Brassicaceae) are congeneric. Novon 11: 292-293.

Arriaga, M.O. \& M.E. Barkworth. 2006. Amelichloa: A new genus in the Stipeae (Poaceae). Sida 22: 145-149.

Bailey, C.D., I. Al-Shehbaz \& G. Rajanikanth. 2007. Generic limits in tribe Halimolobeae and the description of the new genus Exhalimolobos (Brassicaceae). Systematic Botany 32: 140-156.

Barros, M. 1947. Cyperaceae en Descole, Genera \& species plantarum argentinarum 4(1): 1-243, 92 lám.; 4(2): 255539, 105 lám. (Rhynchospora)

Bernardello, L.M. \& A.T. HunziKer. 1987. Estudios sobre Solanaceae XXVI. Revisión taxonómica de Phrodus. Kurtziana 19: 69-76.

Bonifacino, J.M. 2008. Reinstatement of Ocyroe (Compositae: Asteraceae). Brittonia 60(3): 205-212.

Bonifacino, J.M. \& G. SAncho. 2004. Guynesomia (AsteraceaeAstereae) a new genus from central Chile. Taxon 53(3): 673-678.

Briggs, B.G. \& L.A.S. Johnson. 1998. New genera and species of Australian Restionaceae (Poales). Telopea 7(4): 345-373.

CAro, J.A. 1961. El género Pitraea (Verbenaceae) en la República Argentina. Kurtziana 1:271-282.

Charters, M.L. California Plant Names: Latin and Greek Meanings and Derivations. http://www.calflora.net/botanicalnames/ index $2 . h t m l$

Correa, M. N. 1969-1988. Flora Patagónica, 8 vols. INTA, Argentina.

DAvies, A.M. 2010. A systematic revision of Chaetanthera Ruiz \& Pav., and the reinstatement of Oriastrum Poepp. \& Endl. (Asteraceae: Mutisieae). SVH Südwestdeutscher Verlag für Hochschulschriften, 303 pp.

Dhooge, S., P. Goetghebeur \& A.M. Muasya. 2003. Zameioscirpus, a new genus of Cyperaceae from South America. Plant Systematic and Evolution 243: 73-84.

FeuilléE, L. 1714-25. Journal des observations physiques, mathématiques \& botaniques, Faites par l'ordre du Roy sur les Côtes Orientales de l'Amérique Méridionale, \& dans les Indes Occidentales, depuis l'année 1707, jusques en 1712. (París) - Tres vols.

Funk, V. A. 1997. Xenophyllum, a New Andean Genus Extracted from Werneria s.1. (Compositae: Senecioneae) Novon 7: 235-241.

GAY, C. 1845-1854. Historia Física y Política de Chile, Botánica. 8 vols., 1 atlas.

Gledhill, D. 2008. The Names of Plants, 4 ed., Cambridge, 426 pp.

GunCKel, H. 1982. Significado de nombres genéricos de algunas plantas de la flora chilena. Academia 4: 157-180.

Hechenleitner, P. 2007. Systematics of chilean Ribes (Grossulariaceae). Thesis presented for the MSc, The Biodiversity and Taxonomy of Plants, University of Edinburgh, Royal Botanic Garden Edinburgh. 86 pp.

Ibisch, P., C. Neinhuis \& P. Rojas. 1996. On the biology, biogeography, and taxonomy of Arachnitis Phil. nom. cons. (Corsiaceae) in respect to a new record from Bolivia. Willdenowia 26: 321-332.

Johnston, I.M. 1927. Studies in the Boraginaceae. VI. A revision of the South American Boraginoideae. Contr. Gray Herb. 78: $1-118$.

Jussieu, A.L. de, 1804. Mémoire sur le Loasa, genre de plantes qui devra constituer avec le Mentzelia, une nouvelle famille. Annales du Muséum d'Histoire Naturelle 5: 18-27, 5 lám.

Katinas, L., J. Pruski, G. Sancho \& M. C. Tellería. 2008. The Subfamily Mutisioideae (Asteraceae). Botanical Review (Lancaster) 74: 469-716. 
Kellermann, J., D. Medan, L. Aagesen \& H.H. Hilger. 2005. Rehabilitation of the South American genus Ochetophila Poepp. ex Endl. (Rhamnaceae:Colletieae). New Zealand Journal of Botany 43: 865-869.

Les, D.H. \& D.J. Crawford. 1999. Landoltia (Lemnaceae), a new genus of duckweeds. Novon 9: 530-533.

Lewis, G, B. Schrire, B. Mackinder \& M. Lock (eds.). 2005. Legumes of the world. The Royal Botanic Gardens Kew, $577 \mathrm{pp}$.

Marticorena, C. 1990. Contribución a la estadística de la flora vascular de Chile. Gayana, Botánica 47(3-4): 85-114.

Marticorena, C. 1992. Bibliografía Botánica Taxonómica de Chile. Monographs in Systematic Botany, Missouri Botanical Garden, Vol. 41, 587 pp.

MarticorenA, C. 1996. Bibliografía Botánica Taxonómica de Chile. Suplemento I. Gayana Botánica 53(1): 1-263.

Marticorena, C. \& M. Quezada. 1985. Catálogo de la flora vascular de Chile. Gayana, Botánica 42(1-2): 1-157.

Moreira-Muñoz, A. 2010. Acerca de la desintegración de las Scrophulariaceae y la clasificación de los taxones chilenos. Revista Chagual 8: 31-36.

Moreira-MuÑoz, A. 2011. Plant Geography of Chile. Plant and Vegetation, vol.5, Springer, $343 \mathrm{pp}$.

Mosyakin, S. L. \& S.E. Clemants. 2002. New nomenclatural combinations in Dysphania R.Br. (Chenopodiaceae): Taxa occuring in North America. Ukrayins'kyi Botanicnyi Zhurnal. Kiev (The Ukrainian Botanical Journal) 59: 380385.

Mosyakin, S. L. \& S.E. Clemants. 2008. Further transfers of glandular-pubescent species from Chenopodium subg. Ambrosia to Dysphania (Chenopodiaceae). J. Bot. Res. Inst. Texas 2: 425-431.

Muasya, A.M., D. Simpson \& P. Goetghebeur. 2000. New combinations in Trichophorum, Scirpoides, and Ficinia (Cyperaceae). Novon 10: 132-133.

Munz, P.A. \& D. Keck. 1959. A California Flora. University of California Press, 1681 pp.

MuÑoz, C. 1966. Flores silvestres de Chile. Edic. Univ. Chile, 245 pp.

MuÑoz, M. 1980. Flora del Parque Nacional Puyehue. Edit. Univ. $557 \mathrm{pp}$.

MuÑoz, M. 1985. Flores del Norte Chico. DIBAM- I.Municipalidad La Serena. $95 \mathrm{pp}$

Murillo-Aldana, J. \& E. Ruiz 2011. Revalidación de Nothomyrcia (Myrtaceae), un género endémico del Archipiélago de Juan Fernández. Gayana Botánica 68(2): 129-134.

Nicora E.G. \& Z.E. Rúgolo De Agrasar. 1981. Los géneros de Gramíneas de América Austral. Argentina, Chile, Uruguay y áreas limítrofes de Bolivia, Paraguay y Brasil. Buenos Aires, $611 \mathrm{pp}$.

Niemeyer, H. \& S. Teillier. 2007. Aromas de la flora nativa de Chile. Universidad de Chile - FIA, 446 pp.
O’Leary, N., Y-W. Yuan, A. Chemisquy \& R.G. Olmstead. 2009. Reassignment of Species of Paraphyletic Junellia s.1. to the New Genus Mulguraea (Verbenaceae) and New Circunscription of Genus Junellia: Molecular and Morphological Congruence. Systematic Botany 34(4): 777-786.

Panero, J.L. 2007. Calorezia, a new genus of tribe Nassauvieae (Asteraceae, Mutisioideae). Phytologia 89(2): 198-201.

PARODI, L.R. 1938. Gramíneas austroamericanas nuevas o críticas. Notas Museo de La Plata. Botánica tomo 3, n¹7: 15-33. (Gymnachne).

Pelser, P.B., E.J. Tepe, A.H. Kennedy \& L.E. Watson. 2010. The fate of Robinsonia (Asteraceae): sunk in Senecio, but still monophyletic? Phytotaxa 5: 31-46.

Quatrocchi, H. 1999. World Dictionary of Plant Names: Common Names, Scientific Names, Eponyms, Synonyms, and Etymology. 4 vols. 7.442 pp.

Ravenna, P. 1972. Famatina gen. nov. Amaryllidaceae. Plant Life 28: 55-62.

RAVENNA, P. 1974. Contributions to South American Amaryllidaceae VI. Plant Life 30:29-79. [Traubia]

Richardson, A. 1977. Monograph of the genus Tiquilia (Coldenia, sensu lato), Boraginaceae: Ehretioideae. Rhodora 79: 467672.

Rodríguez, R. 1995. Pteridophyta. En: C.Marticorena \& R. Rodríguez (eds.), Flora de Chile. Vol. I, págs. 119- 309.

Simpson, B. 1989. Pollination Biology and Taxonomy of Dinemandra and Dinemagonum (Malpighiaceae). Systematic Botany 14(3): 408-426.

Soreng, R.J., P.M. Peterson, G. Davidse, E.M. Judziewicz, F.O. Zuloaga, T.S. Filgueiras \& O. Morrone. 2003. Catalogue of New World Grasses (Poaceae): IV. Subfamily Pooideae. Contributions from the United States National Herbarium 48: 1-730. (Vahlodea).

TRYON, R.M. 1956. A revision of the American species of Notholaena. Contr. Gray Herb. 179:1-106, 1 lám.

Viruel, J., J.G. Segarra-Moragues, E.. Pérez-Collazos, L. Villar \& P. CATALÁN. 2010. Systematic Revision of the Epipetrum Group of Dioscorea (Dioscoreaceae) Endemic to Chile. Systematic Botany 35(1): 40-63.

Weigend, M. 1997. Nasa and the conquest of South America. München.

Wittstein, G.C. 1856. Etymologisch-botanisches. Handwörterbuch. $2^{\circ}$ ed. Erlangen, $952 \mathrm{pp}$.

Zuloaga, F. O., O. Morrone \& M. J. Belgrano (eds.). 2008. Catálogo de las Plantas Vasculares del Cono Sur (Argentina, Sur de Brasil, Chile, Paraguay y Uruguay), en Monographs of the Missouri Botanical Garden, $n^{\circ} 107$ (vol. 1 Pteridophyta, Gymnospermae y Monocotyledoneae; vol. 2 Dicotyledoneae: A-F; vol. 3 Dicotyledoneae: F-Z. 3348 pp.

http://www.calflora.net/botanicalnames/pageSI-SY.html[Stuckenia] http:/www.calflora.net/botanicalnames/index2.html

Recibido: 05.08.11

Aceptado: 19.07 .12 